Portland State University

PDXScholar

1974

\title{
A Spectrographic Analysis of Bahasa Indonesia Vowel Phonemes Under Primary Stress in CVC Words
}

Ingrid T. Hanna

Portland State University

Follow this and additional works at: https://pdxscholar.library.pdx.edu/open_access_etds

Part of the Linguistic Anthropology Commons

Let us know how access to this document benefits you.

\section{Recommended Citation}

Hanna, Ingrid T., "A Spectrographic Analysis of Bahasa Indonesia Vowel Phonemes Under Primary Stress in CVC Words" (1974). Dissertations and Theses. Paper 2138.

https://doi.org/10.15760/etd.2136

This Thesis is brought to you for free and open access. It has been accepted for inclusion in Dissertations and Theses by an authorized administrator of PDXScholar. Please contact us if we can make this document more accessible: pdxscholar@pdx.edu. 
AN ABSTRACT OF THE THESIS OF Ingrid T. Hanna for the Master of Arts in Anthropology presented May 13, 1974.

Title: A Spectrographic Analysis of Bahasa Indonesia

Vowel Phonemes Under Primary Strass in CVC Words.

APPROVED BY MEMBERS OF THE THESIS COMMITTEE:

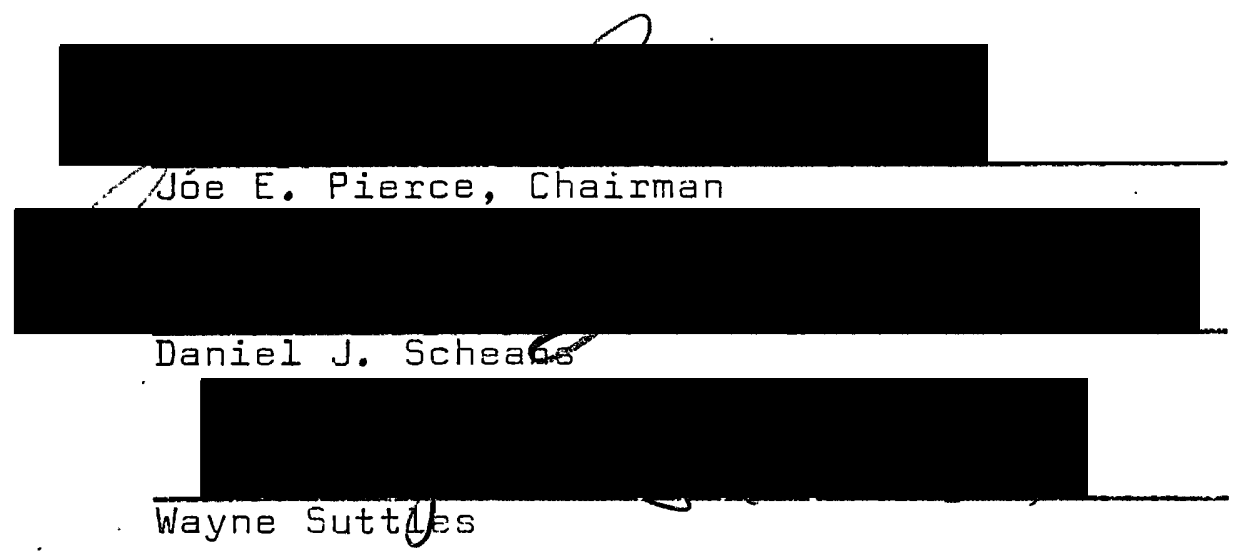

This study is an investigation into the nature of the vowel phonemes of Bahasa Indonesia in monosyllabic words, under primary stress, and consisting of a consorant followed by a vowel followed by a consonant. Bahasa Indonesia is the national language of the Republic of Indonesia. All of the material in the literature relating to the vowel quality of this language is highly impressionistic. Some of the descriptions are comparisons with vowels in various modern Indo-European languages rather than scientific descriptions of strictly Indonesian vowel quality.

In order to derive a more accurate picture of the phonetic qualities of Bahasa Indonesian vowels, the acous- 
tic spectrograph was utilized. This instrument analyzes a complex human speech wave and produces a visual image of the frequencies in the wave which are not filtered out by the articulators. The data consisted of recordings of eighty-eight words as produced by a native speaker. Every phoneme was contrasted with every other vowel phoneme in identical environments. Spectrograms were then made of every phoneme in every environment that it occurred. The information derived from these spectrograms was then charted. These charts show the approximate range of sound quality which native speakers recognize as a particular phoneme in the specified environment.

The results of the study show that Bahasa Indonesia has three front vowels contrasting high, mid and low tongue positions and two back vowels contrasting high and mid tongue positions. The three front vowels have slightly overlapping distributions; this may partially be due to the fact that the words in which the phonemes were found had no contrasting word containing a neighboring phoneme. This differs markedly with the back vowels where the distributions are sharply separated.

The aforementioned charts of vowels have a distinct resemblance to the traditional vowel charts. Thus, after all the evidence was gathered and analyzed, a traditional vowel diagram was drawn for these particular vowels of .. Bahasa Indonesia. 
TD THE OFFICE OF GRADUATE STUDIES AND RESEARCH:

The members of the Committee approve the thesis of Ingrid T. Hanna presented May 13, 1974.

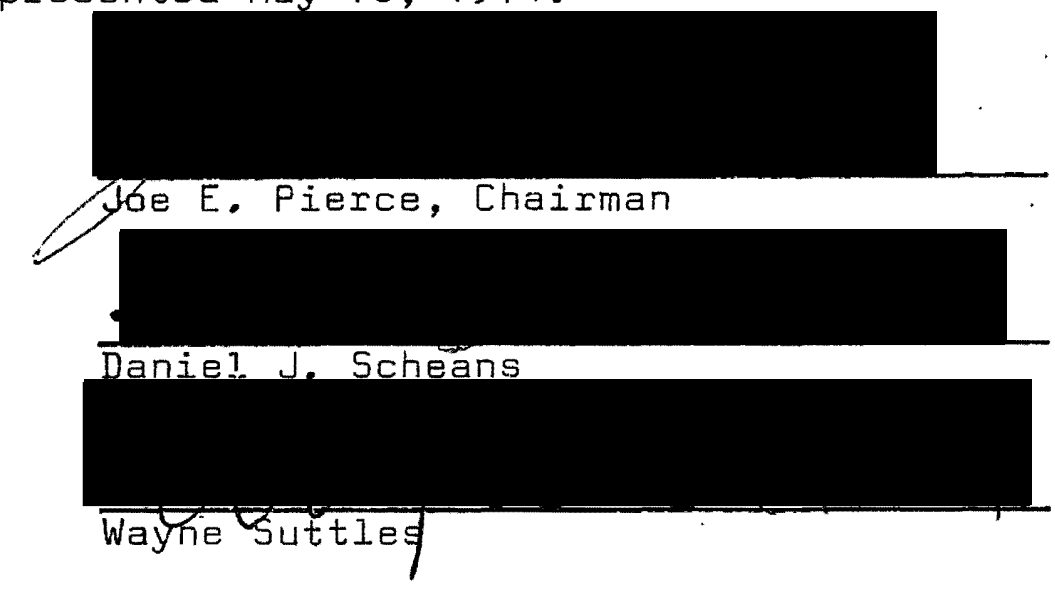

APPROVED:

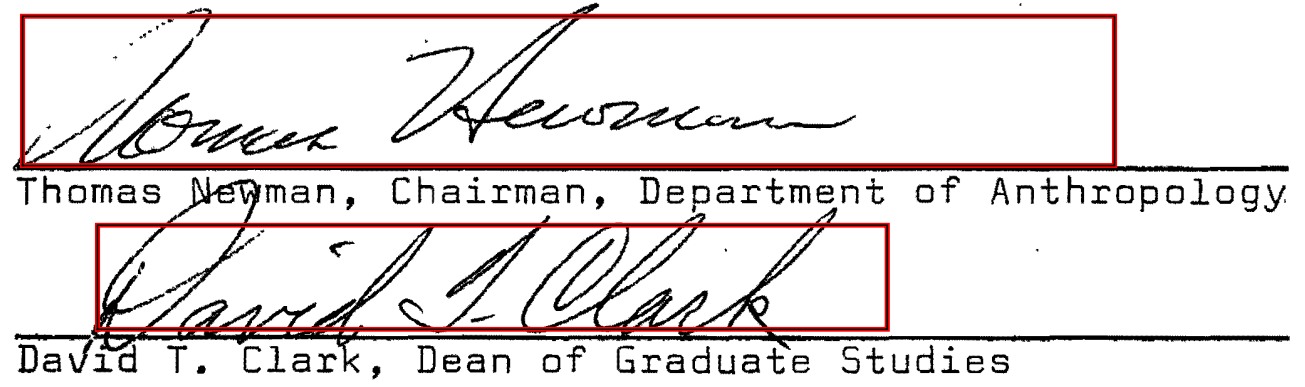

May 13,1974 


\title{
A SPECTROGRAPHIC ANALYSIS
}

OF

BAHASA INDONESIA VOWEL PHONEMES

UNDER PRIMARY STRESS IN CVC WORDS

by

INGRID T. HANNA

A thesis submitted in partial fulfillment of the requirements for the degree of

\author{
MASTER OF ARTS \\ in \\ ANTHROPQLOGY
}

Portland State University 


\begin{abstract}
ACKNOWLEDGEMENTS
I would ljke to thank the faculty members on my thesis committee for their help and contributions. I am especially grateful to Prof. Joe E. Pierce for his continual advise and moral support.

Mostly, I would like to thank my husband, without whose understanding, constant encouragement, and professional advise, I could not have survived the entire effort.
\end{abstract}


TABLE OF CONTENTS

PAGE

ACKNOWLEDGEMENTS

iii

CHAPTER

I INTRODUCTION $\ldots \ldots \ldots \ldots \ldots \ldots \ldots \ldots$

Language

Justification for Study

Statement of the Problem

Delimitations of the Study

I I THEDRETICAL BACKGRDUND ............

Phonetics/Phonemics

Acoustic Theory

Fundamentals/Harmonics

Acoustics vs. Articulation

Spectrograph

II I METHODOLOGY $\ldots \ldots \ldots \ldots \ldots \ldots \ldots \ldots \ldots$

Phoneme Identification

Spectrograms

IV FINDINGS .......................... 24

V SUMMARY AND CONCLUSIONS .............. 67

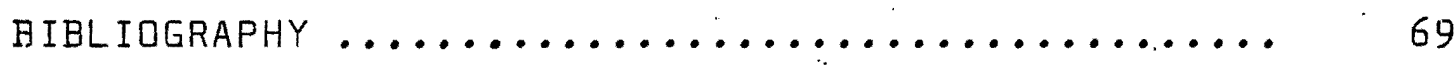

Sources Cited

Sources Consulted

APPENDIX A

List of Words

APPENDIX $B$

Linguistic Symbolization Used 


\section{CHAPTER I}

\section{INTRODUCTION}

\section{Language}

Bahasa Indonesia, the officiel name applied to the Indonesian language, is a member of the Malayo-Polyresian language family. The term, Bahasa Indonesia is often used synonymously with modern. Malay or Malay dialect (Uhlembeck, 1967). References to a similar form of this Malay based language are found as early as the 16 th century by traders such as the Chinese, the Hindu, and the Arabs (Woodman, 1955). Words were added to the language, known as Melaju Pasar or Bazaar Malay, as trade with foreigners increased (Woodman, 1955). These foreign elements in Melaju Pasar formed the essential differences between it and the Malay spoken on the Malay Peninsula (Woodman, 1955). "Bahasa Indonesia differs little from the standard dialect of the Malay Peninsula and does so mainly in its relatively large and growing vocabulary borrowed from European and indigenous languages" (American University, 1970). Bahasa Indonesia is then an adaptation of Malay, inasmuch as it has been changed by the original regional languages and modern European languages (Alisjahbana, 1949). 
Today, Bahasa Indoriesia is the official language of the Republic of Indonesia. It has been estimated that over 200 regional languages are spoken in this country of wide cultural diversity (Woodman, 1955). When Indonesia began to strive for independence from Dutch colonialists, a common language seemed essential in an effort to unify the nation. "Indonesian political leaders, desirous of revitalizing their people, brought (to bare) the most effective means of organizing them in the greatest numbers" (Alisjahbana, 1949). Attention was focused upon the Malay language which was the "Lingua Franca" for most of Southeast Asia. "Javanese was rejected although it possessed a thousand-year-old literary tradition and was the language of the largest ethnic group in the islands" (American University, 1970). The Javanese language has a fairly rigid system of vocabulary differences based on social class. Thus, Malay became the basis of the national language. "At the 1928 conference of the Pertemuan Muda (Meeting of Youth), Malay was chosen to be the basis of the national language" (American University, 1970). By 1930, then, the term "Malay Language" was officially changed to the "Indonesian language" (Uhlenbeck, 1967). It became the language for scholarly endeavors and the language of leaders and officials. During the Japanese occupation in 1942, the language made further gains. In an effort to combat Dutch cultural influence, it was made the compul- 
sory language used in schools from elementary and up. Bahasa Indonesia became the official national language when the Republic of Indonesia was formed in 1.945.

\section{Justification For Study}

Phonemic descriptions of Bahasa Indonesia are almost non-existent and very limited, from a linguistic point of view. Most descriptions of the sounds of Indonesian are of a comparative nature, i.e., Bahasa Indonesian sounds are likened to sounds of modern Indo-European languages. Echols. and Shadily's An Indonesian-English Dictionary describes Indonesian sounds in relation to the similar sounds in English. For instance, they argue that the /e/ in the Indonesian word "sen" is like the /e/ in the English word "make", only shorter. Statements such as the aforementioned may be practical for most purposes, but are not necessarily linguistically sound and almost certainly inaccurate.

Another deficiency which seems to be present in phonemic analyses, not only in Indonesian, is the impressionistic nature of these analyses. When dealing with a language, the linguist must attempt to remove all linguistic biases and comparisons, because "phonetic details may escape the ear of the analyst, especially in a foreign language upon which he is likely to impose, depending upon the degree of his skill, any of the few prejudices of his native phonemic scale" (Pulgram, 1965). Even when the investigator does not 
rely on comparative methods of description, he cannot completely remove all the sounds in his linguistic memory when describing a new language. He will invariably hear sounds that are very similar to those he knows and may not be able to discern certain minor, although perhaps crucial differences. Phonemic descriptions are most often of this impressionistic variety.

Spectrographic analyses of the sounds of a language provide an objective measure of the quality of the sounds of a language. Spectrographs record precise sound qualities produced by a speaker, particularly vowels. This mode of description will delete the impressions of the investigator and will map precise quality for sounds in question, "what shows on a spectrogram is an acoustic reality whether the analyst 'hears' it or not" (Pulgram, 1965). It is these precise sound qualities of Bahasa Iridonesian vowel phonemes that this investigation will attempt to ascertain. "Instrumental testing of hypotheses has been a part of scientific study for many years, but very little has been done to dete in linguistics" (Pierce, 1963). The acoustic spectrograph can provide definite answers as to the phonetic quality of vowels.

The science of phonemics developed out of the realization that some phonetic features of a language differentiate one word from another, while others do not. Edward Sapir (1921) argues: 
Back of the purely objective system of sounds that is peculiar to a language and which can be arrived at only by a painstaking phonetic analysis, there is a more restricted 'inner' or 'ideal' system which, perhaps equally unconscious as a system to the naive speaker, can far more readily than the other be brought to his consciousness as a finished pattern, a psychological mechanism. The inner sound system, overlaid though it may be by the mechanical or the irrelevant, is a real important principle in the life of a language.

Once it was accepted that language had a definite phonological structure, a method was devised to describe this underlying system. This method became the science of phonemics. The phonemic structure of a language represents the minimal number of sound signals which make transmission of information possible. Spectrographic analyses of these minimal sound signals provide objective and empirical measurements of the quality of these minimal sound features.

\section{Statement of the Problem}

This investigation will determine the range of free variation of Bahasa Indonesian vowel phonemes in a given phonemic environment and types of conditioned variation from one environment to another. The nature and range of the vowel quality for each phoneme will be determined by spectrographic measurements.

\section{Delimitations of the Study}

This study will only deal with Bahasa Indonesian vowels, "sounds produced with vibration of the vocal cords, 
by unobstructed passage of air through the oral cavity, and not constricted enough to cause audible friction" (Pei, 1966). They will be the vowels found in monosyllabic Indonesian words under primary stress and in a consonant-vowel-consonant pattern. Each word will also be part of a minimal pair, i.e., every word must be contrasted with another word in which only the medial vowel is different and, to which a different semantic meaning is attached. 


\section{CHAPTER II}

\section{THEORETICAL BACKGROUND}

\section{Phonetics/Phonemics}

Phonetics is the branch of linguistics which deals with the actual speech sounds of a language. When dealing with the phonetic level of linguistic analysis, one describes the sounds of a language in terms of articulation or acoustic features. In articulatory phonetics, one describes sounds in terms of manner of articulation, i.e., whether it is a stop, fricative, etc.; point of articulation, i.e.., bilabial (between the lips), dental, etc.; or vowel quality, i.e., high-front-close (the highest part of the tongue. is very high in the front of the mouth for producing this particular sound), etc. In acoustic phonetics, sounds are described in terms of the distributions of frequencies characteristic of the sounds of a language. The relationship generally accepted as existing between articulatory and acoustic phonetics is that certain articulations produce certain distinctive patterns of frequency distributions. It must be emphasized at this point that both of the aforementioned types of descriptions deal with all human speech sounds, not necessarily those which perform a signalling function in a particular aspect of the language. 
"Distinctive features" are used to denote signalling functions. The label "distinctive feature" is used in the literature to mean two quite different things. Bloomfield describes the categorization, "with examples which imply that distinctive sound feature means any feature of the vocal sound, which, when changed, changes the meaning of a given word, e.g., pill and bill, sin and sing, etc." (Pierce, 1965). There Bloomfield labels $/ p /$ as a distinctive sound feature and /b/ as a different sound feature. Later, Roman Jakobson, Gunnar M. Fant and Morris Halle in their Preliminaries of Speech Analysis, take the phonemes of a language and break them down into their component phonetic features, some of which are distinctive, e.g., voicing in English /b/ vs. /p/, while others are not, e.g., aspiration in English /p/ in pin as opposed to $/ p /$ in spin. "Any one language code has a finite set of distinctive features..." (Jakobson, fant and Halle, 1961). In English, the feature of voicing in the /b/ of bill as opposed to the absence of voicing for the $/ p /$ in pill is the phonetic feature which distinguishes these two sounds. A similar presence vs, absence of aspiration does not alter the meaning of any English utterance, in fact, it is difficult to make English speakers aware of the fact that aspiration is or is not present. Implicit in this theoretical approach is the concept that the variation in human speech, for the most part, represents presence vs. 
absence of non-distinctive features of sound.

One theoretical approach to linguistic structures

views the phoneme as "concurrent bundles of distinctive features" (Jakobson, Fant and Halle, 1961). Each language has a "finite set of rules for grouping them (distinctive features) into phonemes" (Jakobson, Fant and Halle, 1961). Every phoneme in the language, then, is composed of a unique set of distinctive features such that it is different from any other phoneme by at least one of such distinctive features. This manner of linguistic signalling has important implications toward phonemic analysis of sound systems. As previously mentioned, a phoneme is a bundle of distinctive features, which, when altered changes meaning. In order to verify whether a sound is a phoneme or not, one must show a word in which the replacement of at least one distinctive feature makes another word, i.e., a minimal pair, differentiated by only a single distinctive feature, and having two distinct grammatical or semantical meanings.

Phonemics, the study of phonemes is the level of linguistic analysis which answers the question of how language utilizes sound matter, selecting certain of its elements and adapting them for various ends. The primary functions of sound in a language is to distinguish one utterance from another in normal conversation. "Phonemic analysis as an operation examines available data in order to discover an underlying structure... not an operation which forces a mass 
of data into a structure" (Pulgram, 1965). The nature of each feature is of the essence. Thus, the composition of each phoneme becomes of primary importance in a language. "The phoneme can only be defined in reference to the larger frame which is the language of which it is a structured feature" (Pulgram, 1965). It is the shortest stretch of sound which serves a signalling function.

\section{Acoustic Theory}

Distinctive feature theory, as previously described, seems to handle such phonemes as stops, fricatives and nasals quite well, e.g., the airflow out of the mouth is either stopped, or it is allowed to escape. On the other hand, vowels seem to be ranges of phonetic quality which are extremely difficult, if not impossible to distinguish in terms of presence vs. absence of distinctive features. Since this study will not be concerned with consonants but only with vowels, it is only necessary to discuss the acoustic nature of vowel qualities from this point on.

\section{Fundamentals/Harmonics}

Vowel quality is determined by a combination of a fundamental and its harmonics. A vowel quality displayed on an oscilloscope shows a very complex single wave form. This wave form is in reality the mathematical sum of a number of simple wave forms, or at least for theoretical purposes 
can be treated as such. These wave forms are generated in the oral tract by the opening and closing of the glottis. The fundamental wave is a sine wave with a frequency equal to the number of times the glottis opens and closes each second, and an amplitude which is directly proportional to air pressure in the lungs. Because of the nature of sound waves, a harmonic is generated at every multiple of this fundamental, e.g., if the fundamental is 100 cycles per second, then a harmonic is generated at 200, 300, $400, \ldots \infty$. As soon as the complex wave leaves the vocal chords, harmonics are filtered out by the nature of the tissue surrounding the oral tract, as weIl as the cavities in and adjoining the oral tract. The complex wave emerging from the mouth is the mathematical sum of fundamental and the harmonics which have not been filtered out by the oral tract, cf. Martin Joos, Acoustic Phonetics (1948), chapters 1 and 2 for a fuller explanation of this process.

\section{Acoustics vs. Articulation}

In the last century, far too much energy has been expended in attempts to relate acoustic features to specific articulatory movements. Bloch (1942) illustrates this by stating, "qualities are identified by ear, but in linguistic works they are traditionaliy defined in terms of their assumed production by the vocal organs." This type of study is misdirected because the only things that impinge on the 
human ear are the harmonics which were not filtered out. The articulatory movements which cause the filtration, i.e., movement of the tongue from front to back creating a series of filters, each of which removes different harmonics from the complex waves, are irrelevant. Pike (1943) argues, one should "analyze and describe the sounds (or sound waves) themselves rather than the movements producing them."

It has long been noted by acousticians that a variety of articulatory movements remove the same harmonics and result in the production of very similar sounds. Pierce (1962) illustrates this by saying:

As long as the formants are in their proper positions, $i . e$. the proper frequencies are passed through the speech mechanism, it does not matter whether the unwanted frequencies are filtered out by rounding the lips or moving the tongue to the back. Thus, when Holbrook and Carmody give one front-back position for the tongue for a given English vowel and IPA (International Phonetic Alphabet) gives another, it is quite probable that both are completely correct, and that the formant shift is made by compensating for the lack of tongue movement in the speech of some speakers by additional lip rounding....

Since the hearer of a stream of speech can hear only those harmonics which emerge from the mouth as components of the final complex wave, the placement of the formant is of primary importance, not the articulation which produced the sound.

Therefore, a study of the phonetic quality of vowels demands an instrument which is capable of making an accurate record of the presence or absence of all the harmonics having sufficient amplitude to significantly alter the final wave form. The acoustic spectrograph is such an instrument, 
it "was the first instrument to make large scale acoustic analyses a practical possibility" (Ladefoged, 1967).

\section{Spectrograph}

The acoustic spectrograph is a device which records a stream of speech 2.4 seconds or less in length. "This recording is then fed into the analyzing part of the spectrograph, where at each successive playing one frequency, or rather one frequency band is lifted out of the total by the variable filter" (Pulgram, 1965). A black marking is made on a piece of electro-sensitive paper each time there is a harmonic present within the frequency band being analyzed. Since the articulators are constantly moving and changing the filtration characteristics of the vocal tract, the black markings, made by a stylus, reflect the movements of the articulators in a very broad sense. More important, however, it makes a precise record of the stimulus, i.e., the harmonics which reach the ear of the listener. Dunn (1950) says "the vowels have associated with them different frequency regions, in which the sound is more intense than elsewhere in the spectrum. The name 'formant' has been applied to these regions."

The next problem then, is to relate the concentrations of power mentioned above, i.e., the formants, to human perception of speech sounds. The most widely utilized technique in this area is one devised by Martin Joos (1948), 
generally referred to as his 2 formant Theory. This technique represents the plotting of formant 1 and formant 2 in a specific way on a particular chart, cf. Chart 1 on p. 23. This technique is clearly described by Ladefoged (1967).

The relations between the formant structures of the vowels in a number of words can be conveniently represented by means of formant charts which show the frequency of the first formant at a time in the word when the formant structure is changing at a minimum rate plotted against the frequency of the second formant at the same time.

When making these kinds of plots, a. charting is derived of vowels for any language, which is remarkably like the traditional impressionistic vowel charts of the 19 th century. Esner (1947) illustrated that if the frequency of the first formant was plotted against the frequency of the second formant, it seemed to equal "the relation between formant frequency and the traditional vowel diagram."

Basically, this study will reproduce such vowel charts for a number of examples of each sound in Bahasa Indonesia. Formant 1 will be plotted against formant 2 for each vowel phoneme in a variety of phonemic environments. The purpose of this will be to determine the range of variation for every vowel in each environment as produced by a single native speaker. 


\section{CHAPTER III}

\section{METHODOLOGY}

\section{Phoneme Identification}

In order to assess the phonetic quality of vowel phonemes, one must first ascertain the number and relationship of sound contrasts in a language, i.e., the phonemes. The visual representation of the actualization of the phoneme, i.e., the spectrogram can only be made on the basis of a preceding decision of the linguist on the types and number of phonemes in the language to be anaiyzed (Pulgram, 1965): "Phonemic analysis cannot be made with phonetic data alone; it must be made with phonetic data plus a series of phonemic premises and procedures" (Pike, 1947). A spectrogram conveys phonetic information which aids the linguist in determining which phonetic features are consistently present in order to reach the most accurate phonetic description.

There are a variety of premises and procedures which the investigator may utilize in order to discover the phonemic structure of a language. Pike (1947) argues that the investigator must have at hand observable native reaction to native sounds and/or know structural facts pertaining to the phonetic nature of the sounds and their distribution. As stated before, a phoneme is a bundle of sound features 
which, when substituted for another bundle, creates a difference in meaning. Since the creation of a different morpheme is the result of the substitution of a different sound feature, these sound features are said to be phonemes.

A pair of words in which the first word is the same as the second except for the fact that one segment is replaced by a different but phonetically similar segment in the second word constitutes proof that the two similar segments are phonemically distinct. ... Word pairs of this type are said to be MINIMALLY DIFFERENT because no smaller difference in the language can make a difference in meaning in words (Pike, 1947).

Hence, minimal pairs of words were used to find phonemes. "Minimally different word pairs prove to be the beginner's single most important tool for the analysis of phonemic differences" (Pike, 1947).

Thus, Echol's and Shadily's An Indonesian-English Dictionary (1968) was utilized to find three-phoneme words containing two consonant sounds with a vowel in medial position. The process was simply to go through all the words beginning with consonants and find minimally different three phoneme words. This was done on a purely anthroposcopic basis on the part of the investigator. If a different letter was employed to distinguish a different meaning, it was assumed to be a different phoneme. The following word pairs and their meanings are examples of the words found in the dictionary:

$$
\begin{aligned}
& \text { ban--tire } \\
& \text { das-- a shot }
\end{aligned}
$$$$
\text { bin--son of }
$$$$
\text { dos--small box, carton }
$$ 


$$
\begin{array}{ll}
\text { pal--pole. } & \text { pel--field } \\
\text { rang--rank, position } & \text { ring--ring } \\
\text { teh--tea } & \text { toh--yet, nevertheless }
\end{array}
$$

After having obtained the words from the dictionary, a native informant was called upon to verify the difference in meaning in the minimal pairs and to pronounce them so that they could be phonetically transcribed in an impressionistic manner. The informant employed was Kok Djen Su, a student at Portland State University from Yogjakarta; Indonesia. He has been a student in the United States for approximately two years, and speaks broken, although very understandable English. Mr. Su was born to Mr. and Mrs. Su Hendry Su, who both speak Bahasa Indonesia, Javanese and a small amount of Chinese. Since his birth, the informant was exposed to a mixture of Javanese and Bahasa Indonesia, but has employed the national language of Indonesia since the age of three at school. His bilingual upbringing, it seems to the author, does not create a substantial difference in the competence of Mr. Su iri Bahasa Indonesia. In fact, he was able to distinguish the pronunciation of words in both Javanese and in Bahasa Indonesia. The utilization of one informant deletes any regional variation or individual variation between informants. Since here we are attempting to ascertain the relative range of phonetic quality of vowel phonemes in Baha- 
sa Indonesia, the informant's bilingualism ahould cause none or very few phonetic distortions.

After having verified the difference in meaning of the word pairs, Kok Djen Su pronounced the word. The following impressionistic version of the Indonesian voweI system was described:

\begin{tabular}{|c|c|c|c|}
\hline & front & central & back \\
\hline high & I & & $U$ \\
\hline mid & $E$ & & 0 \\
\hline Low & .. & A & \\
\hline
\end{tabular}

\section{Spectrograms}

The phonemic entities symbolized in the preceding section represent range-units of phonetic quality. The symbols and their position on the chart are based on the aural perceptions of the investigator. The purpose of the spectrographic analysis of this data is to determine, as accurately as possible, the actual phonetic range represented by each of the phonemic symbols. 
In order to make spectrograms from which meaningful conclusions can be drawn, one must have a native informant of the language to be studied. Spectrograms were made of the speech of $\mathrm{Mr}$. Su, the informant described earlier.

In order to conserve the time of the informant, a sample of three-phoneme words were recorded. The threephoneme words begin and end with consonants and contain a vowel in medial position. The list appears in Appendix A. The list of words was specifically selected to eliminate, in so far as possible, all variation other than that which is specifically caused by the preceding and following consonants. This is true because by utilizing a single informant, the influence of dialects, both regional and social, are eliminated, and by utilizing one syllable words under primary stress, sequential influences such as the Markov Process ${ }^{1}$ are eliminated, since there is no sequence beyond one phoneme preceding and following the vowel. This being the case, one should be able to derive from a series of spectrograms of those vowels, both the range of free variation and the specific influence of each particular consonant on the vowel quality of each medial phoneme.

The next step in the procedure was to play the taperecordings into the spectrograph, two or three words at a

${ }^{1}$ The Markov Process is a mechanical way of handling entropy in sequential operations. In linguistics, this is stated in terms of the probability of the occurrence of a particular phoneme, morpheme, etc. in a precise sequence. 
time. The machine can handle 2.4 seconds of speech on one spectrogram; thus two or three words could be analyzed at the same time as one, with no loss in quality or precision. Unfortunately, the recordings had to be played into a microphone which picks up some background noise, but, by placing the microphone of the spectrograph very close to the. loudspeaker of the tape recorder and turning the volume up slightly, this background was eliminated for all practical purposes. It would have been better to have had a direct connection between the recorder and the spectrograph, but unfortunately no such device was available. Background noise shows up as very small specks scattered more or less at random, and, unless the volume of such noise is exceedingly strong, does not interfere with the reading of the spectrograms.

Once the machine had completed the analysis and produced the graphic record of the list of words, a frequency measur-, ing device was produced by the machine, cf. example below:

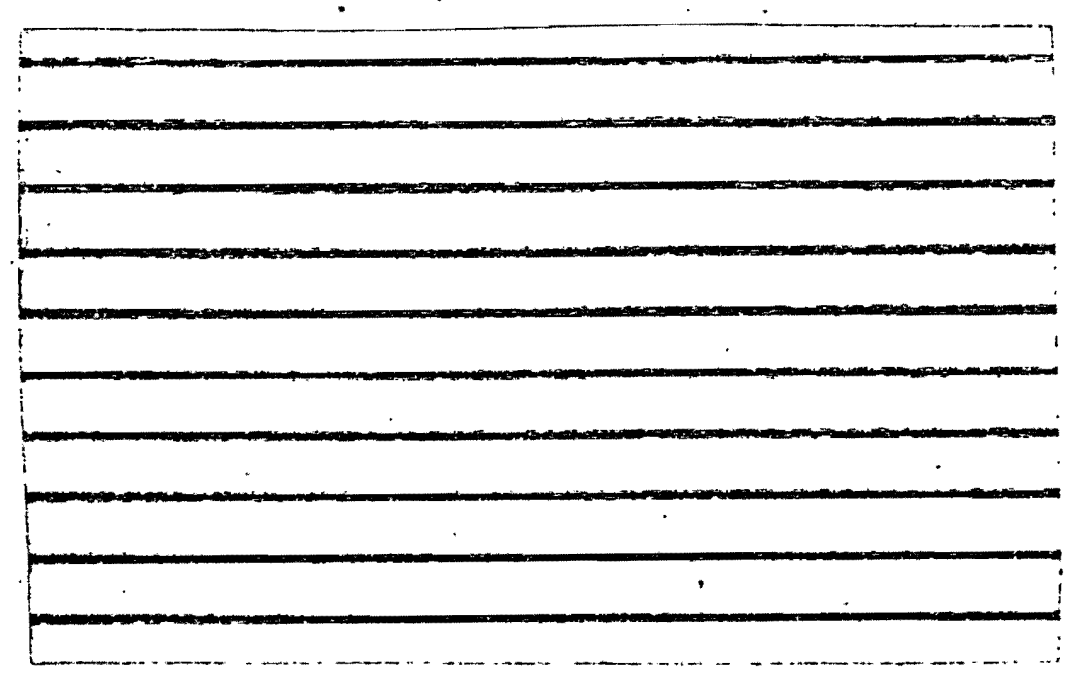


This measuring device is in reality a spectrogram with horizontal markings. The first line on the chart represents a frequency of 0 hertz $(h z$.$) . Each line above the first rep-$ resents a multiple of $500 \mathrm{hz}$. The device is used to locate the center of formants 1 and 2 . Since it is graduated in $500 \mathrm{hz}$. , it is necessary to interpolate when the center of. power for a particular formant falls between two of these lines. This is done by dividing the area between the two lines in half, then dividing one of the halves in half which gives a range of $125 \mathrm{hz}$; within which the measurement falls, and an estimate is made of the precise measurement within the $125 \mathrm{hz}$. range. This should give formant positions with an accuracy of greater than $\pm 25 \mathrm{hz}$.

When visual location of the formant centers becomes difficult, a "section" of the formant can be made, cf. example below. Such difficulties with visual location usually arise when two weak formants overlap. Such overlapping produces what appears to the naked eye to be a band of moderately dark grey bands. The "sectioner" is a built in mech-

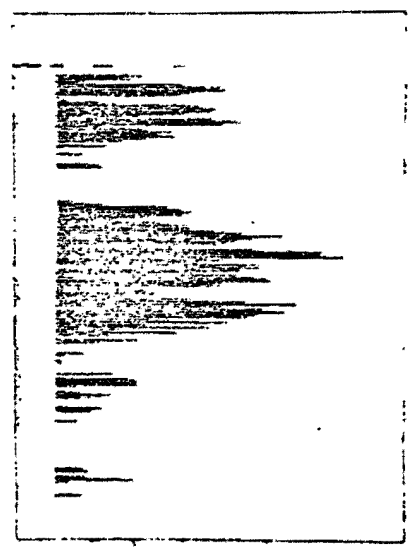


anism capable of handling such problems. In the preceding example, the amplitude of each harmonic is proportional to the length of the line representing that harmonic. This makes it possible to locate formant centers when visual location is difficult.

The measurements were then transferred to formant charts, cf. Chart 1, on the following page. 


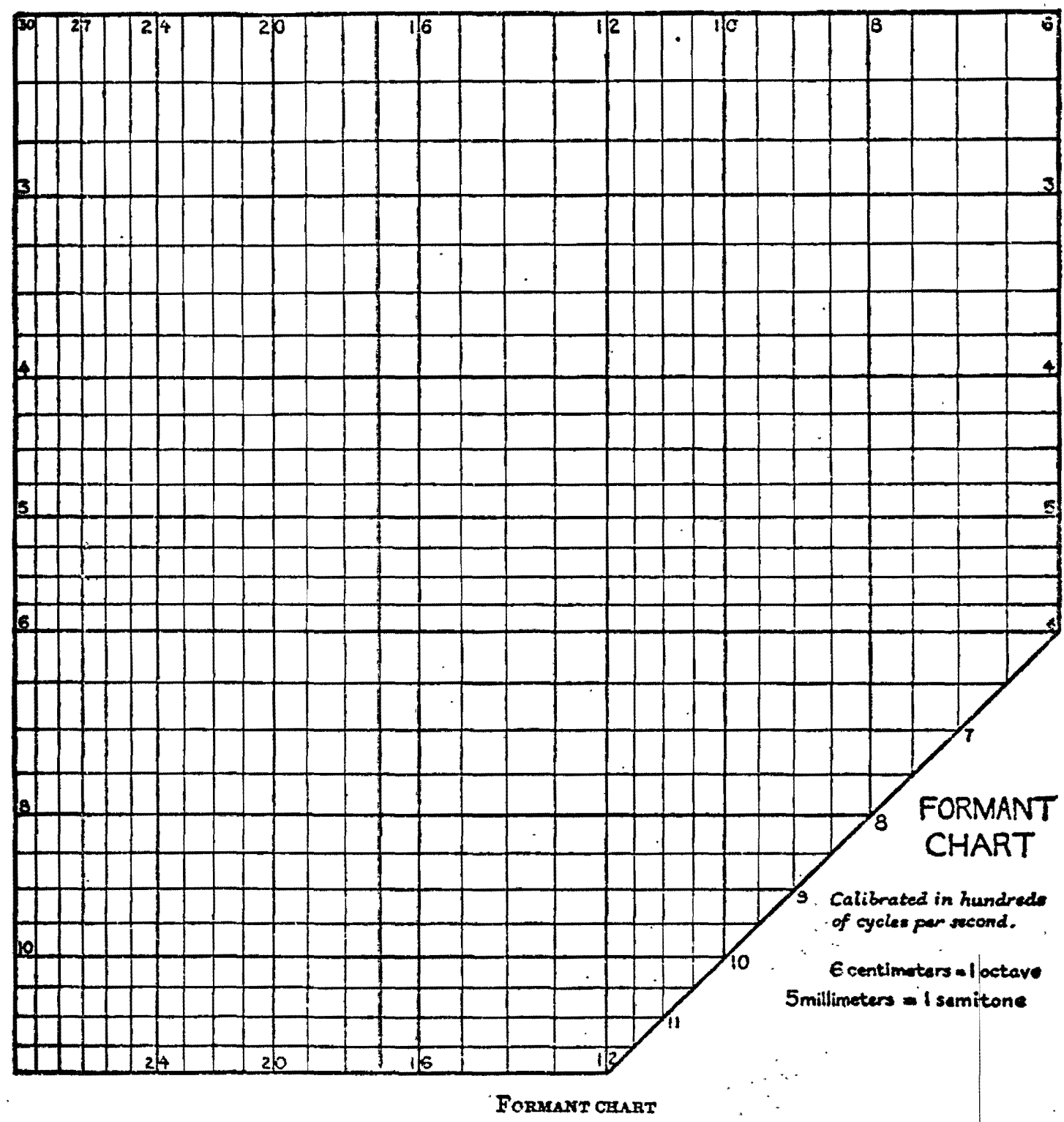

Placing a single point on this chart is an assertion that formants have been observed at two frequencies: one formant at the frequency named along the right or left edge, the other formant, at the frequency named along the top or bottom edge.

ex., Martin Joos, Acoustic Phonetics (1948). 


\section{CHAPTER IV}

\section{F INDINGS}

The data provided by the preceding methodology consisted of a series of scatter patterns on the vowel charts. Each of the dots within the pattern represented one occurrence of a particular vowel. To determine the range of each phoneme, the most divergent points in each pattern were con-. nected by a line. These lines, then, circumscribe an area which included the range of all the vowels in the sample, recognized by the informant as a particular phoneme.

Verbal descriptions, the actual charts of the phonemes, and the spectrograms utilized will be found on the following pages. 
The distribution for the sounds which the informant produced and recognized as the phoneme /I/ ranged on the vowel chart in a broad scattering from $300-500 \mathrm{hz}$. for formant 1 and 1500-2100 hz. for formant 2 .

CHART II

/I/

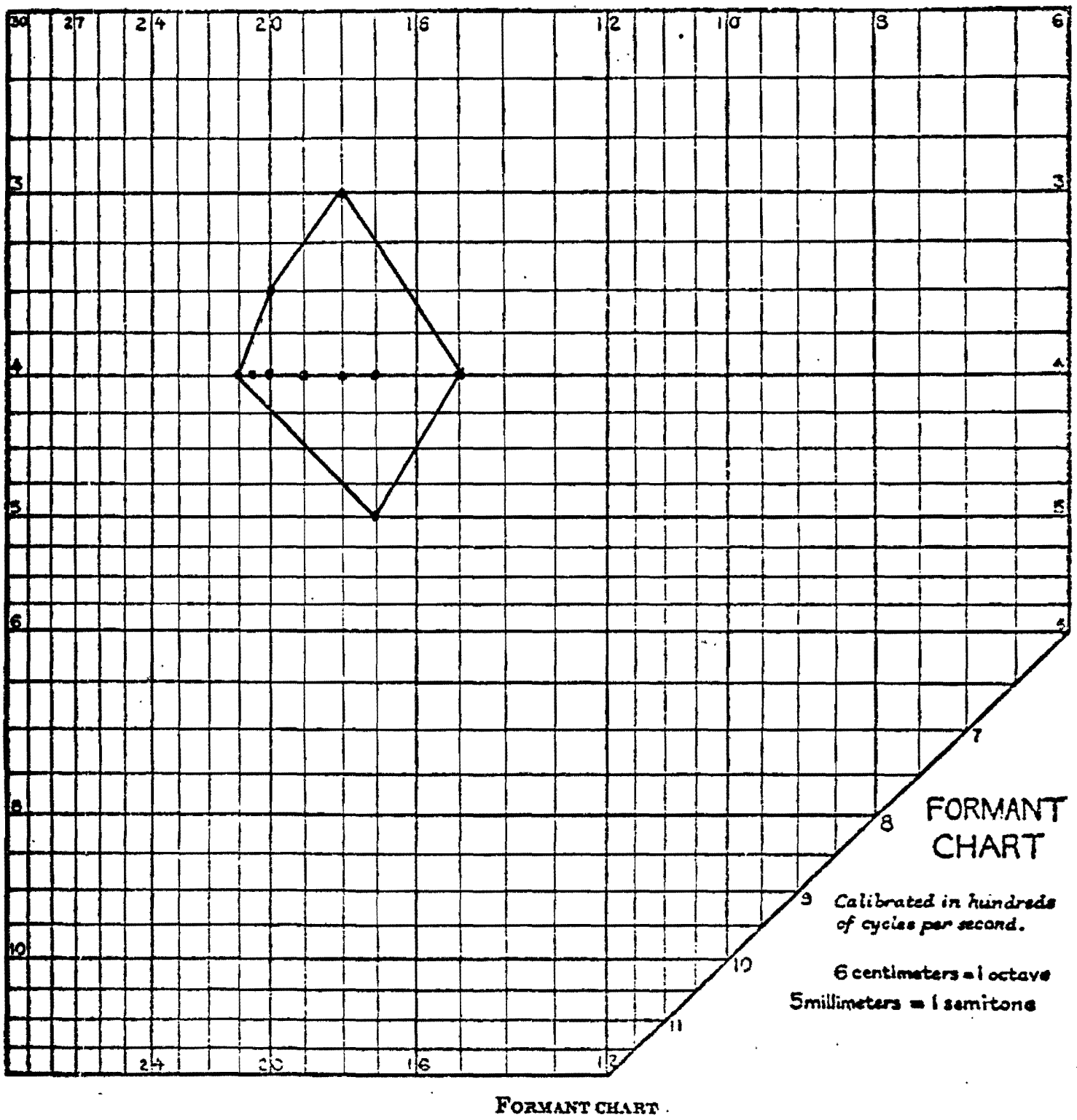

Placing a single point on this chart is an assertion that. formants hava been observed at two frequencies: one formant at the frequercy named slong the right or 'eft sdge, the other formant at the frequency named along the top or bottom edge. 


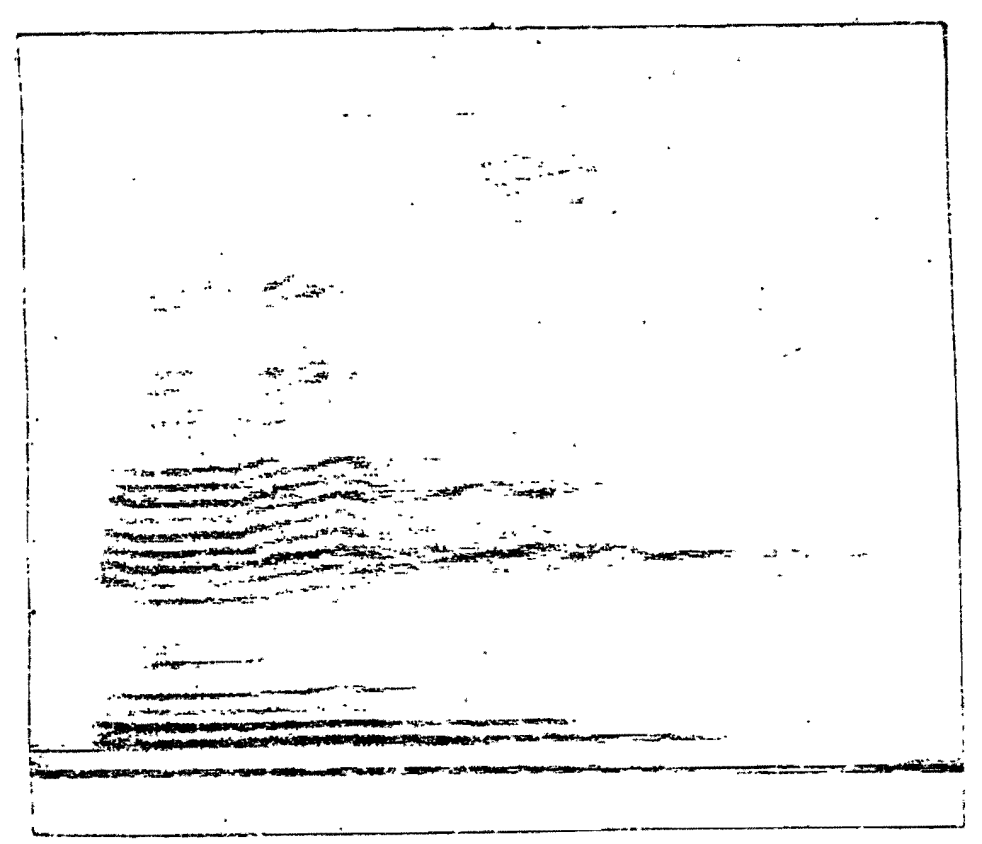

[bIs]

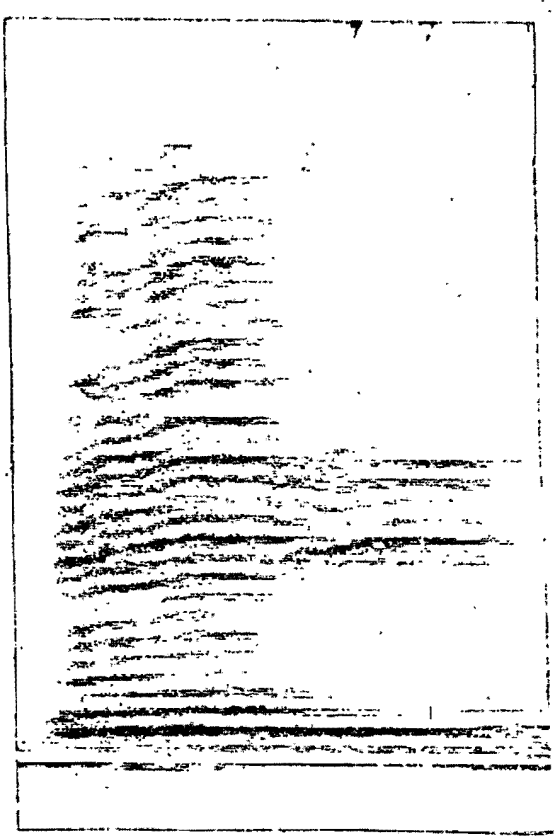

[bIn]

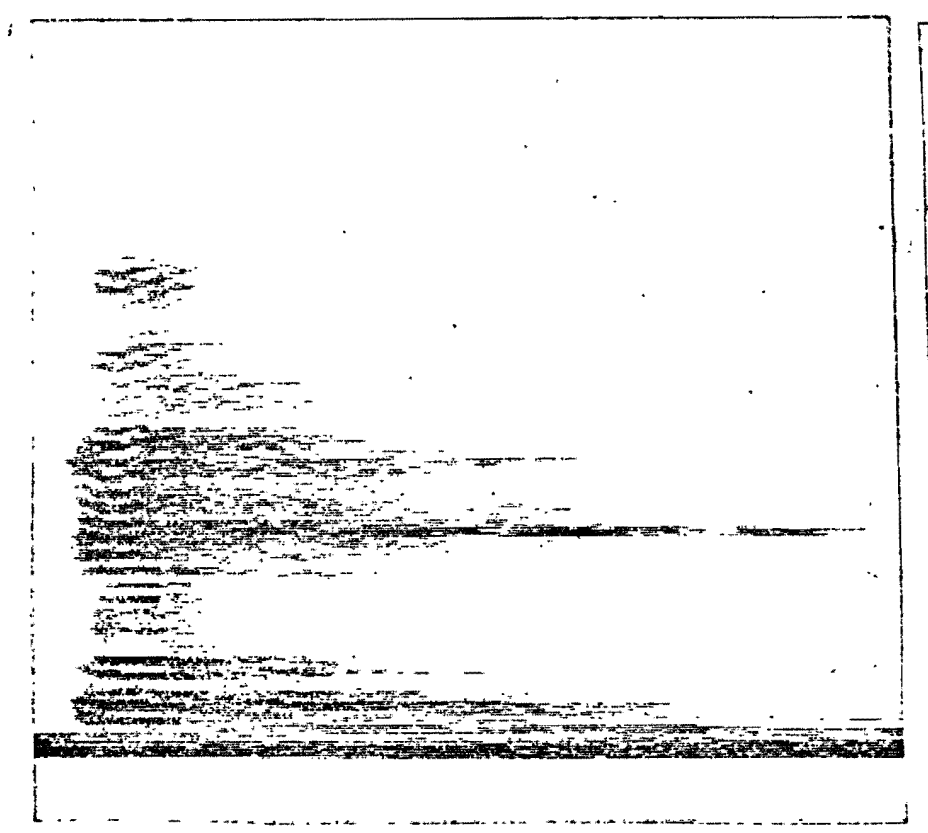

[dIm]

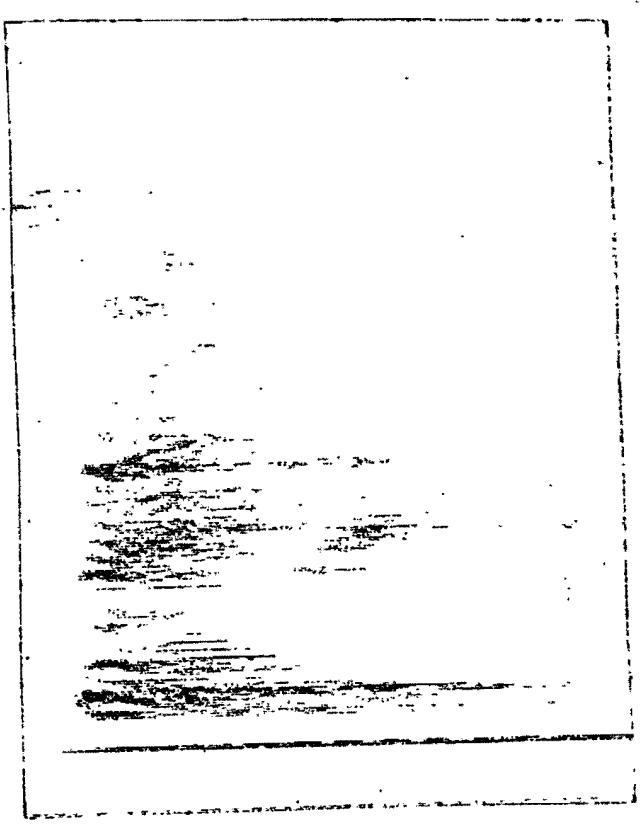

[sIh] 


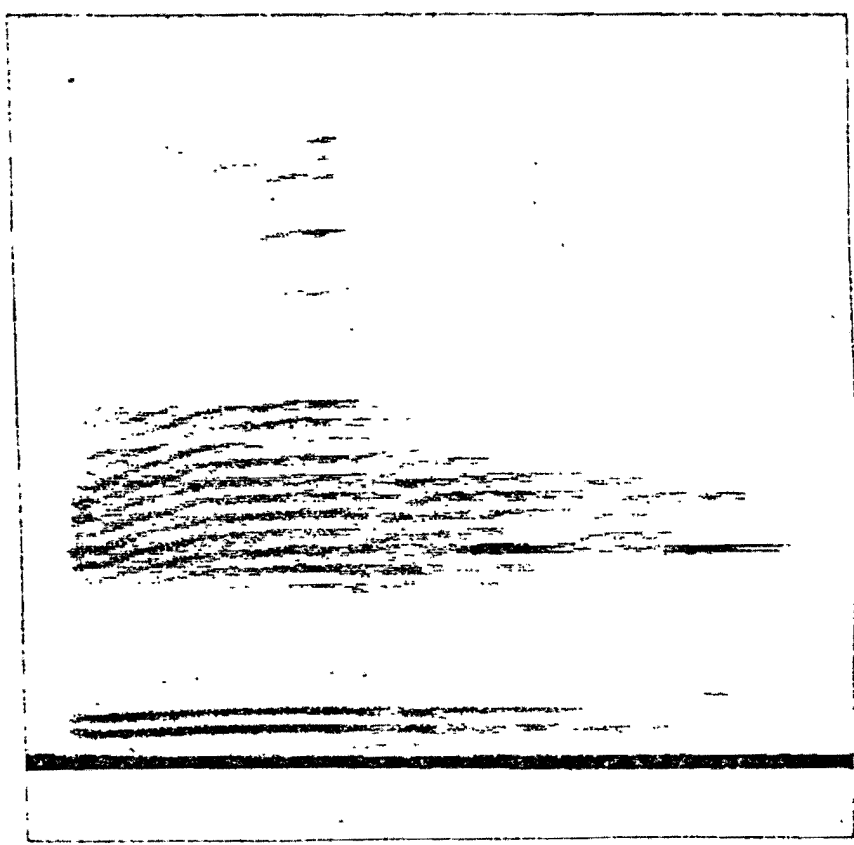

[bIr]
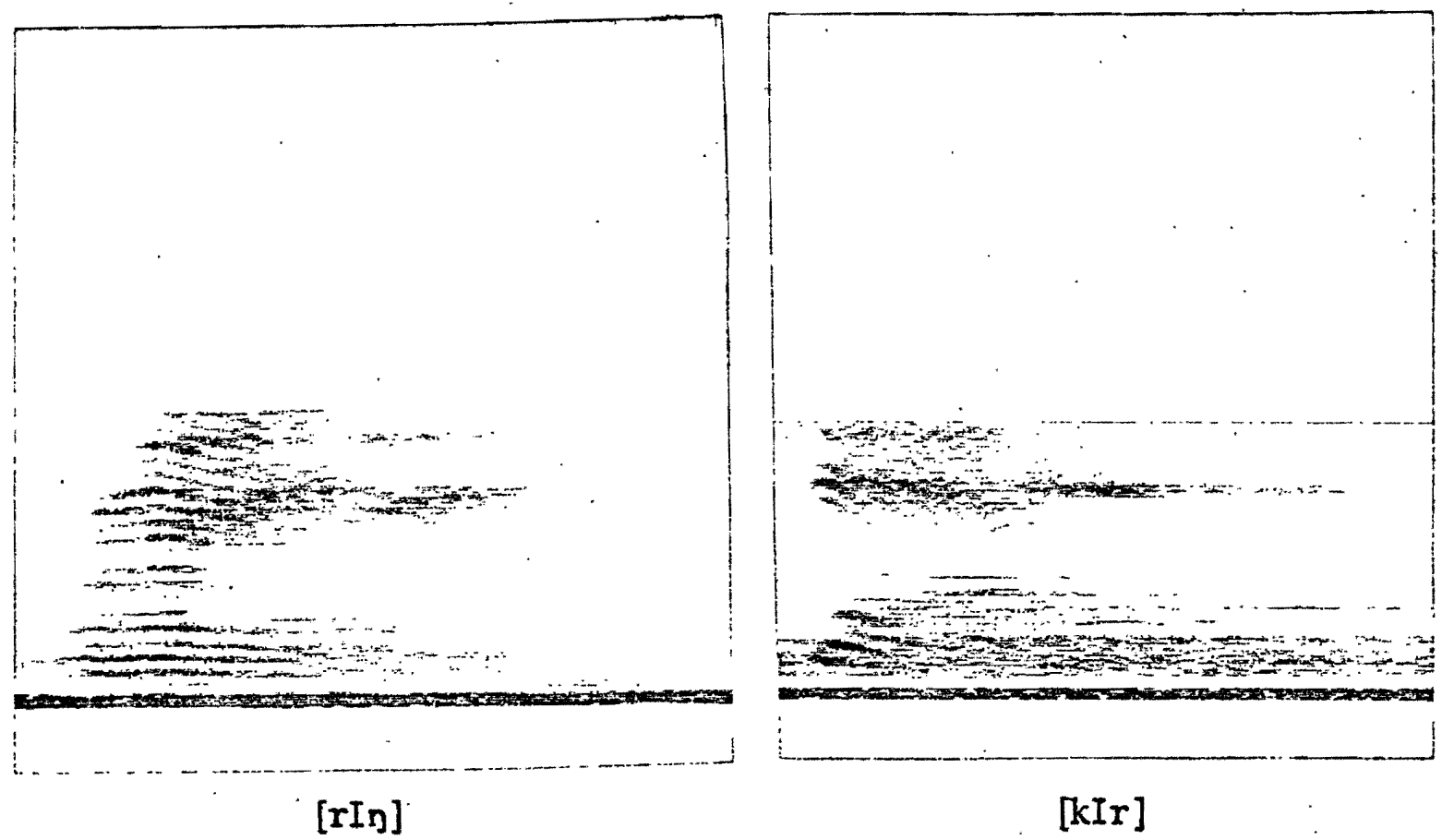

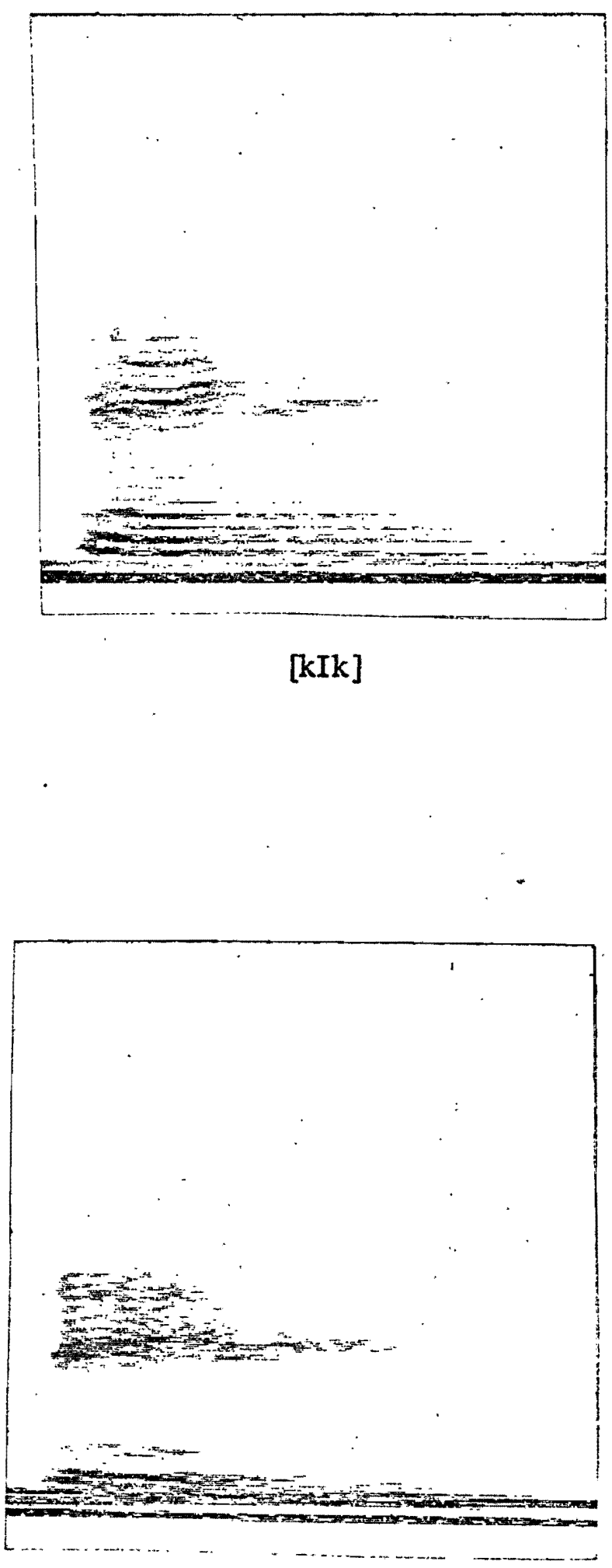

[dIk] 


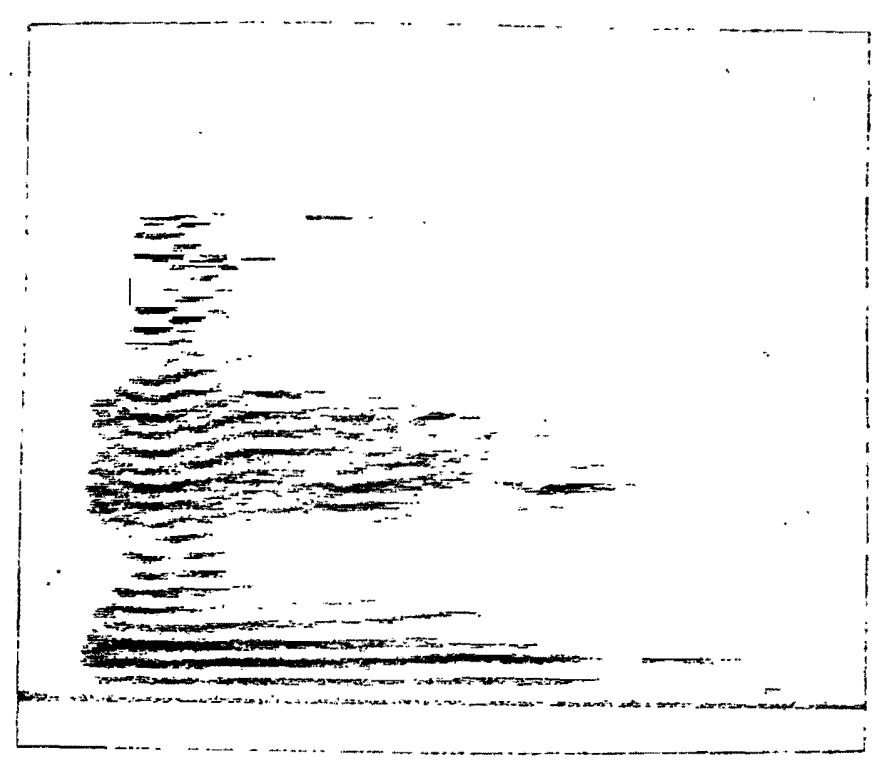

[tIn] 
The distribution for the sounds which the informant produced and recognized as the phoneme /E/ ranged on the vowel chart in a thin oval shaped distribution from 400-625 hz. for formant 1 and from $1400-2000 \mathrm{hz}$. for formant 2 .

\section{CHART III}

/E/

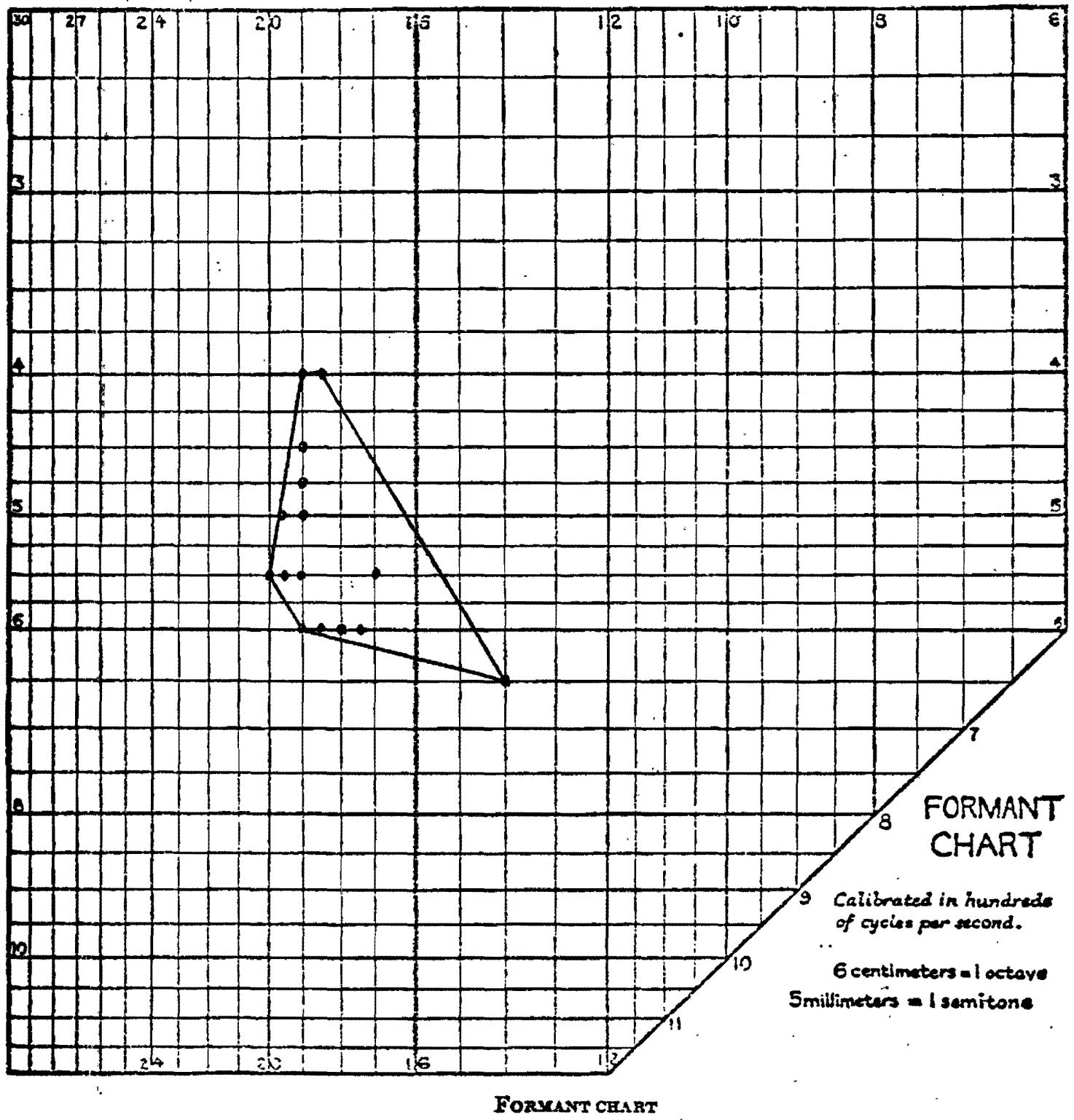

Placing a single point on this chart is an assertion that formants have been observed st two frequencies: one formant at tive fraquency named along the right or left sdge, the other formant at the frequency named along the top or bottom edge. 


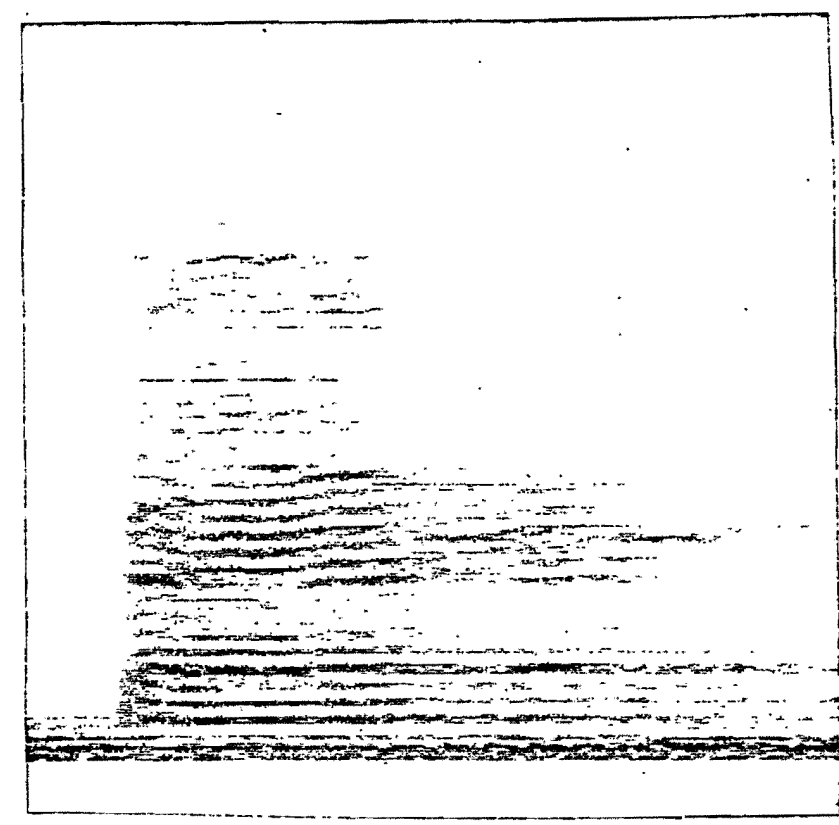

[pEs ]

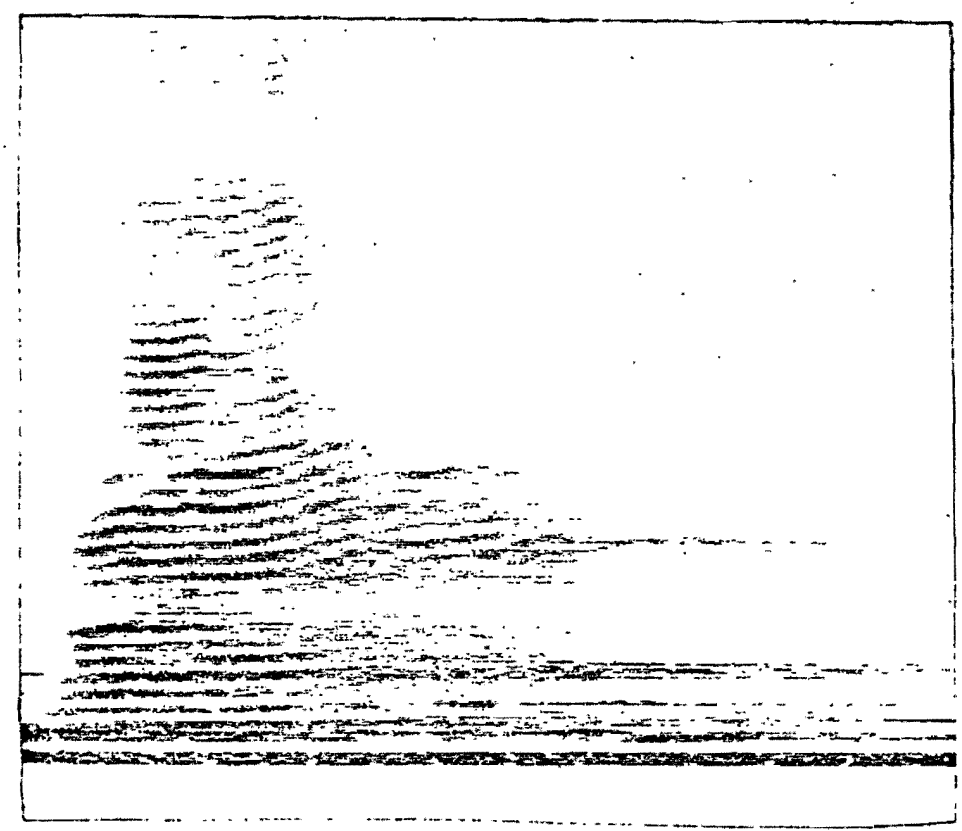

[rEm] 

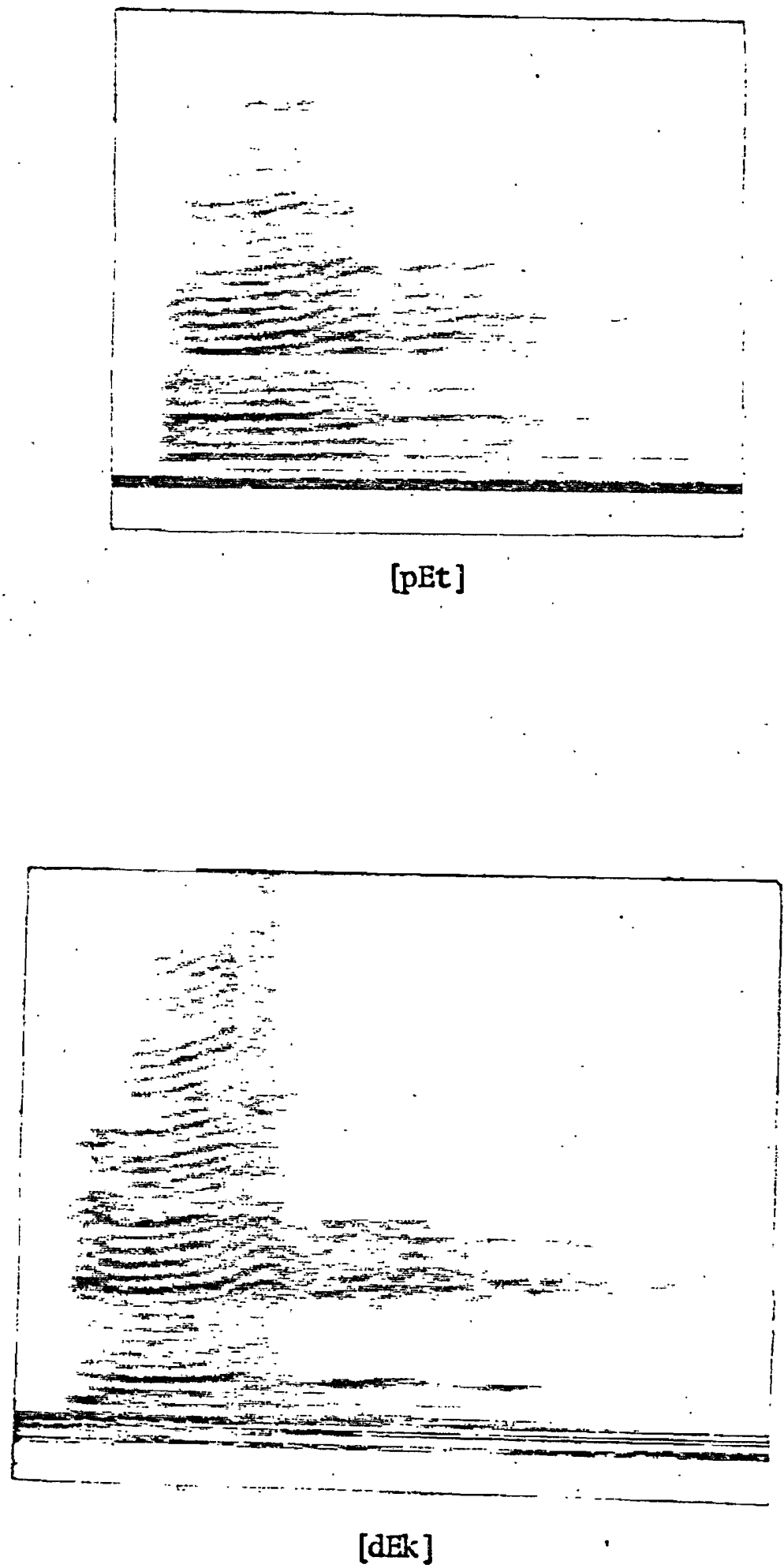


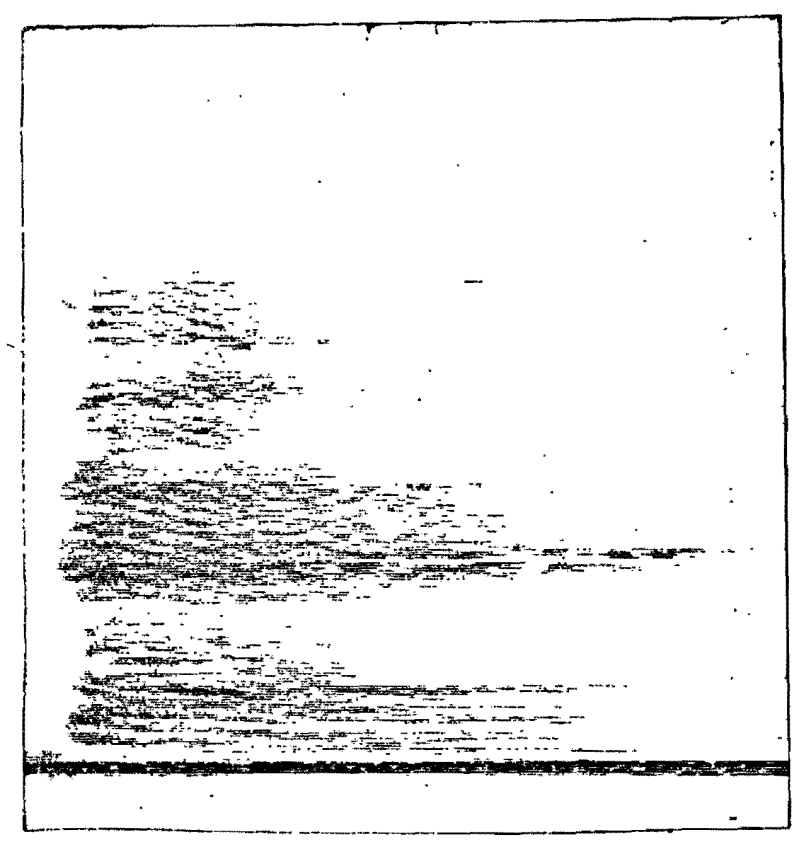

[dEn]

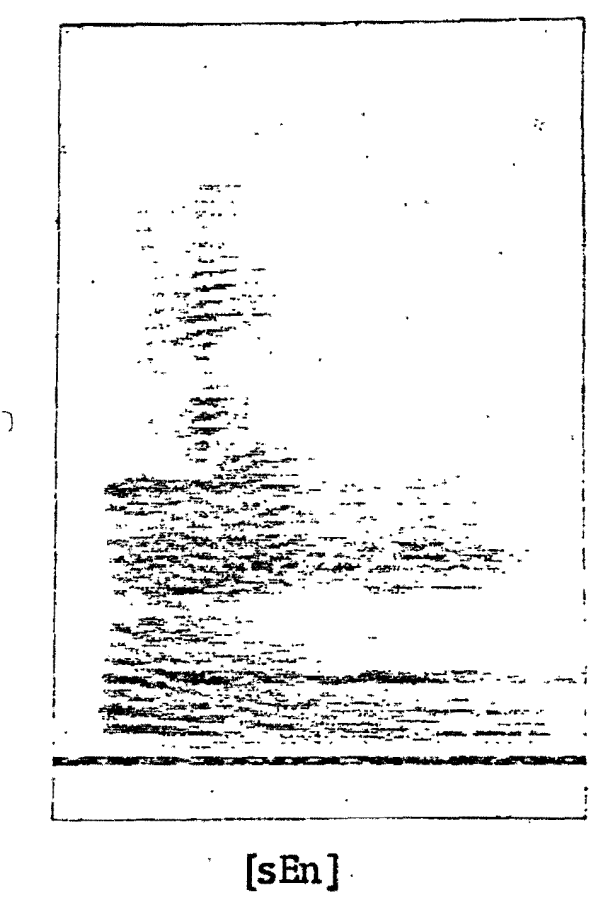

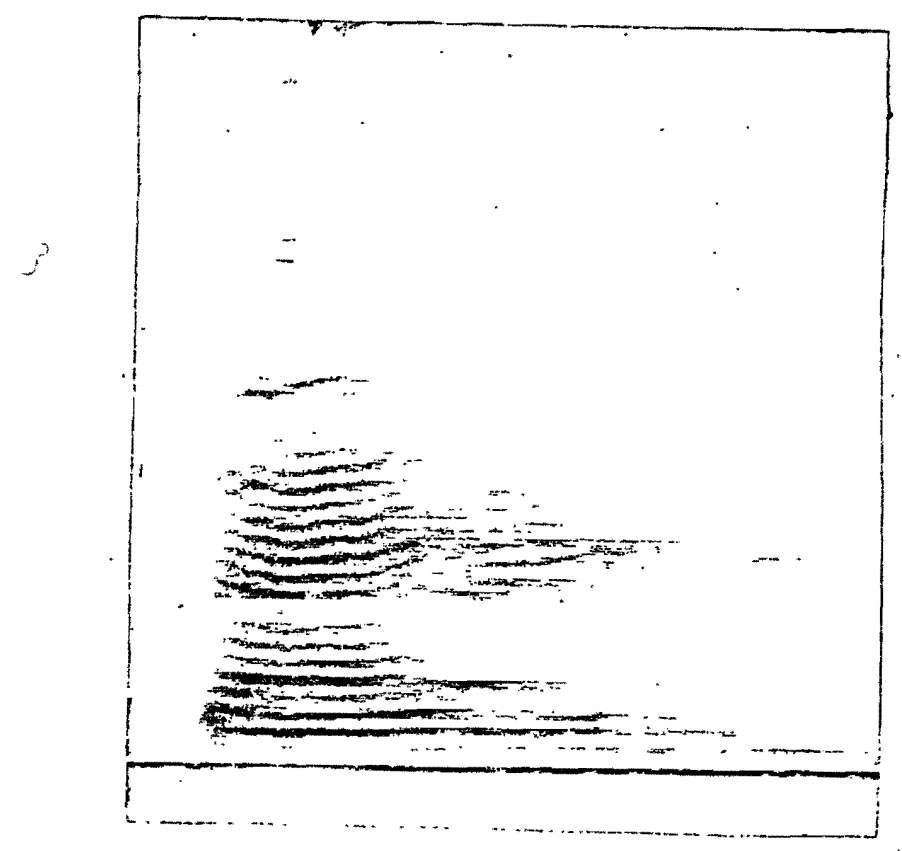

[ČEn]

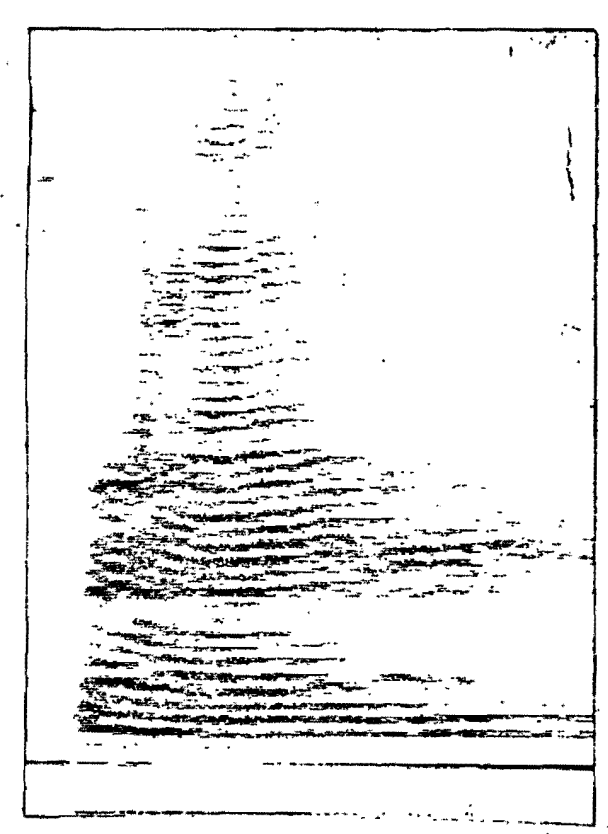

[sEn] 


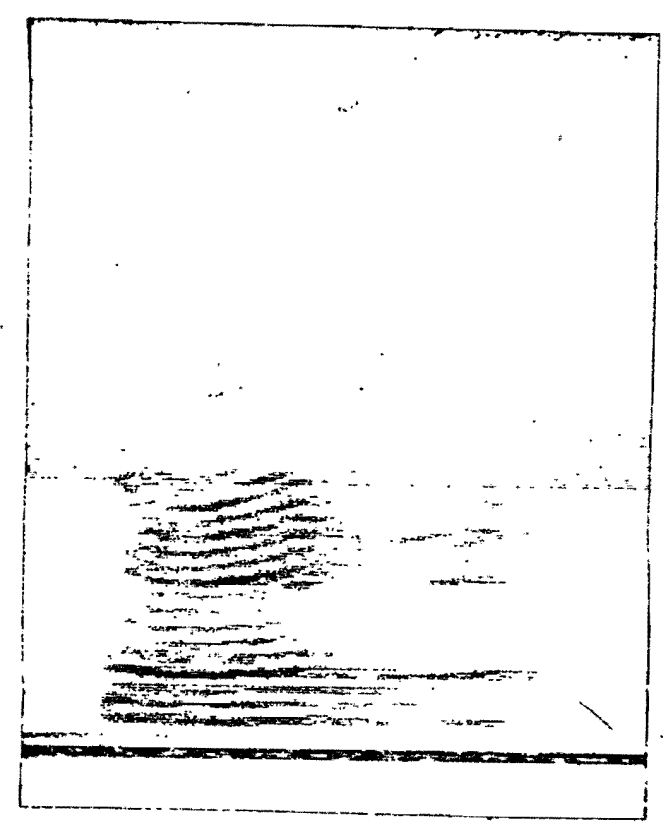

[sEp]

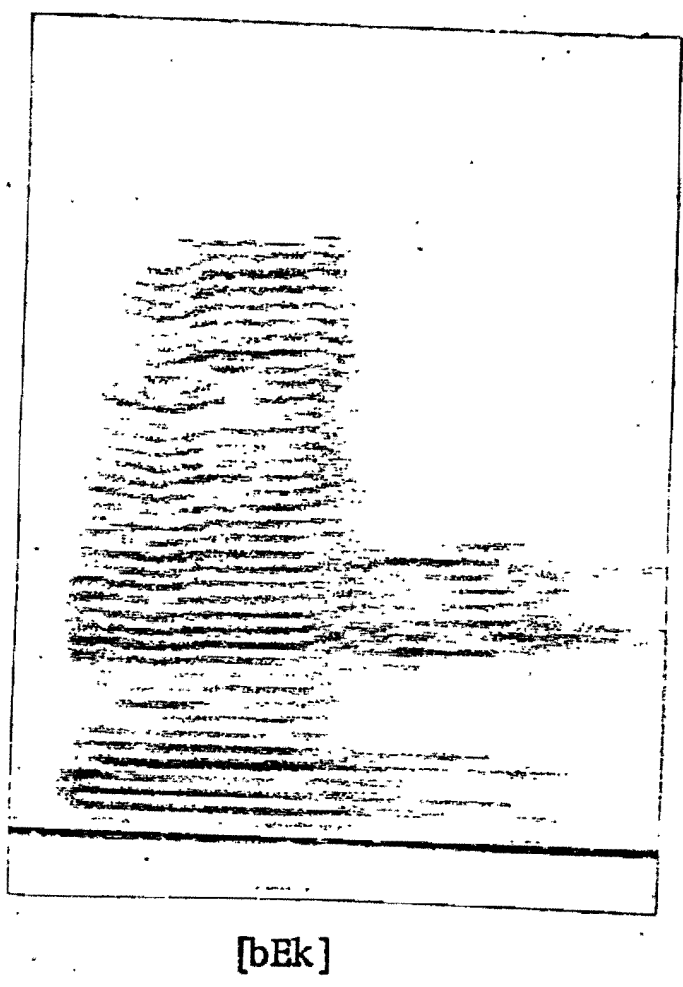

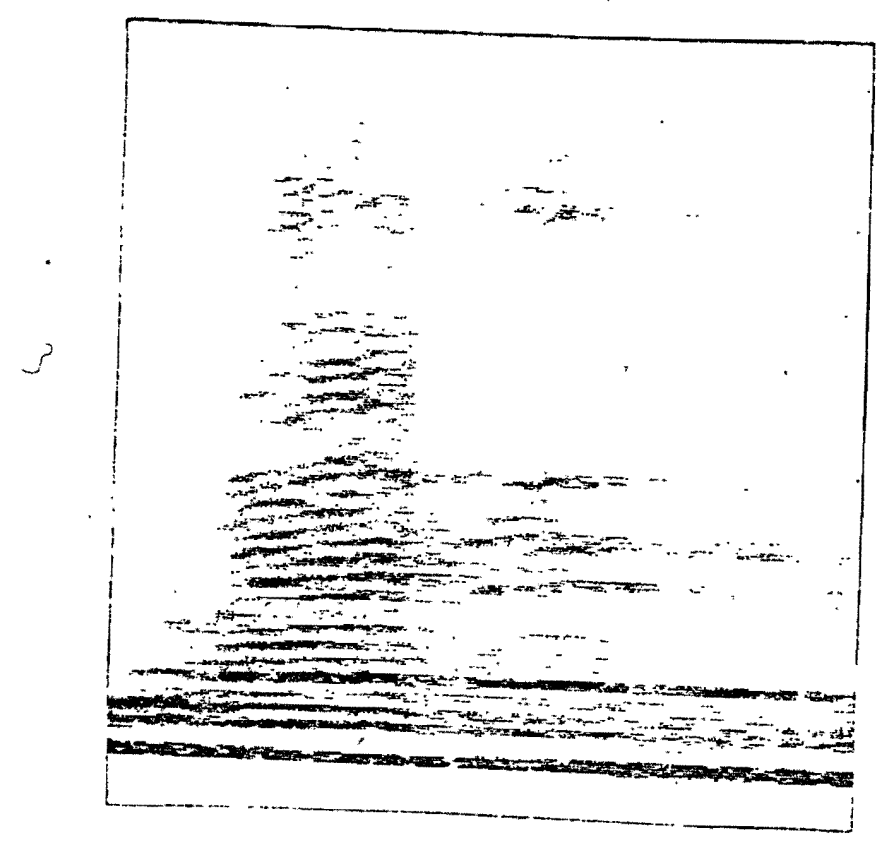

[1Es]

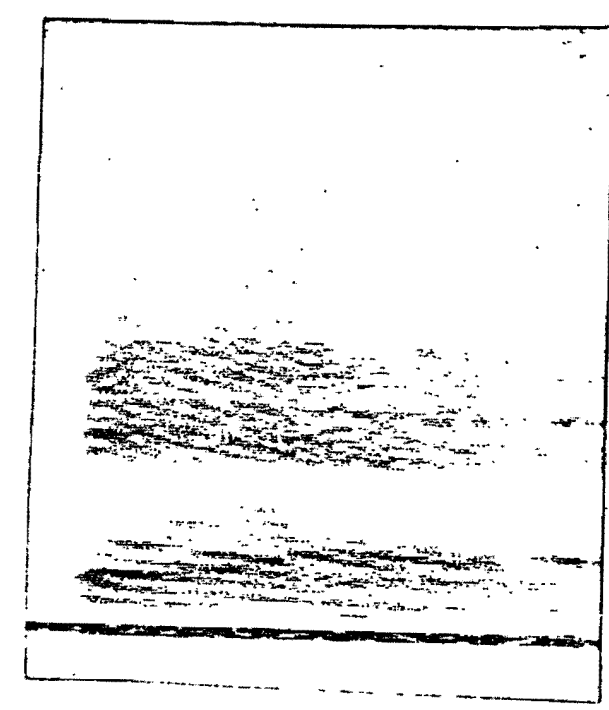

[bE1] 


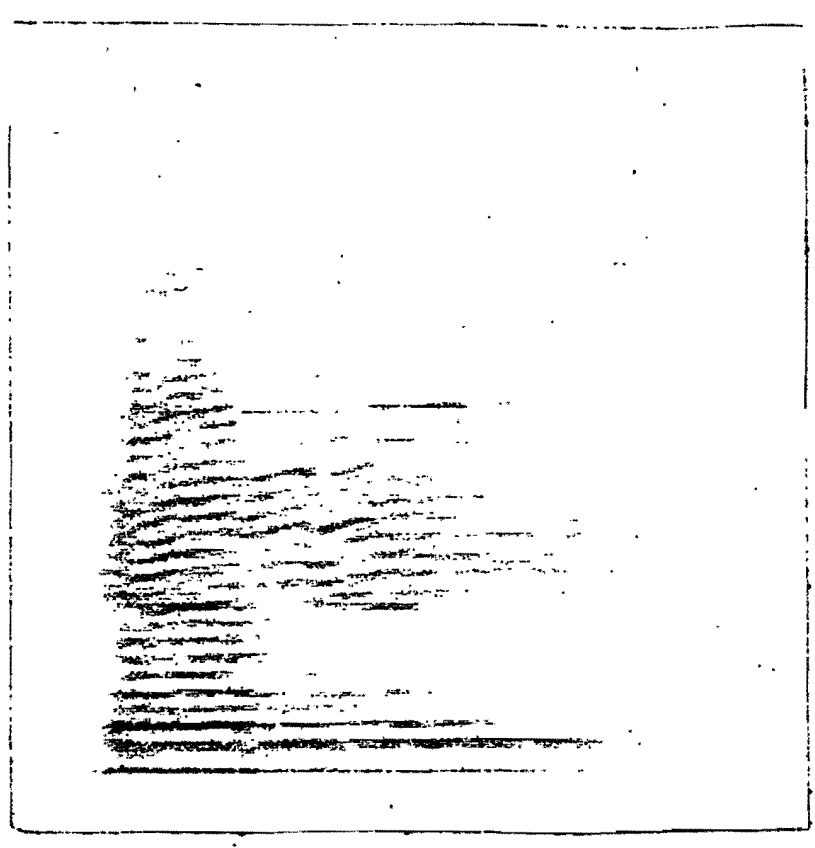

[dEm]

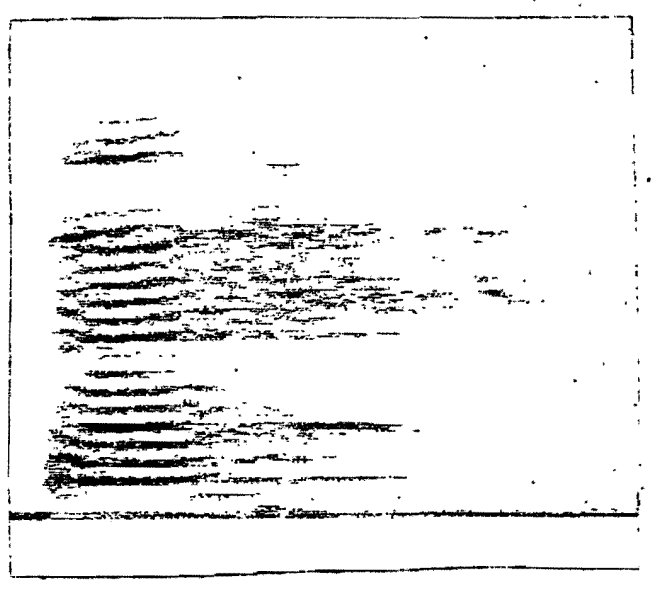

[tEh]

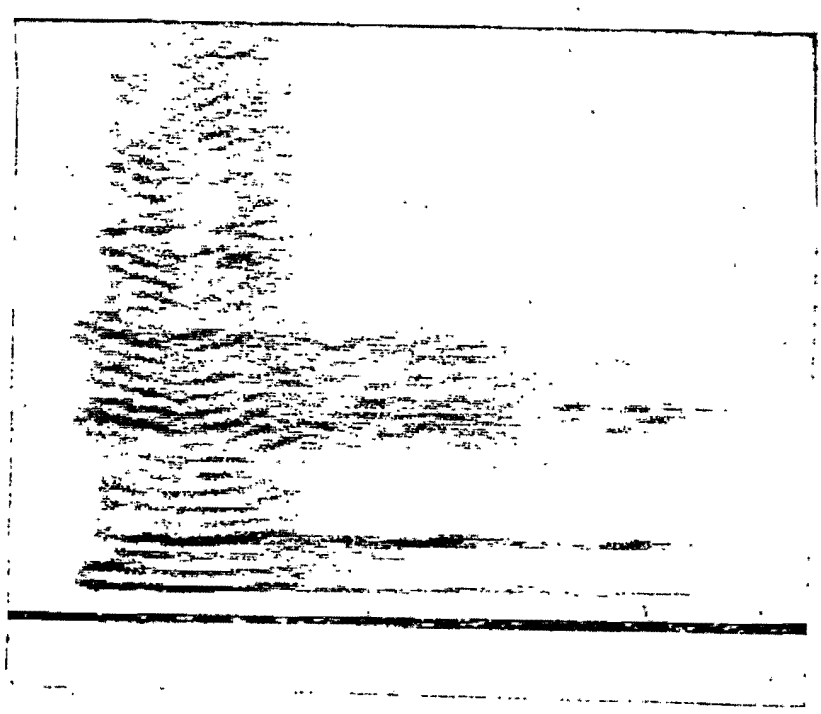

[dEp] 
The distribution for the sounds which the informant produced and recognized as the phoneme / A / ranged on the vowel chart from $600-750 \mathrm{hz}$. for formant 1 and from 1600-2300 hz. for formant 2 .

CHART IV

/A /

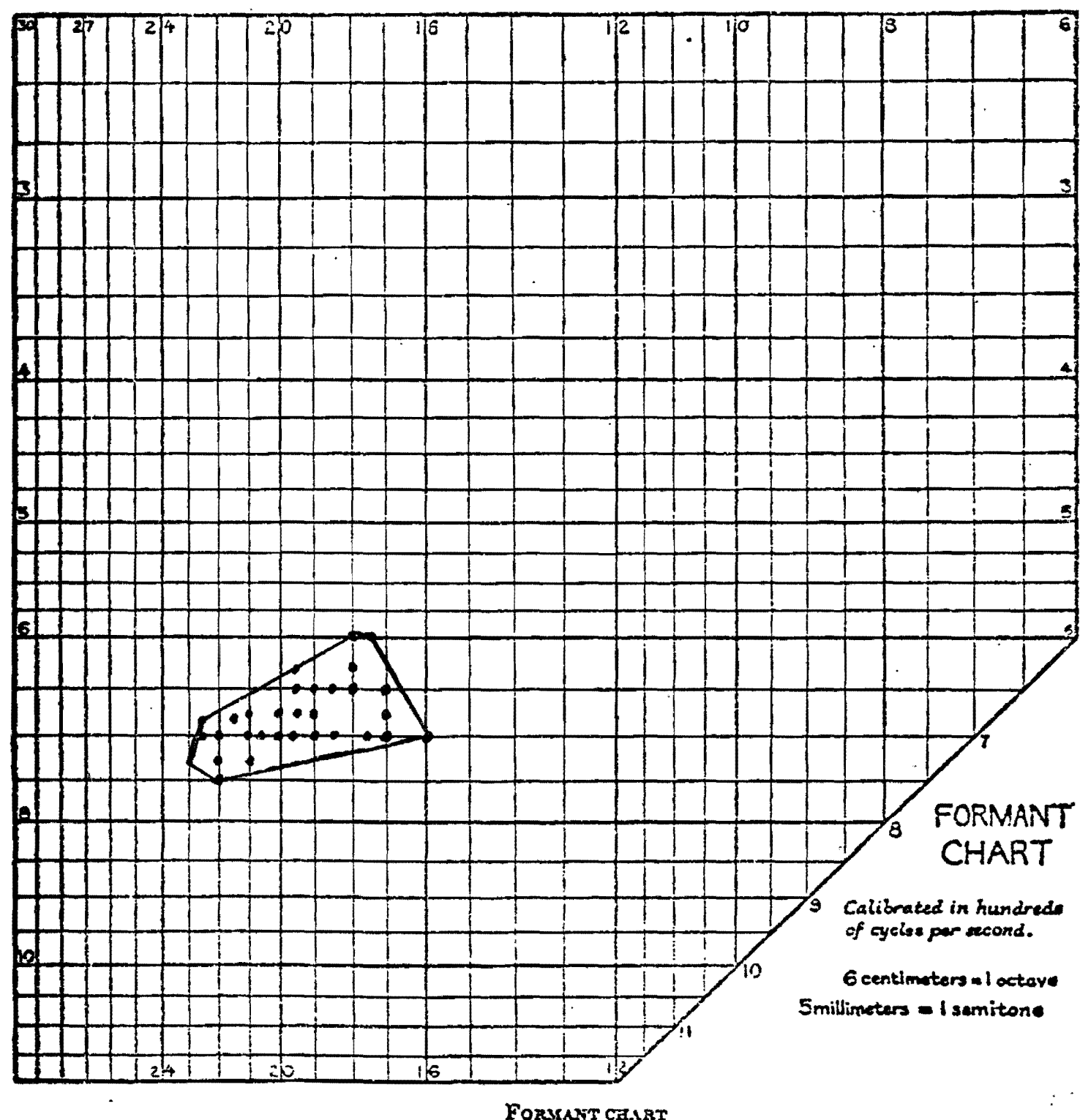

Placing a single point on this chart is an assertion that formints have been observed at two frequencies: one formant at the frequency named yiong the right or 'eft adge, the other formant at the frequency named along the top or bottcm edge. 


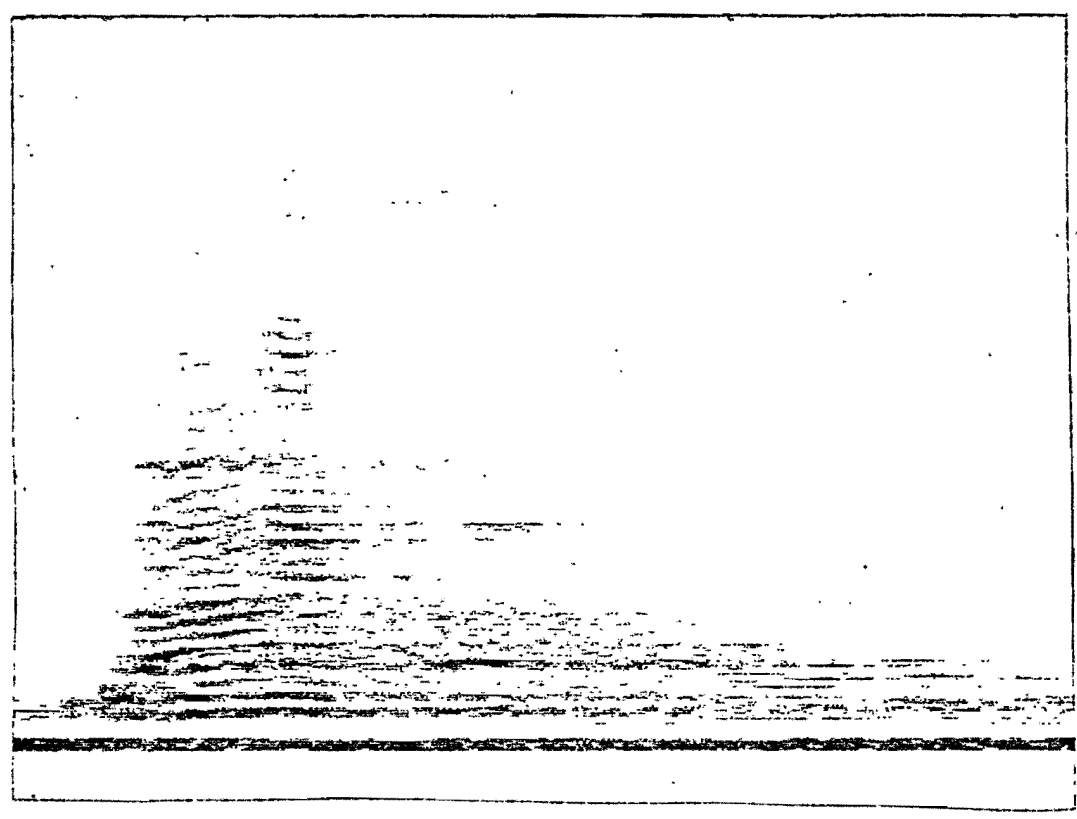

[1As ]

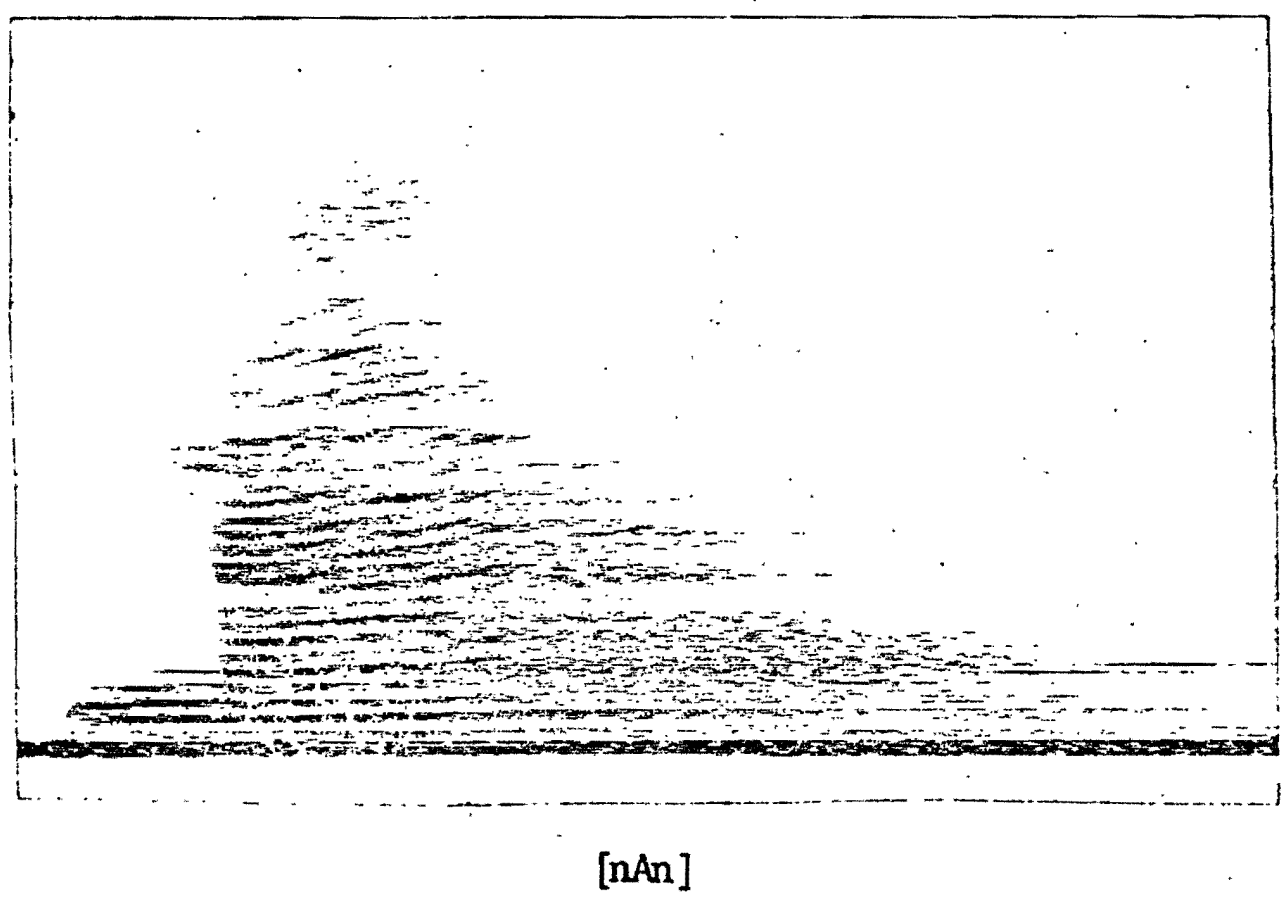




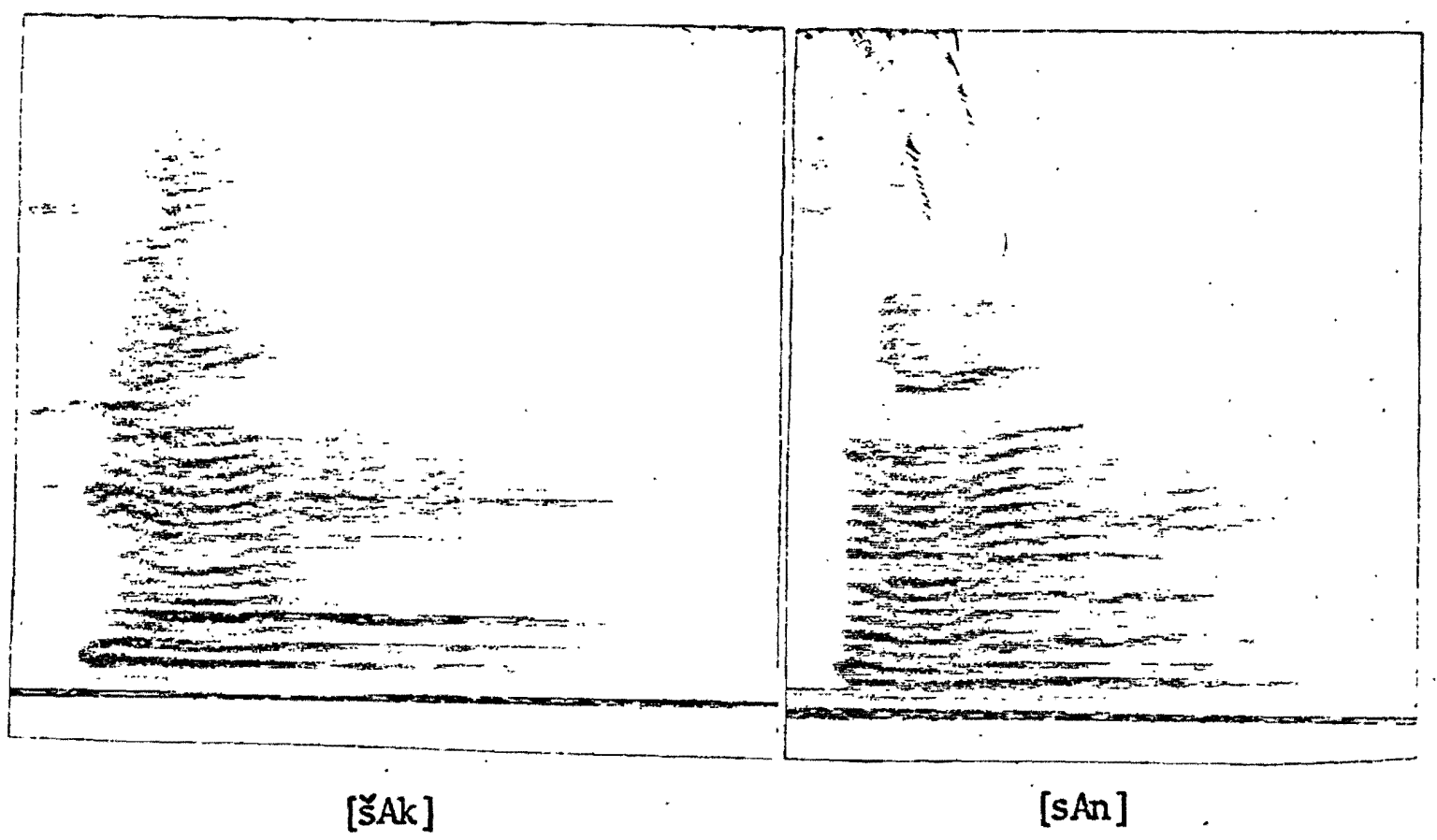

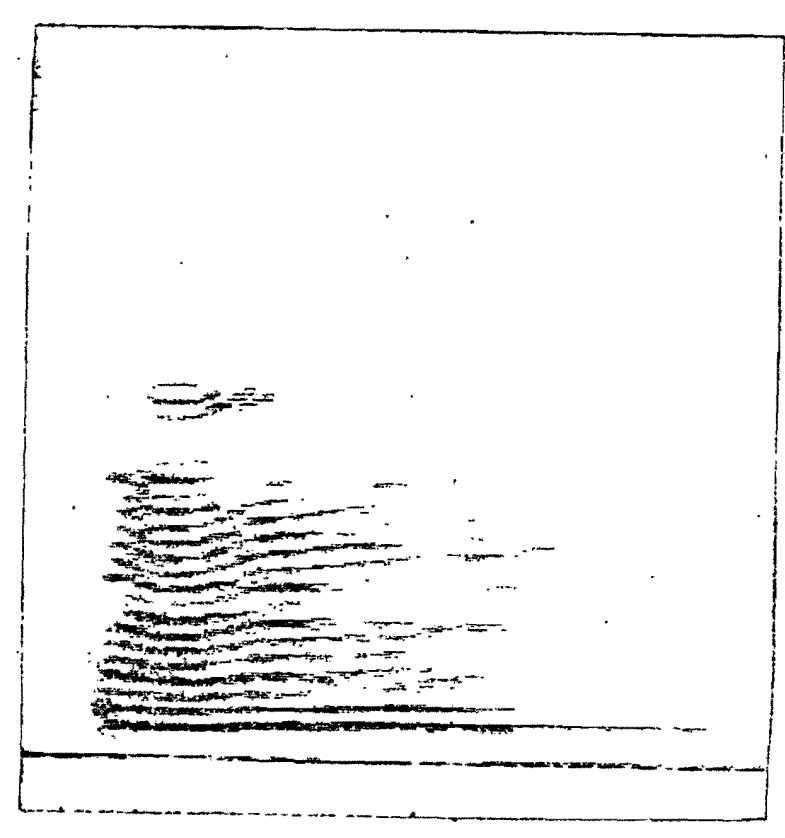

[SAn]

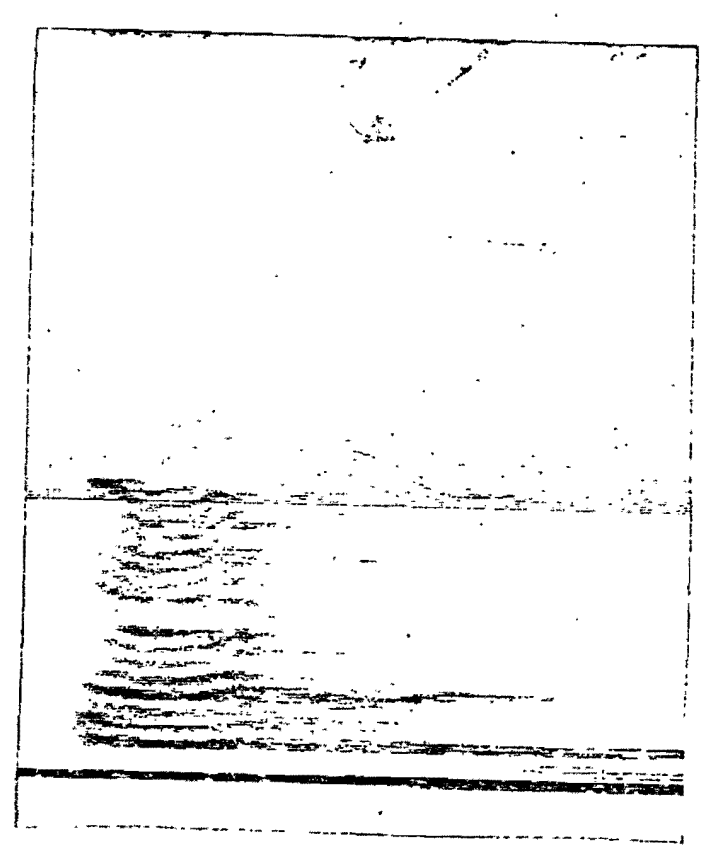

[sAp] 


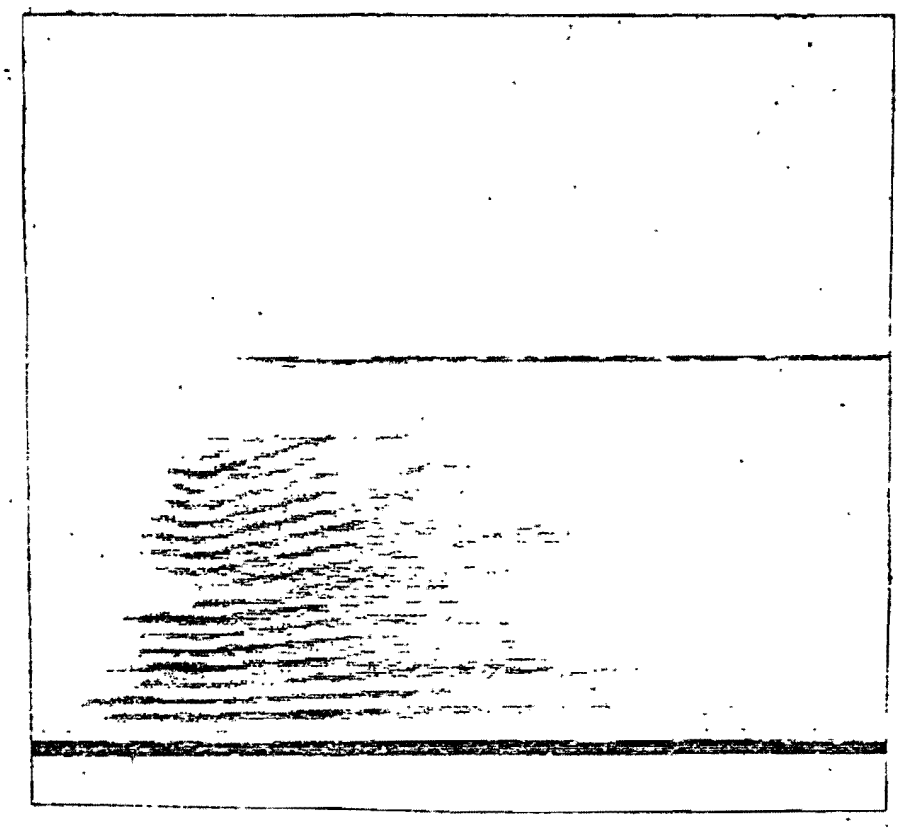

[bAk]

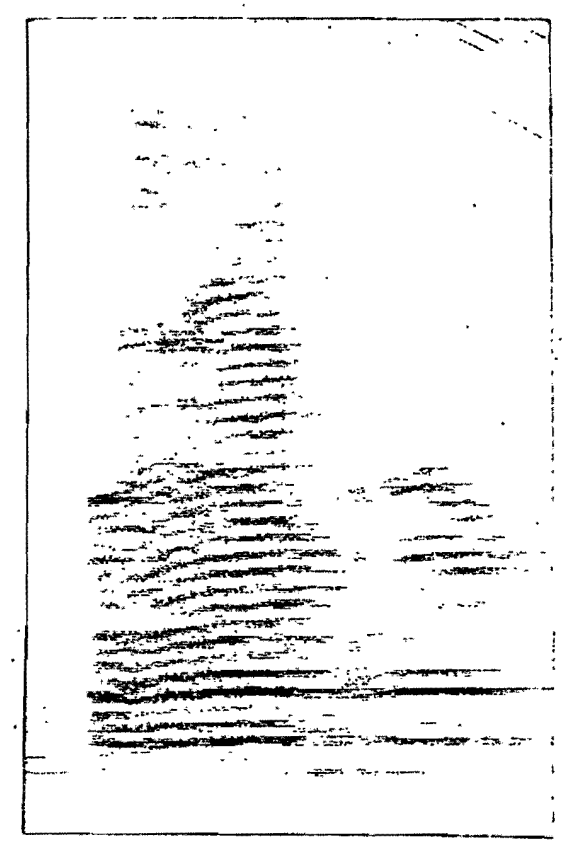

[rAn]

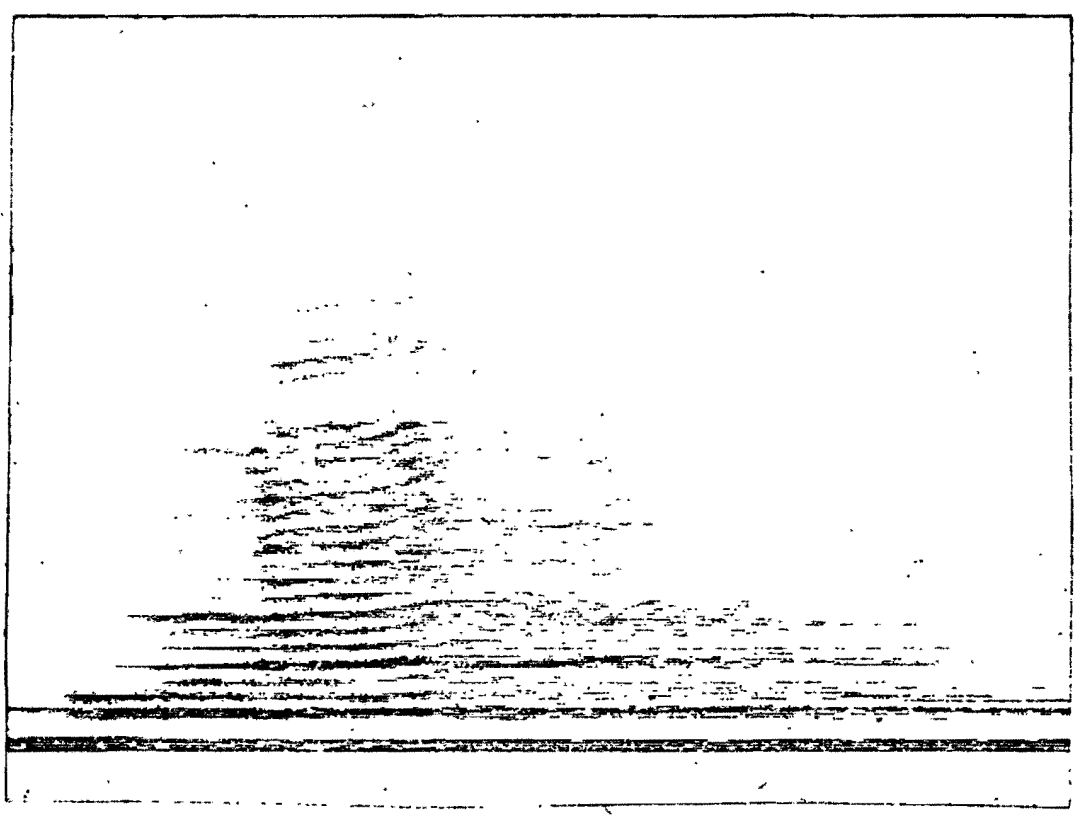

[1Ap] 


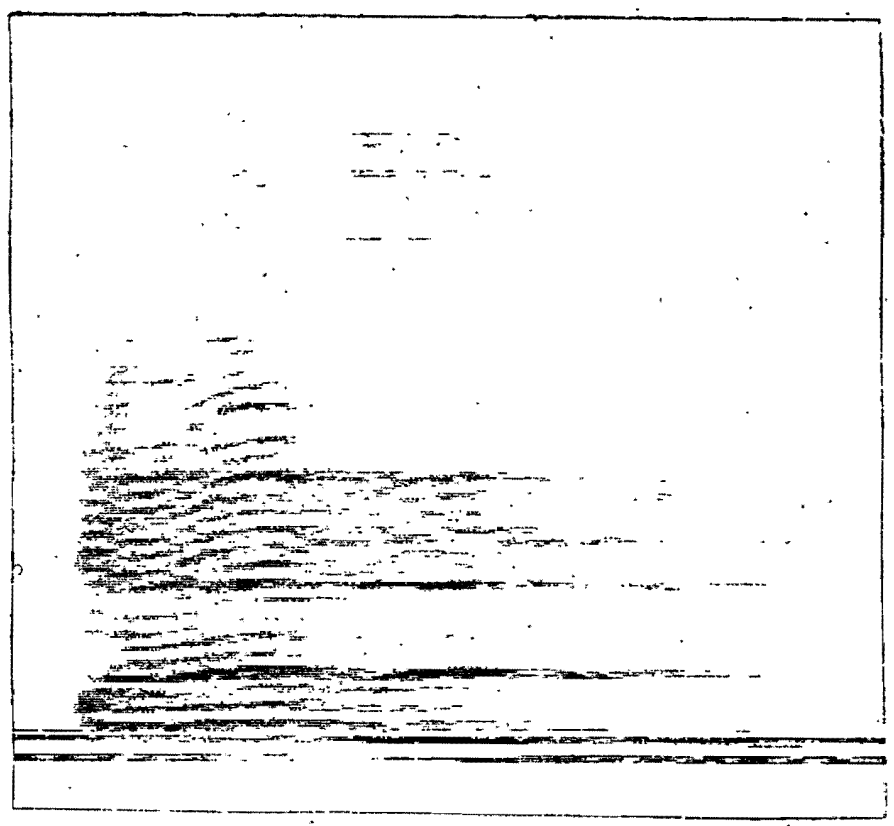

[dAs ]

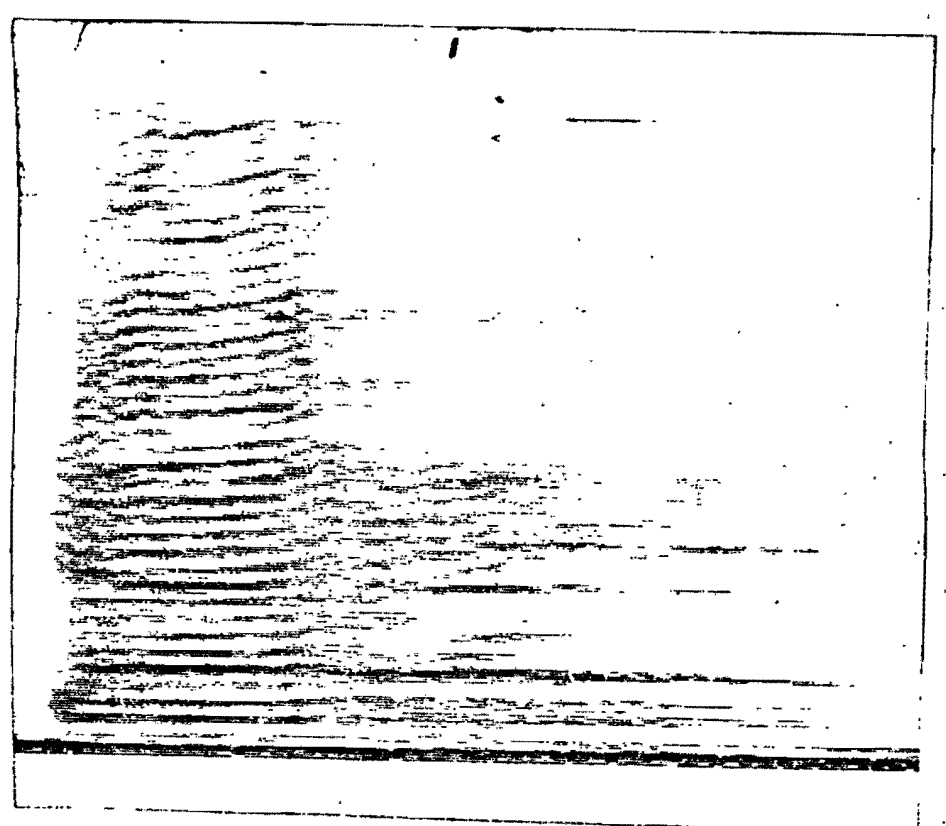

[dAr] 

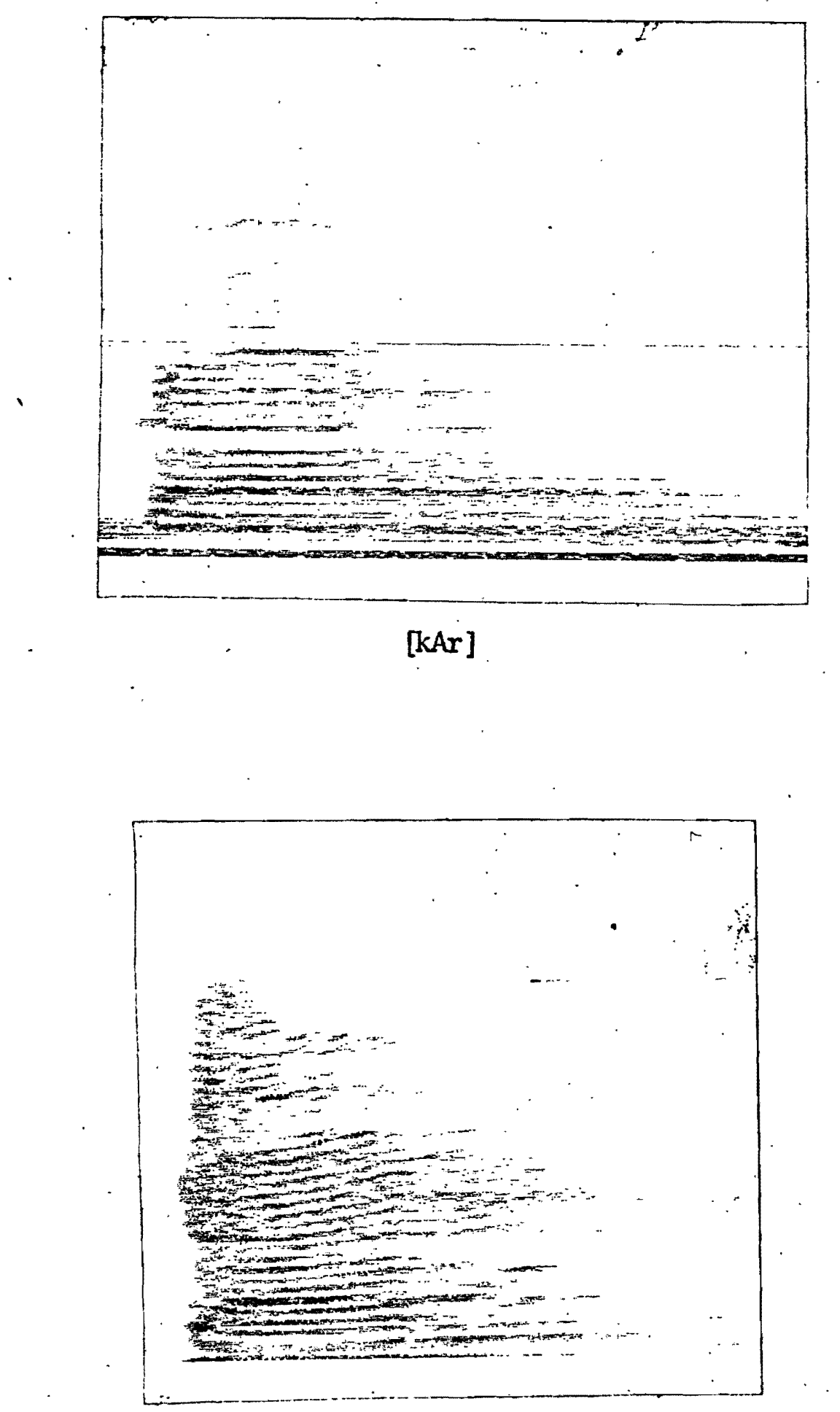

[dAin] 


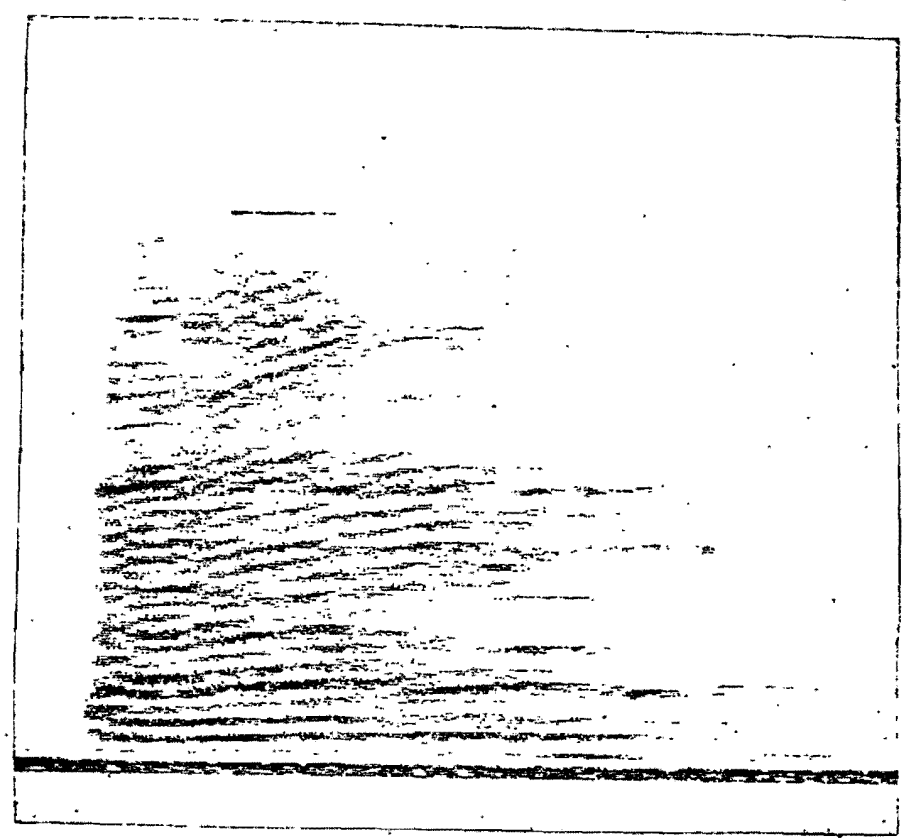

[bAm]

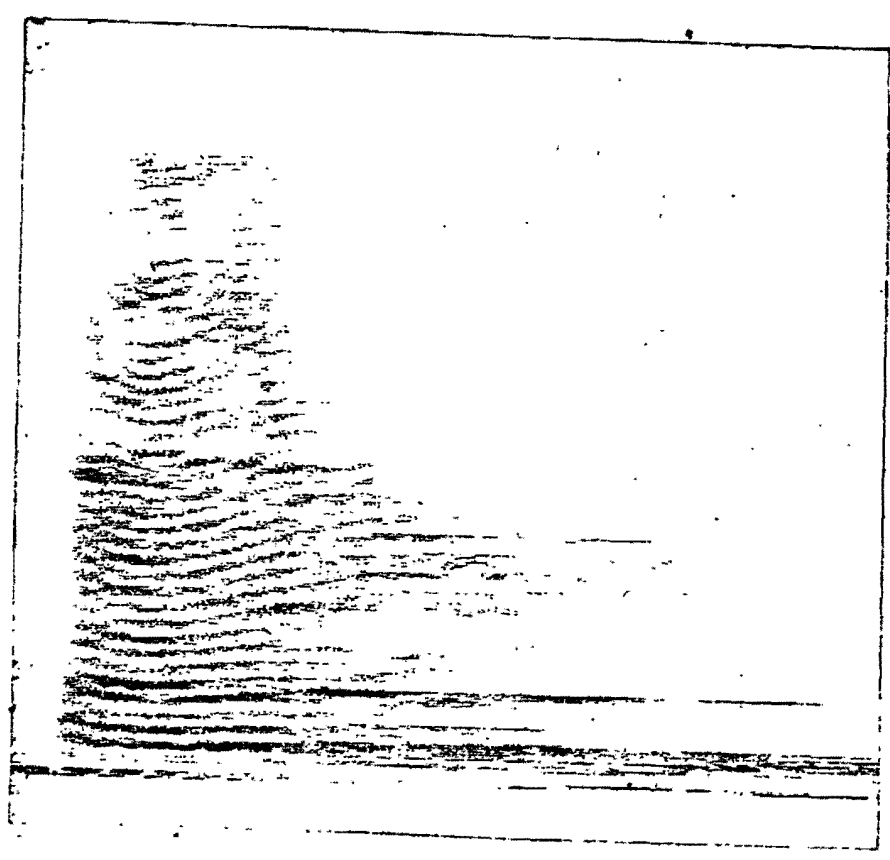

[bAn] 

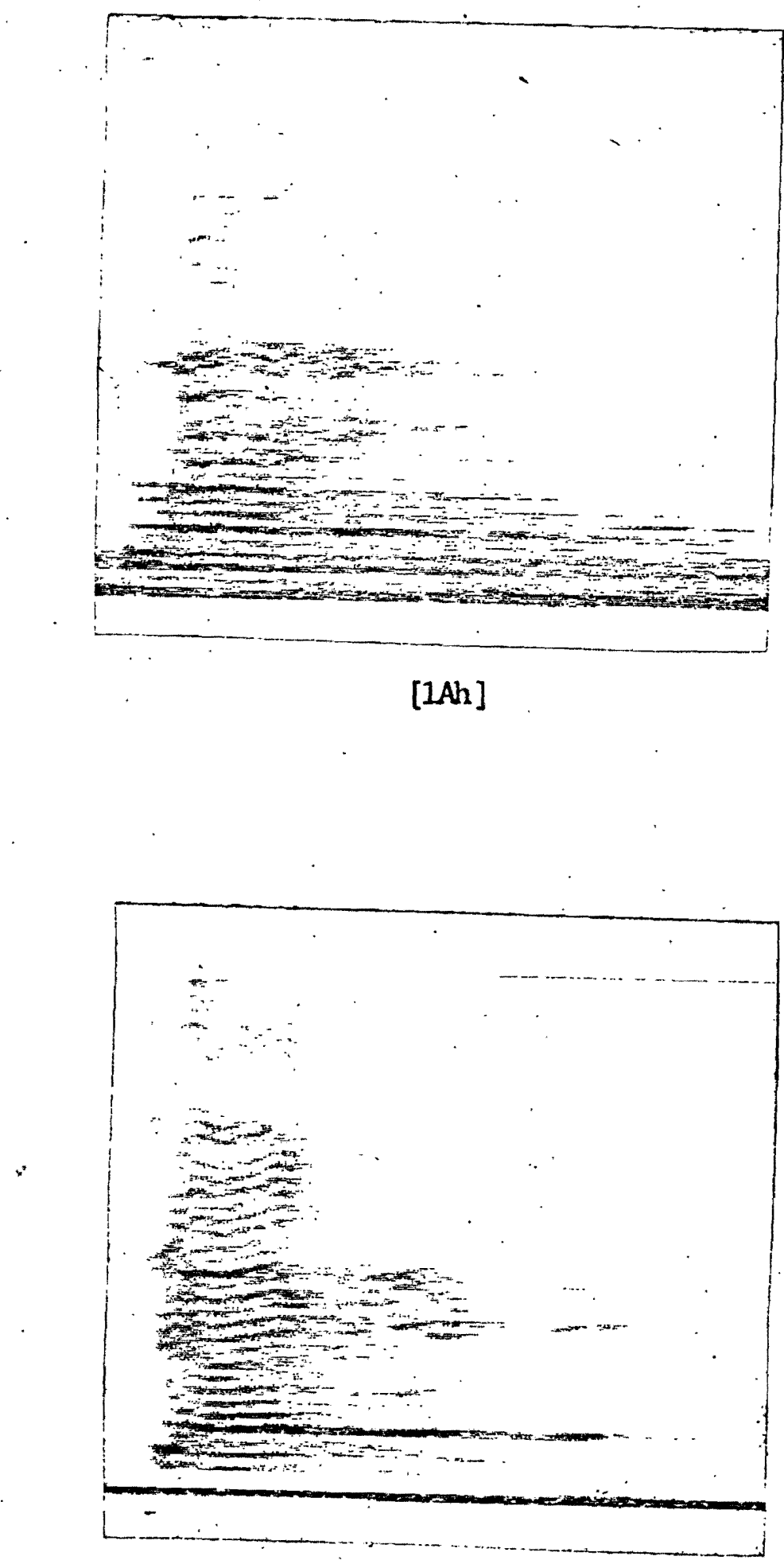

[ǰAk] 

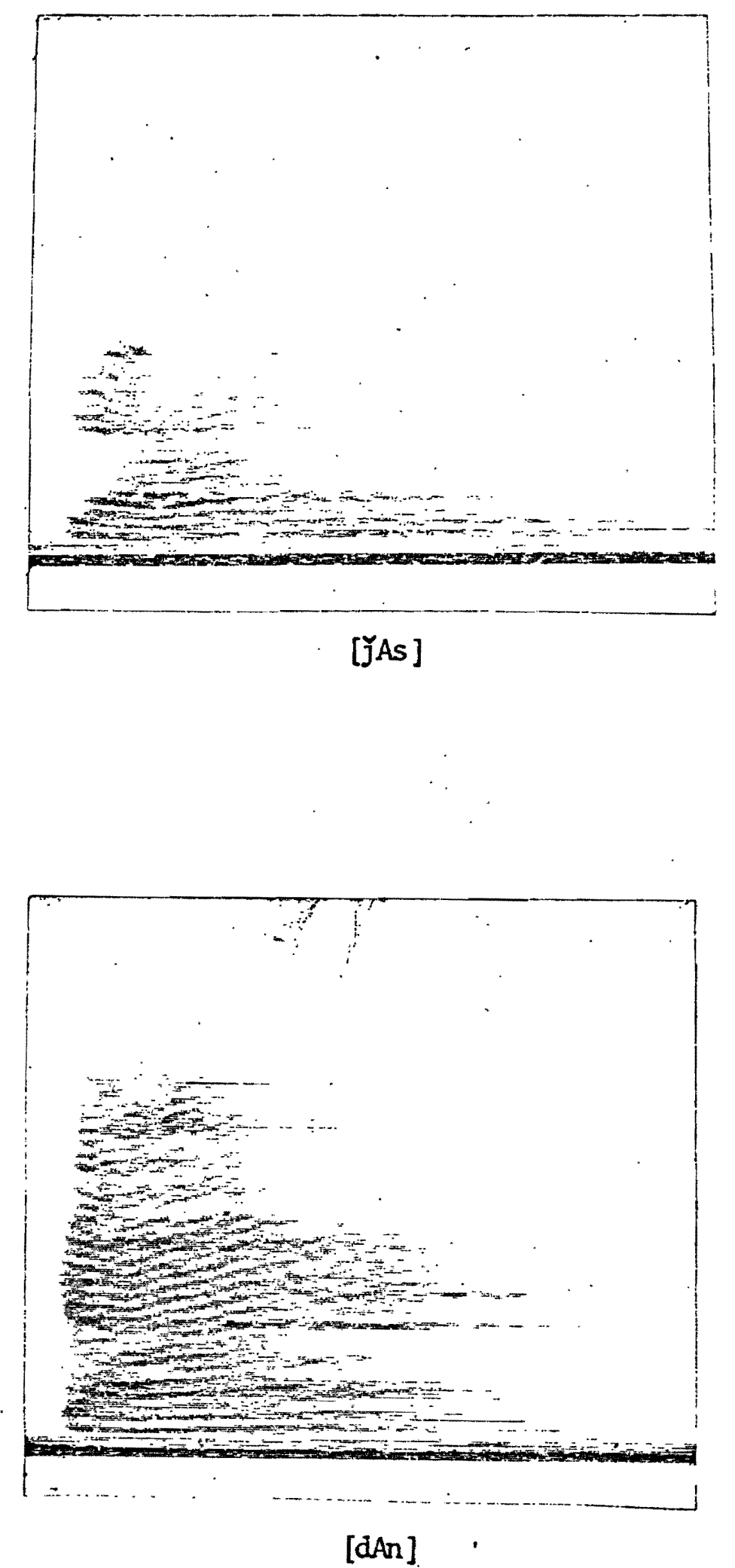

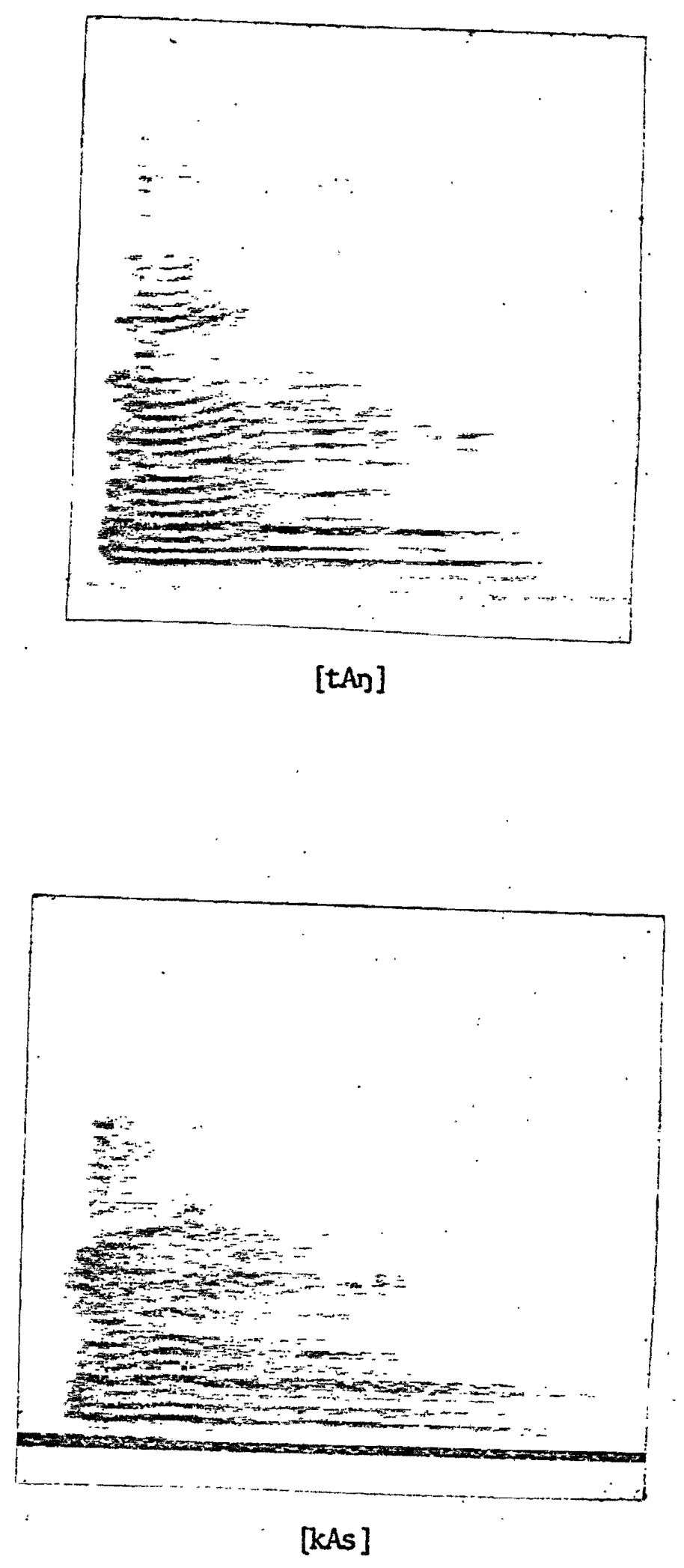


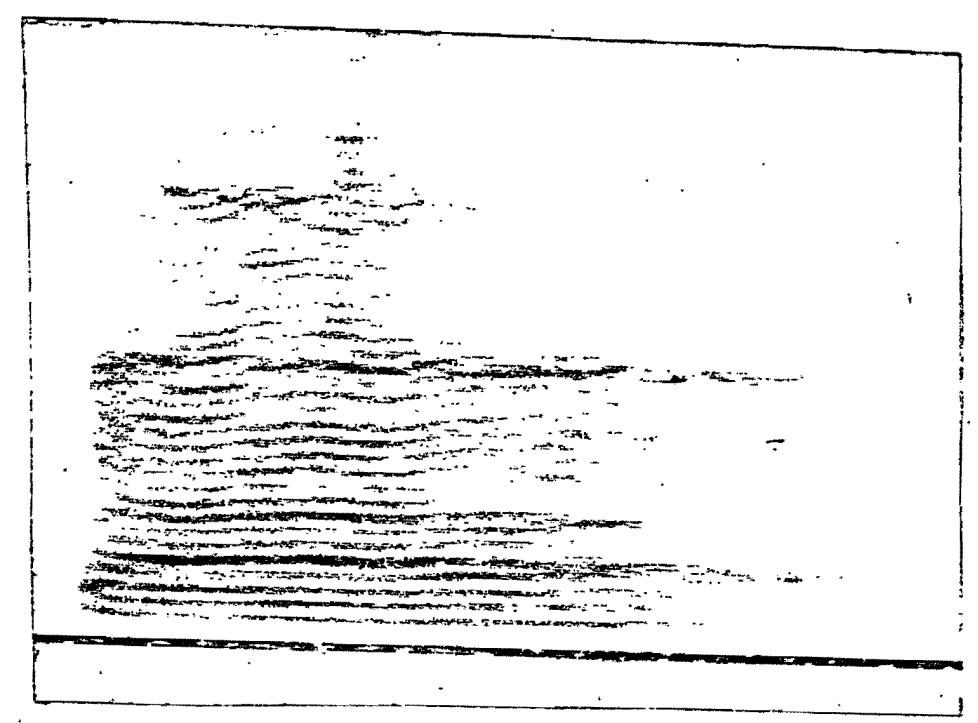

[bAl]

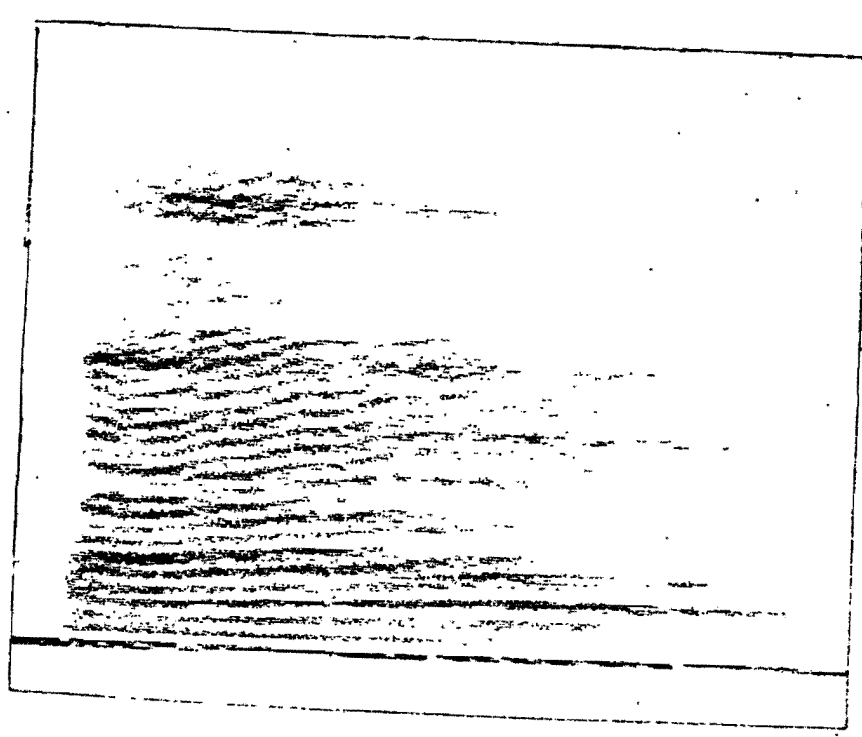

[bAD] 


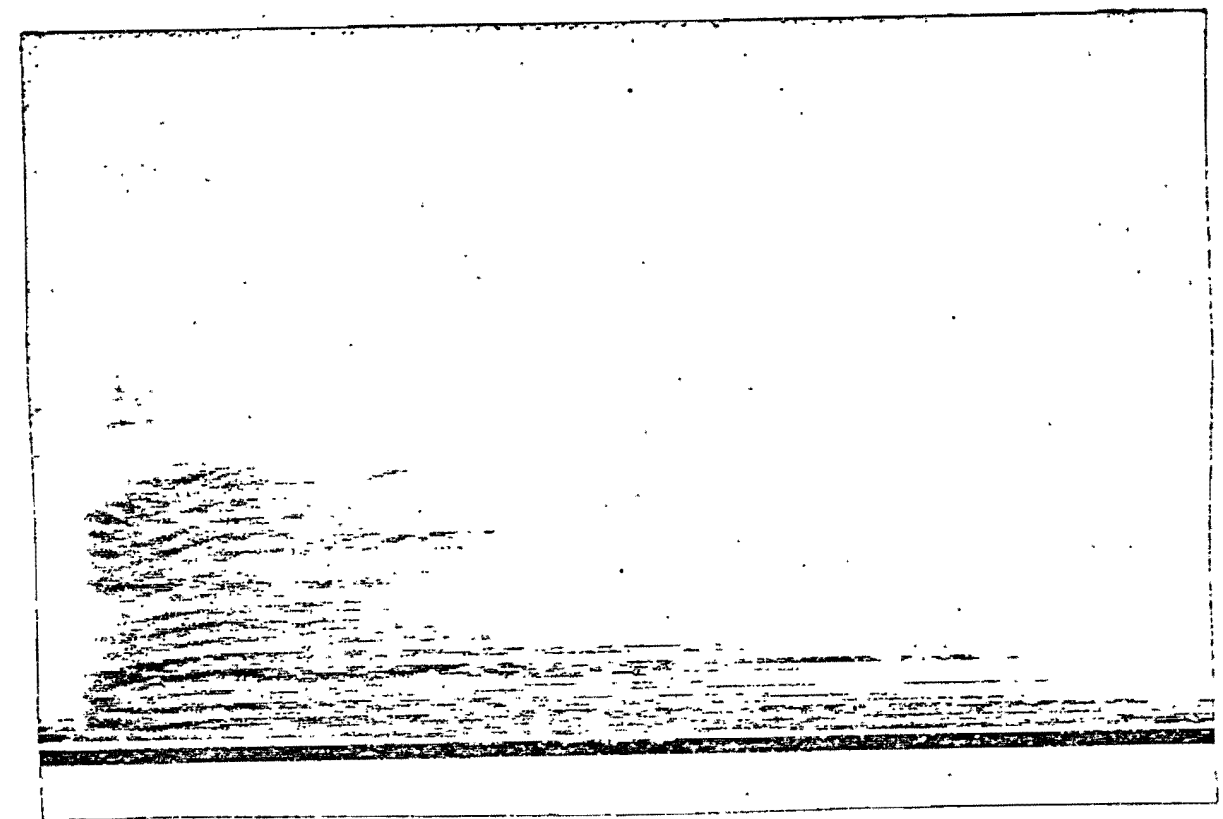

[kAp]

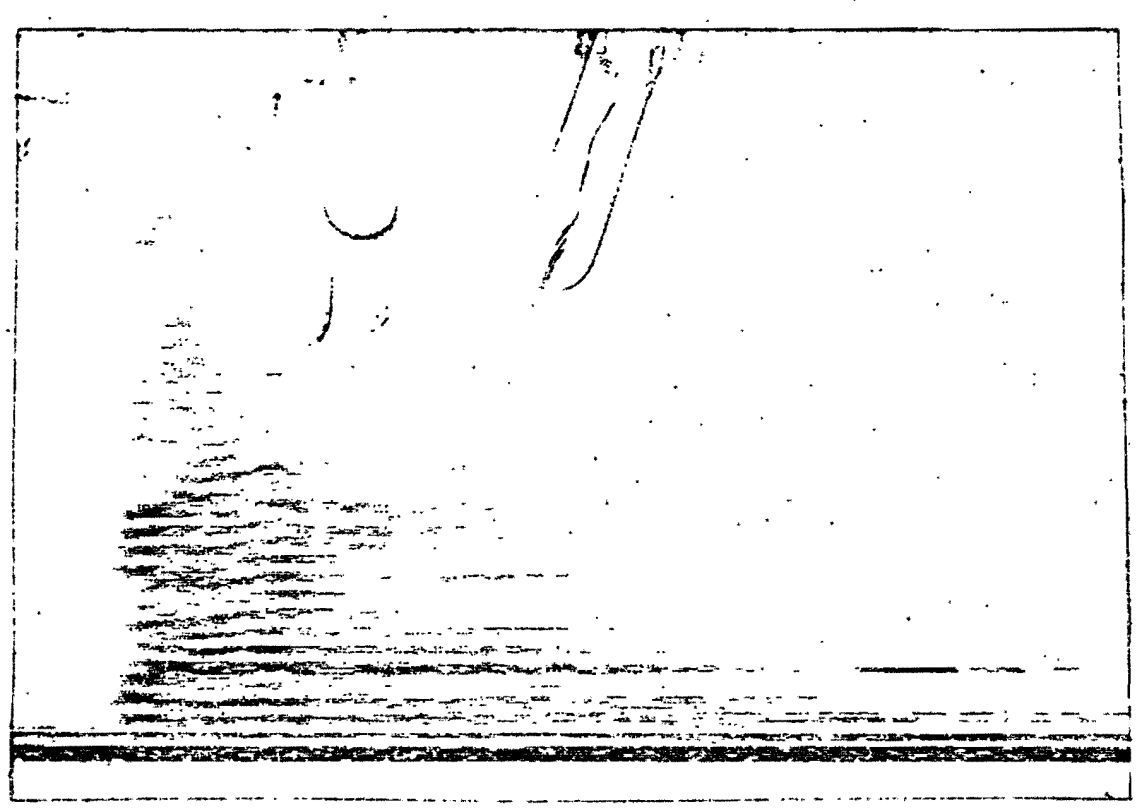

[kAk] 

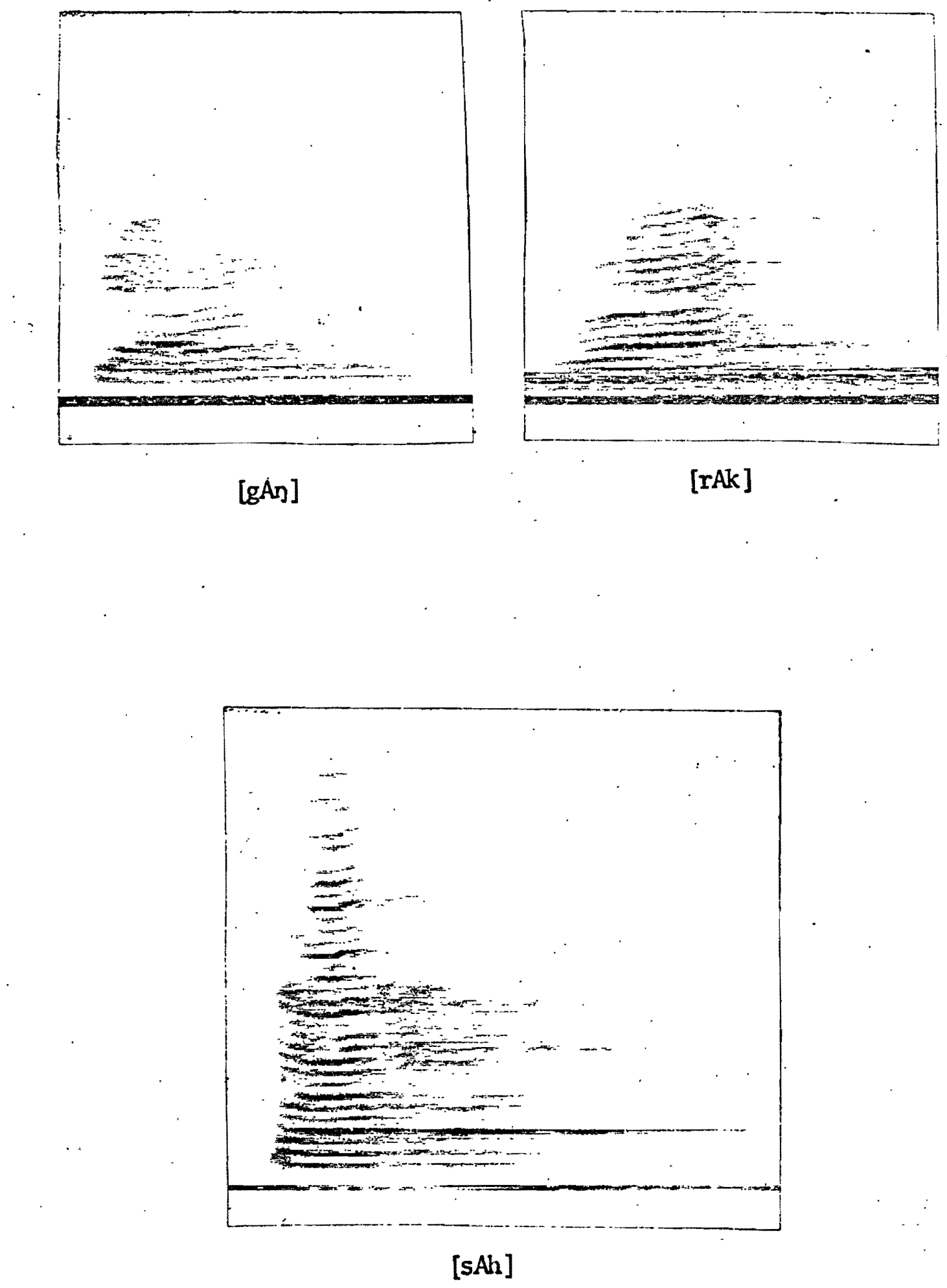

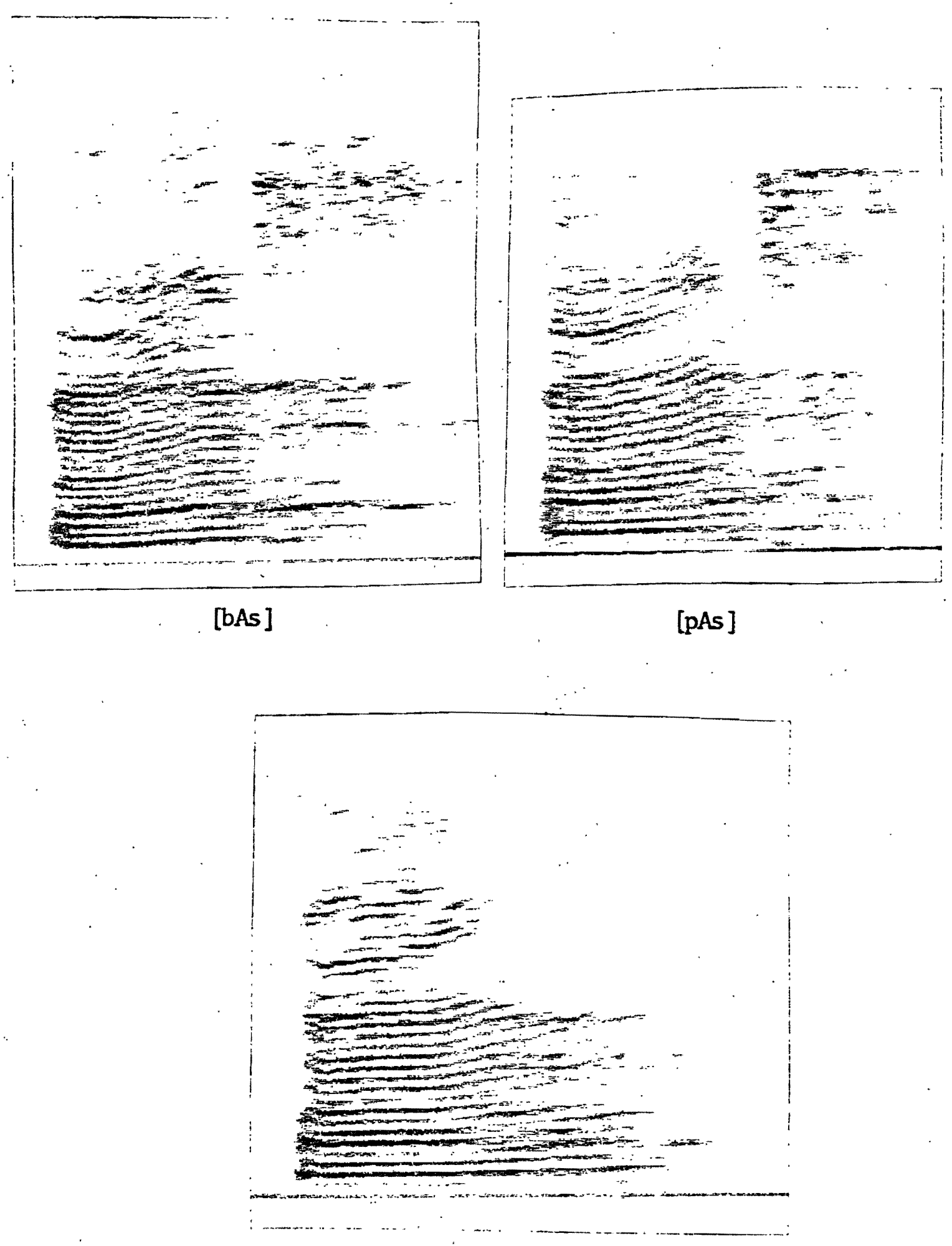

[pA1] 
The distribution for the sounds which the informant produced and recognized as the phoneme /0/ ranged on the vowel chart from $400-525 \mathrm{hz}$. for formant 1 and from 700-1000 hz. for formant 2 .

\section{CHART $V$}

$10 /$

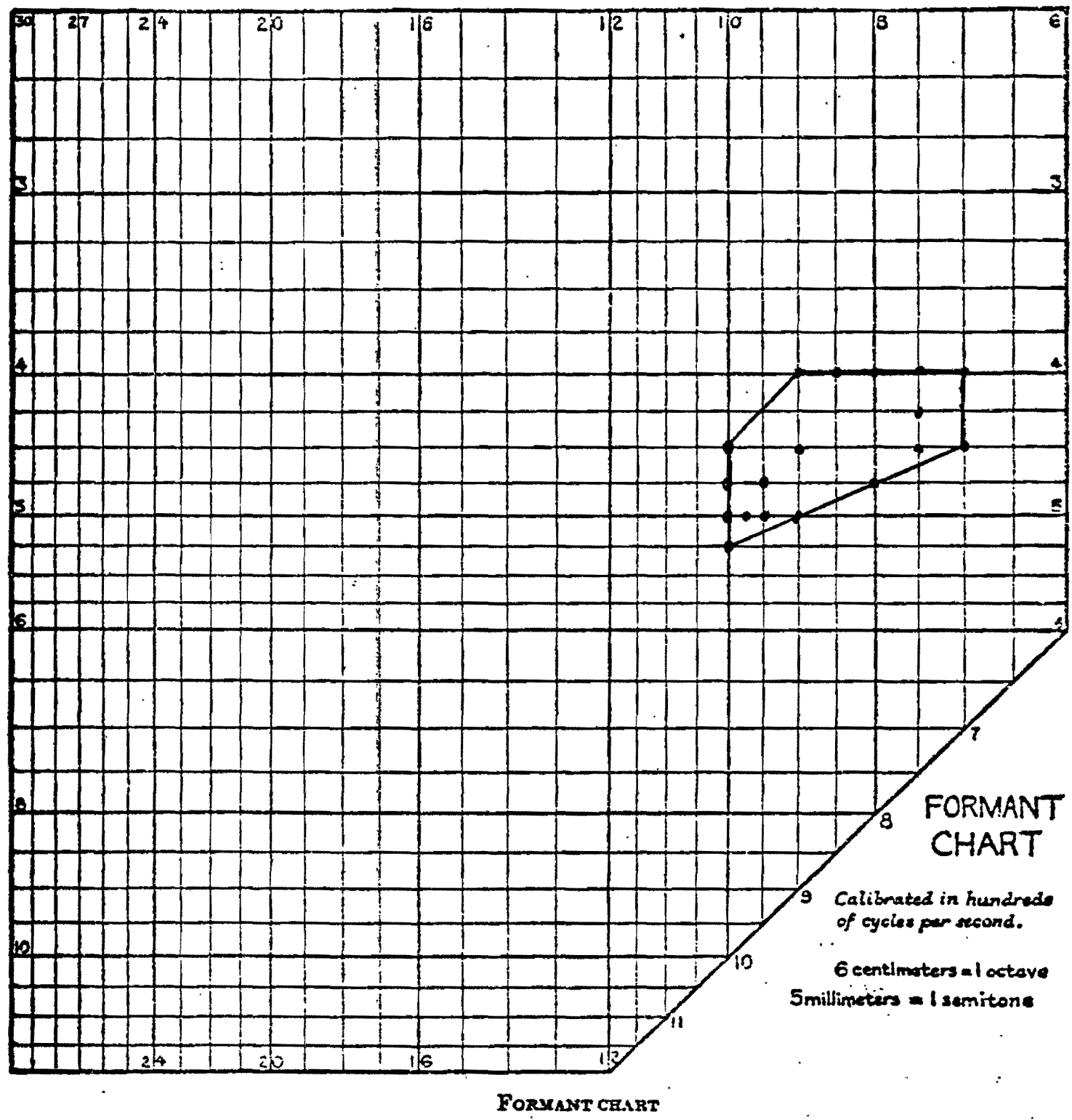

Placing a single point on this chart is an assertion that formants have been observed at two frequencies: cne tormant at the frequency named wiong the right or left od ze, the other formant at the frequency named along the top or bottom edge. 

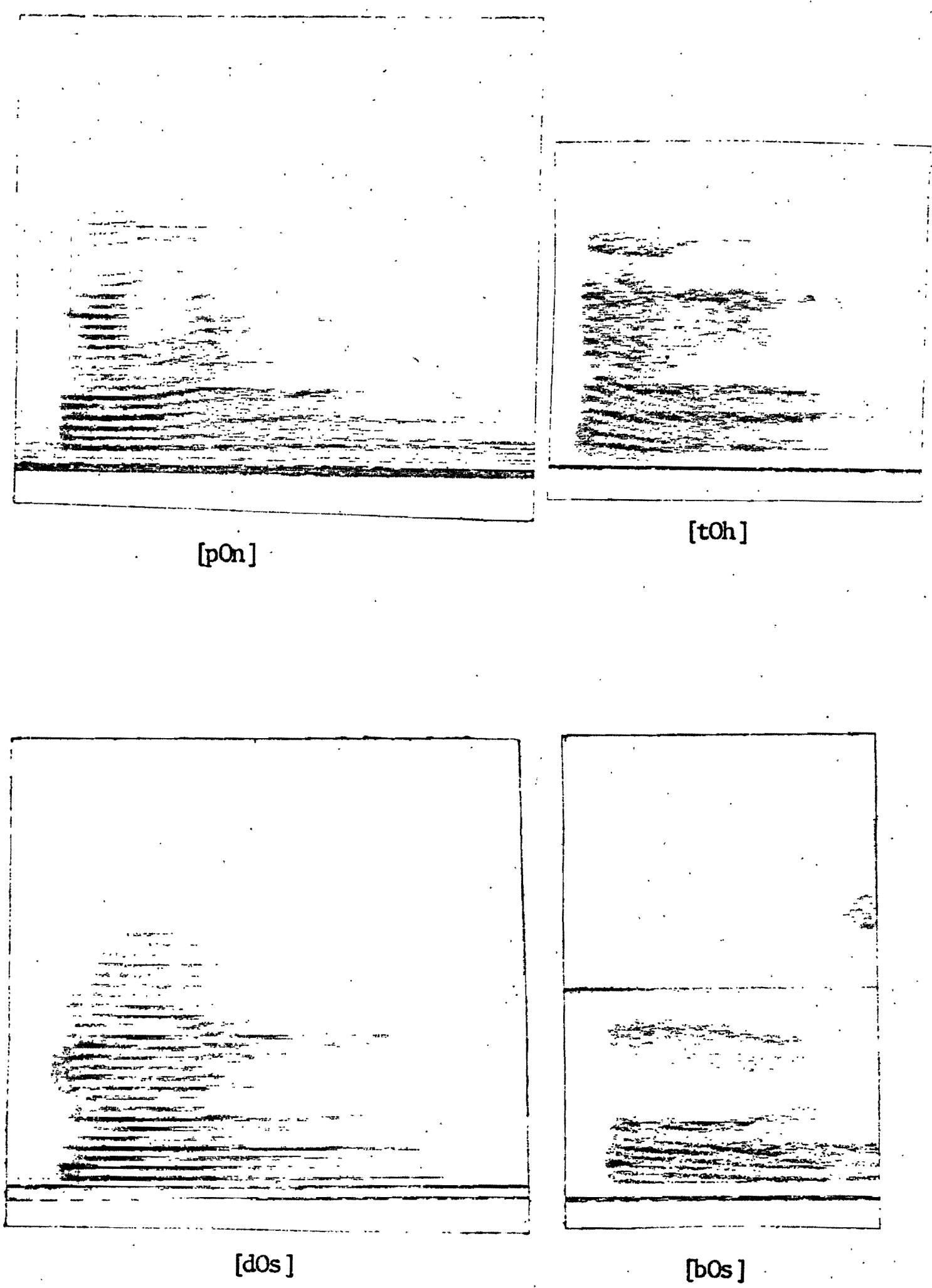

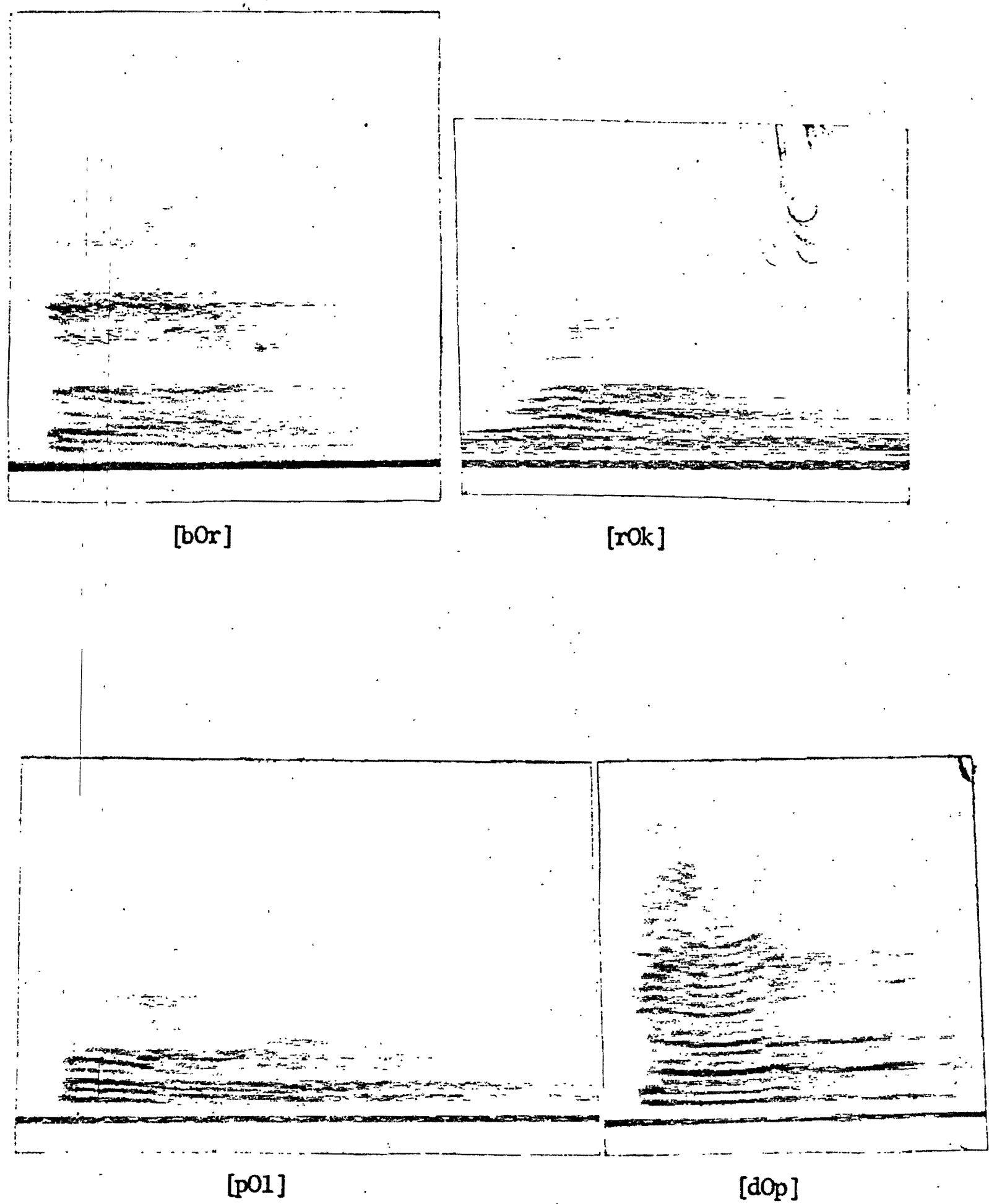

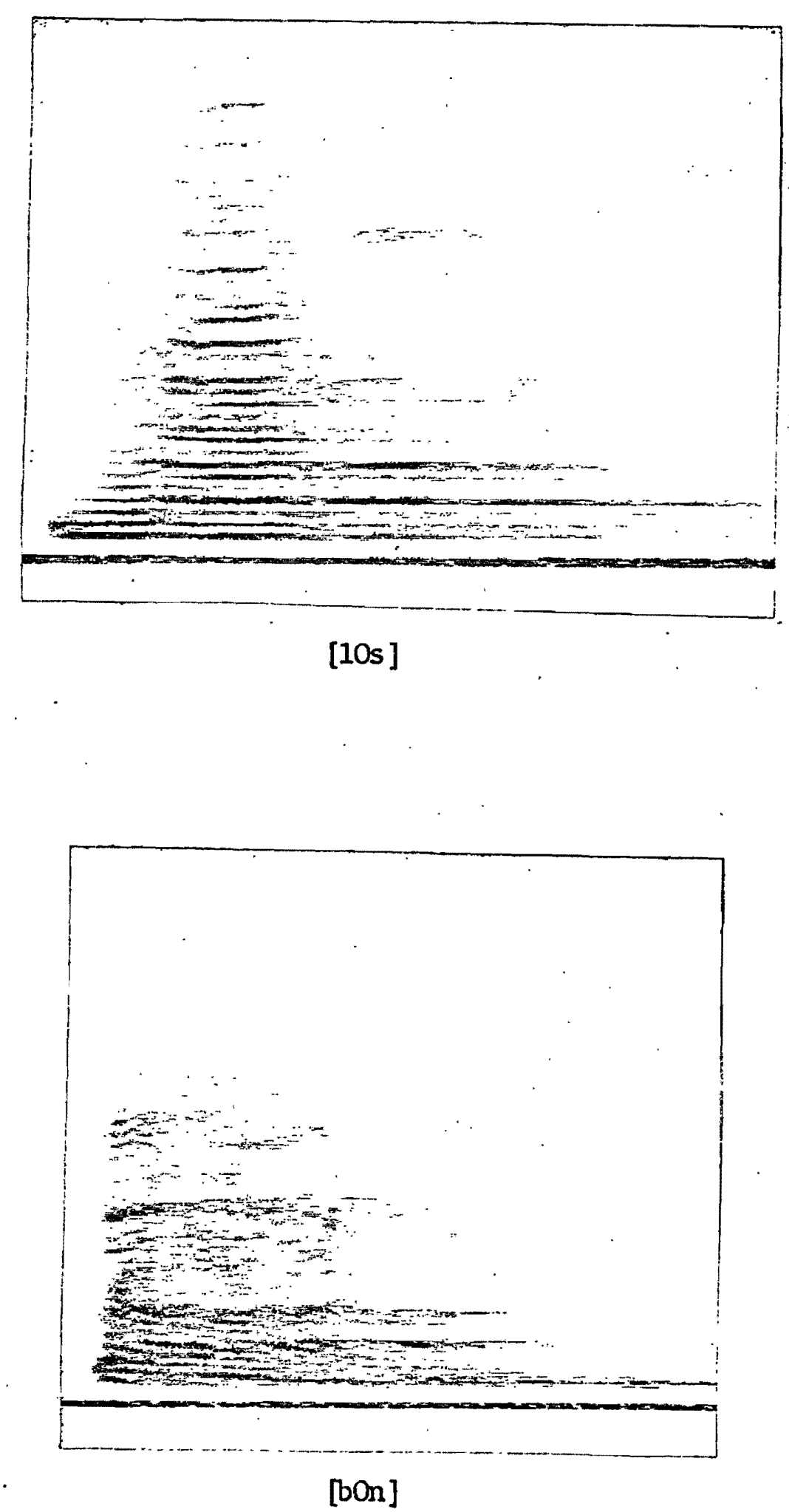

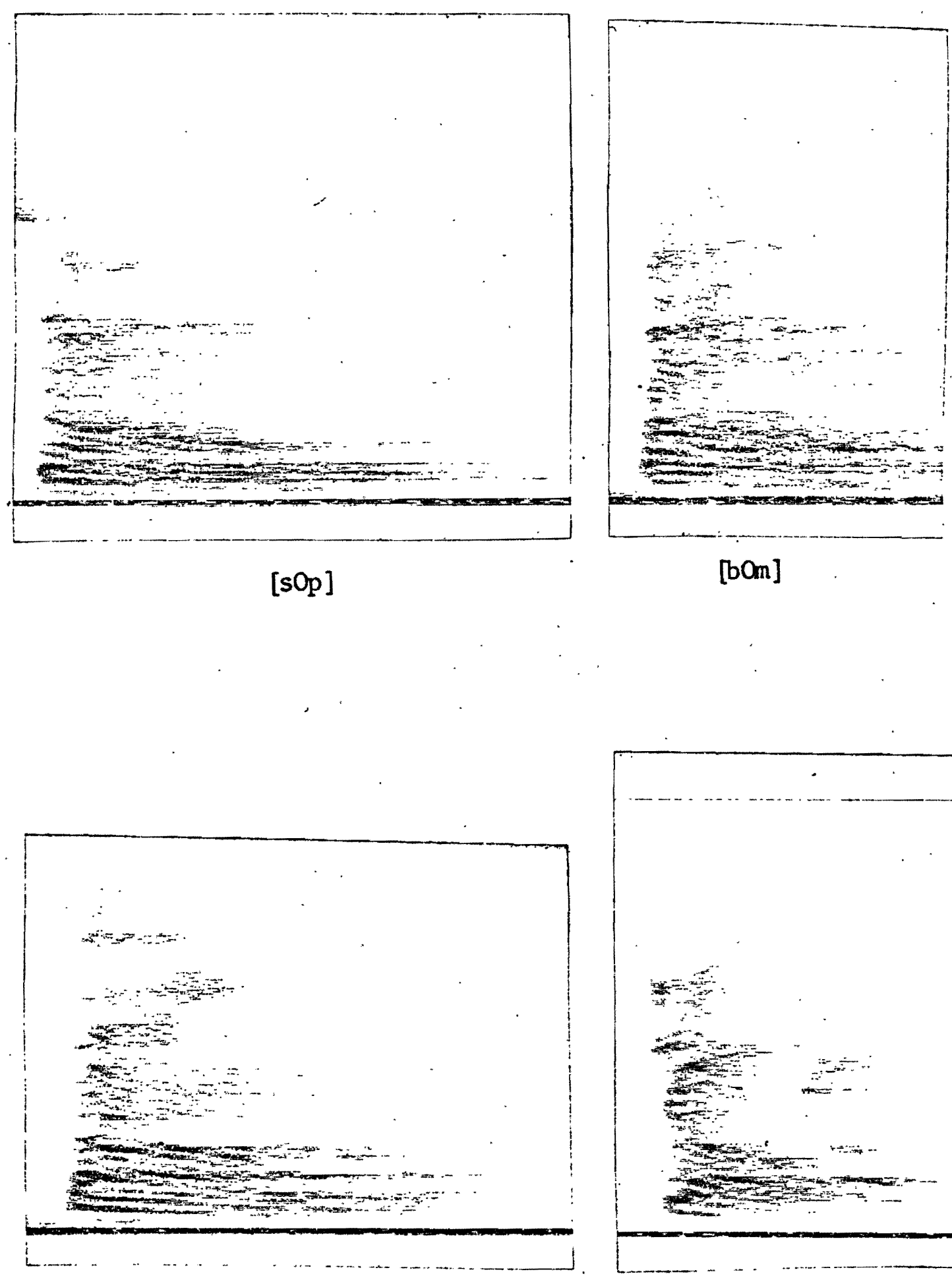

[ton]

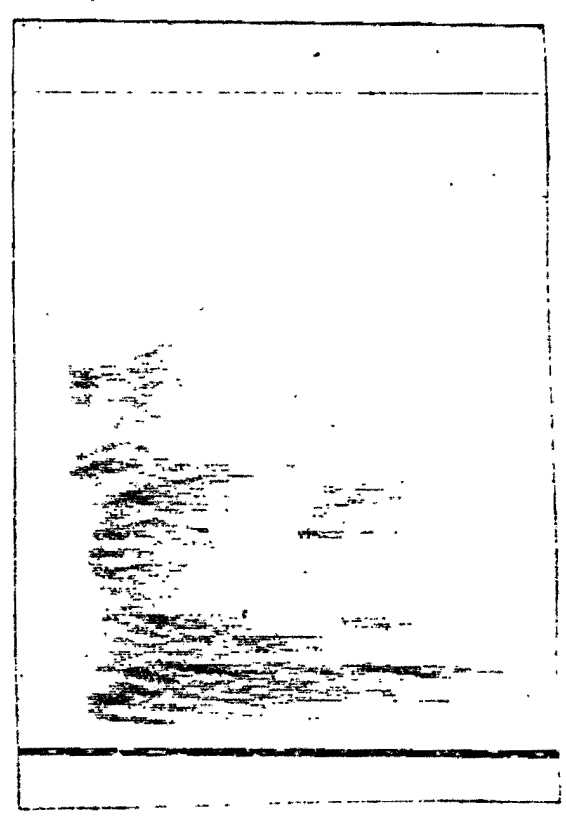

[jok] 


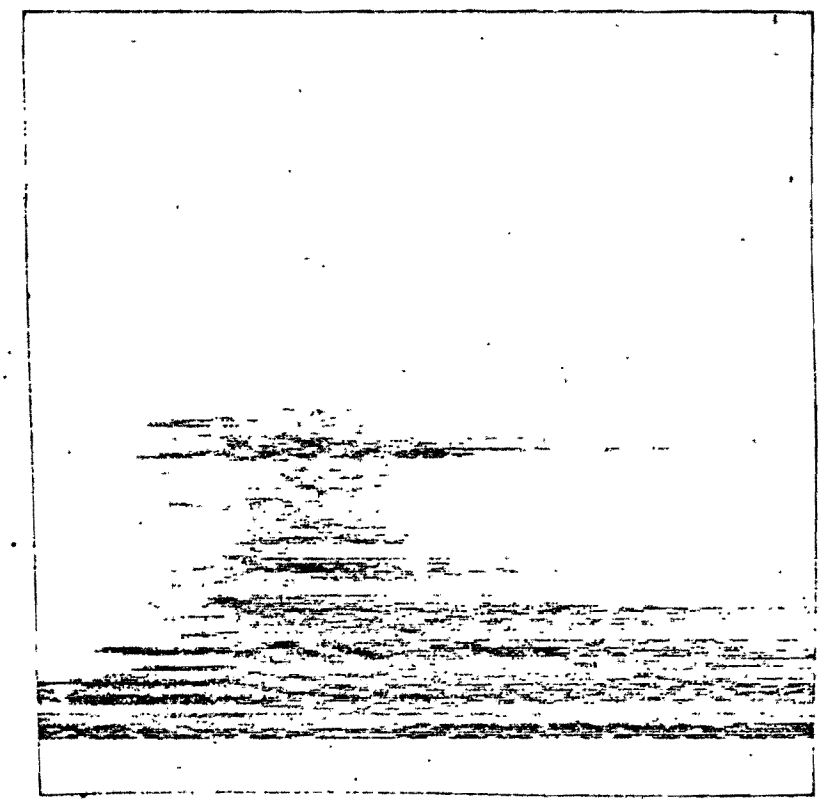

[10h]
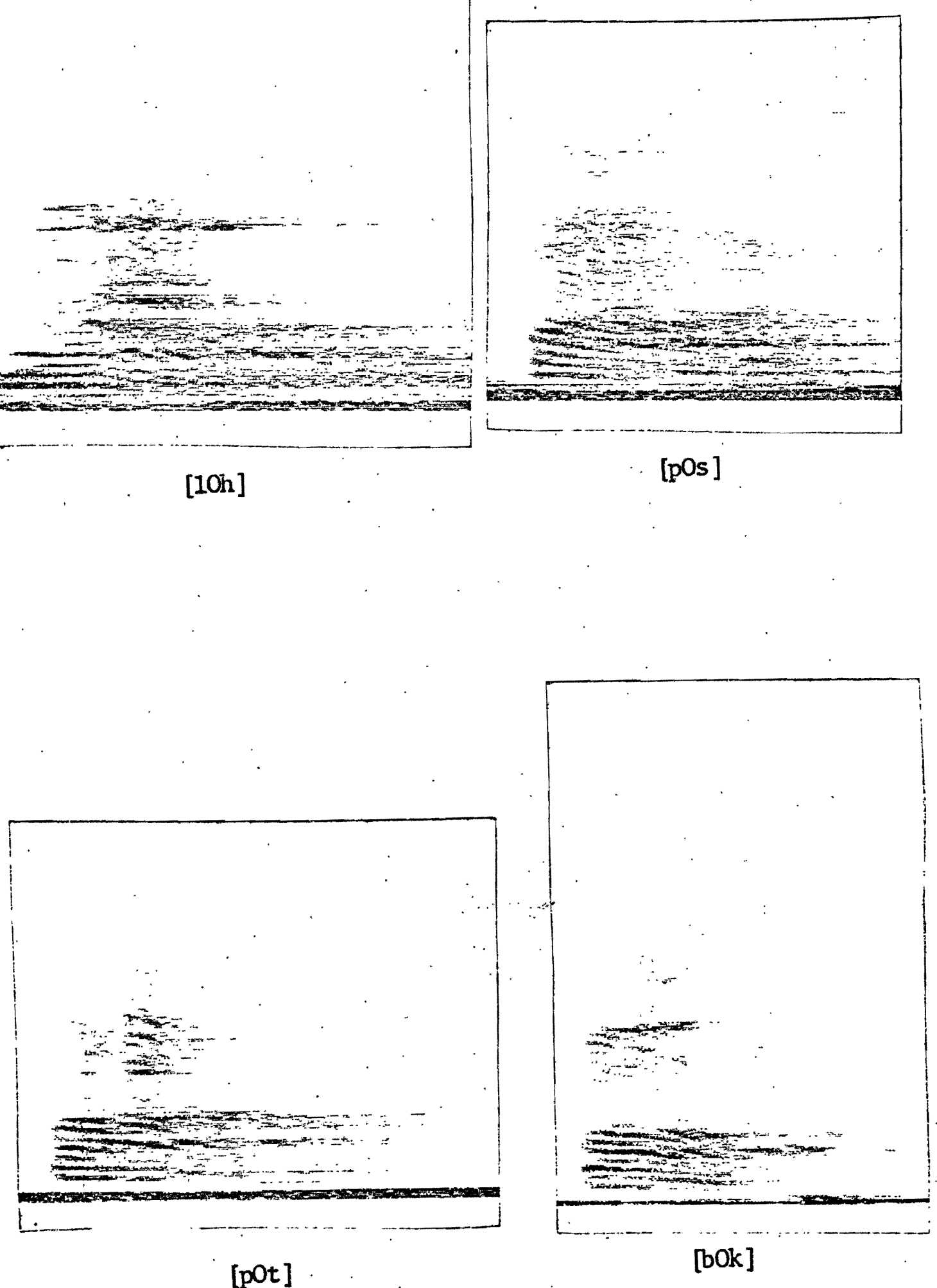
The distribution for the sounds which the informant produced and recognized as the phoneme /U/ ranged on the vowel chart in an almost square-like pattern from 250-350 hz. for formant 1 and from $700-1000 \mathrm{hz}$. for formant 2.

\section{CHART VI}

UI

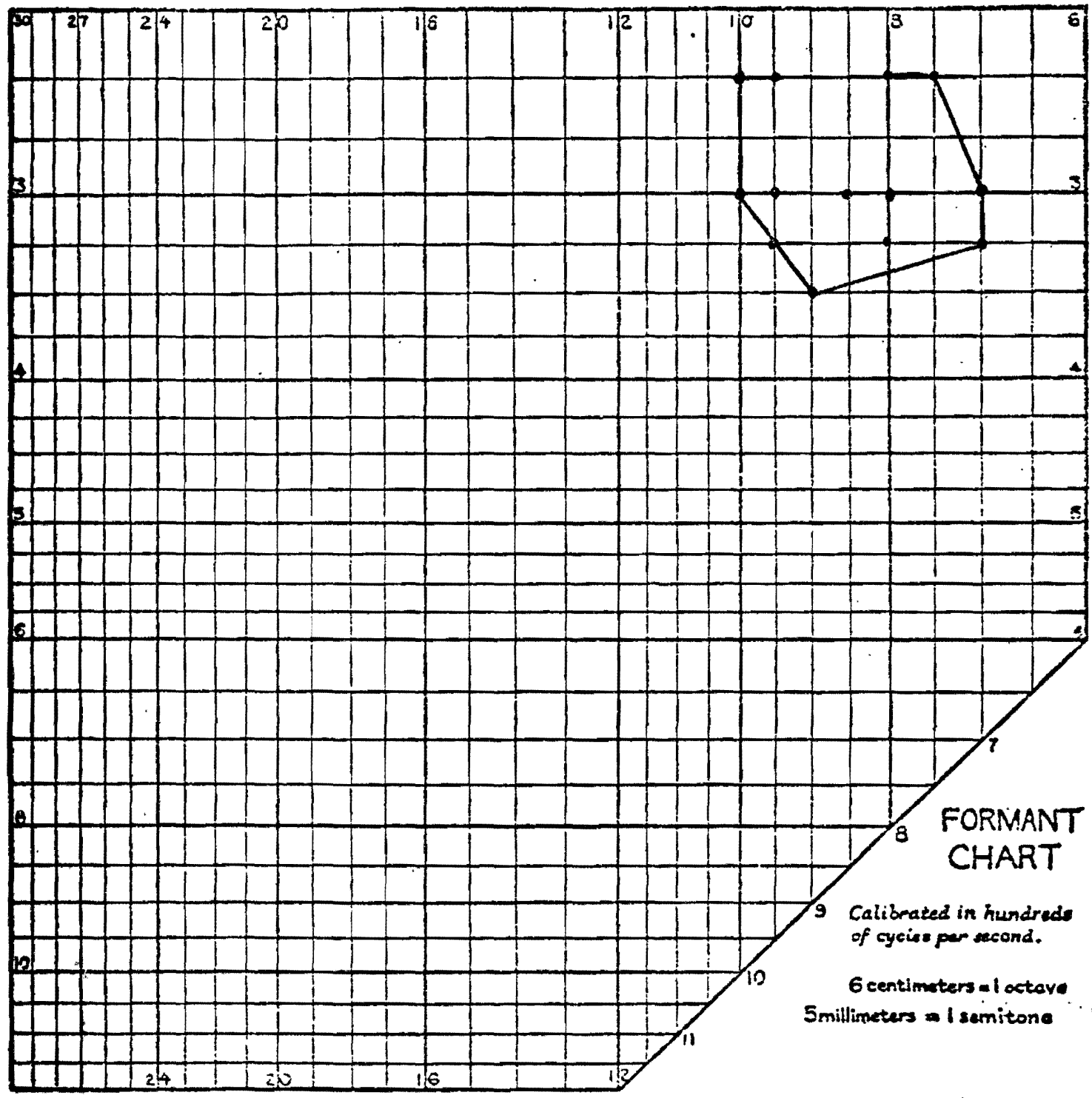

\section{Formant chart}

Placing a single point on this chart is an assertion that formants have been observed at two frequencies: one formant at the frequency named uiong the right or 'eft sd ze, the other formant at the frequency named along the top or bottom edge. 
57
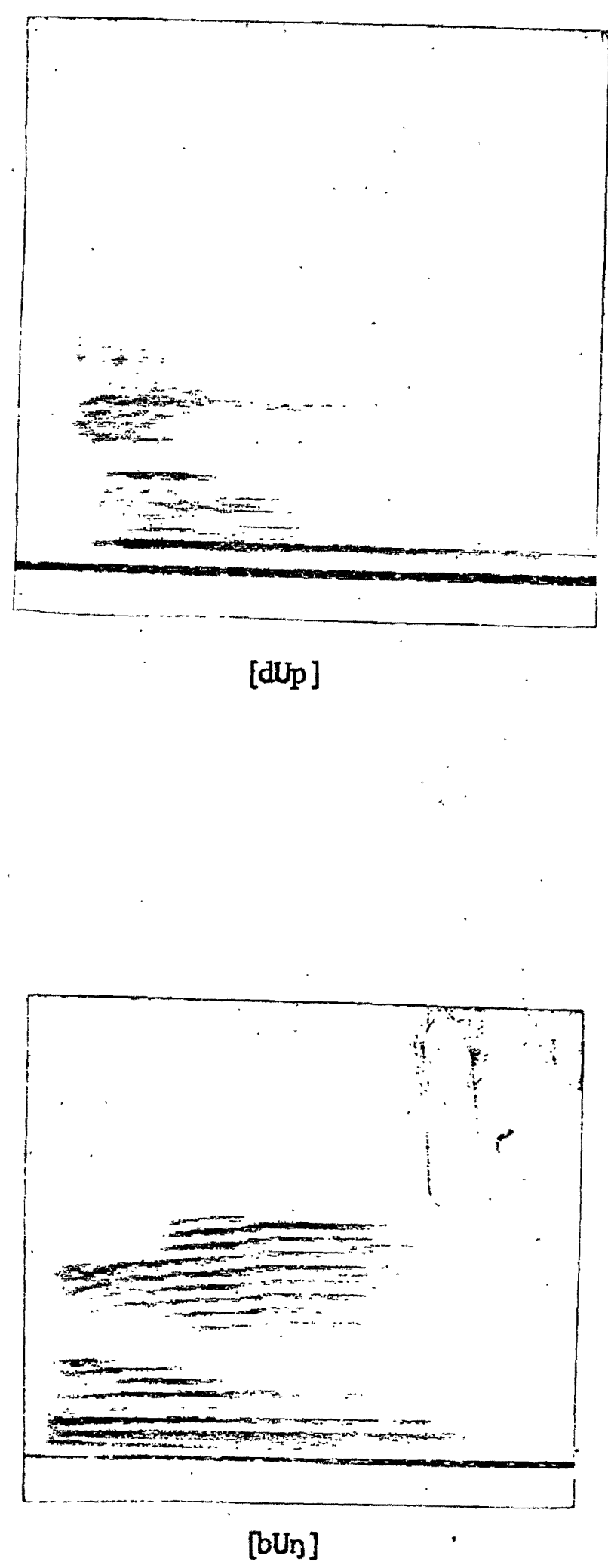


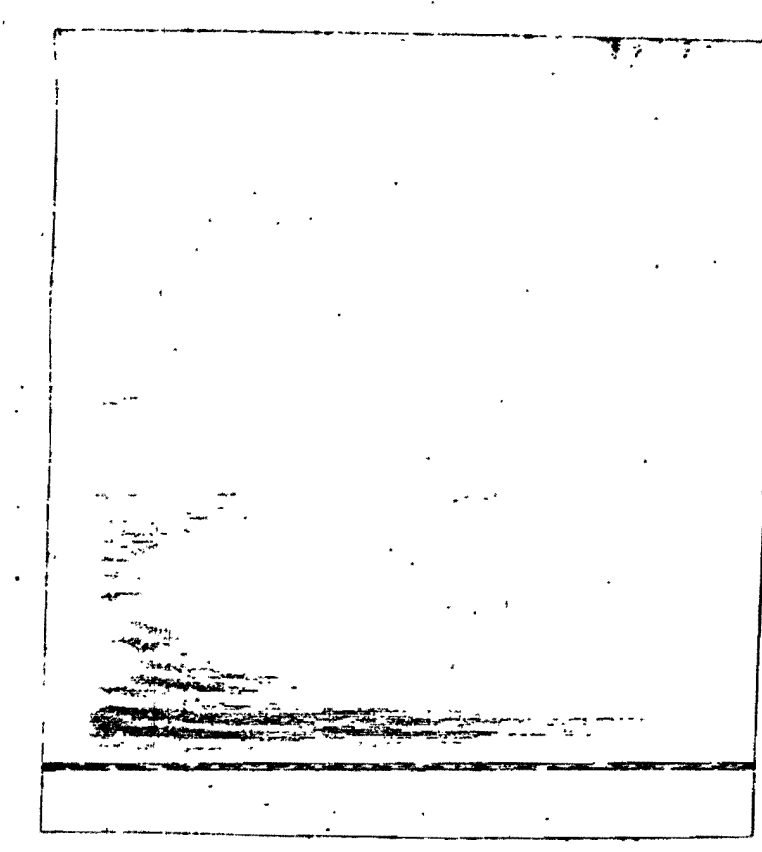

[čn]

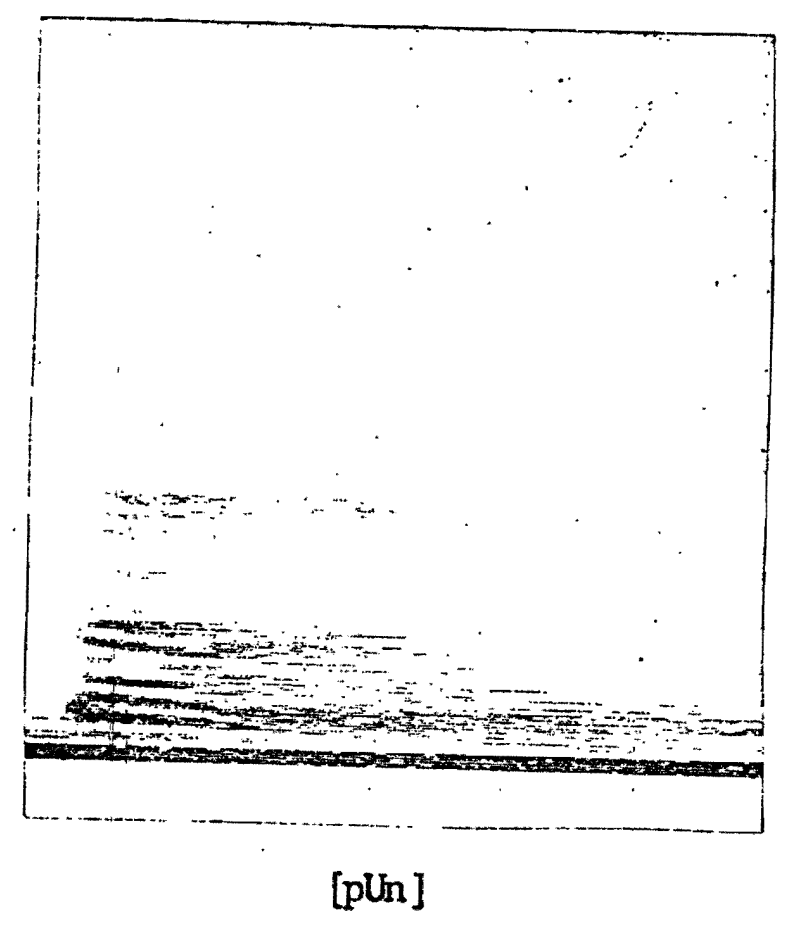

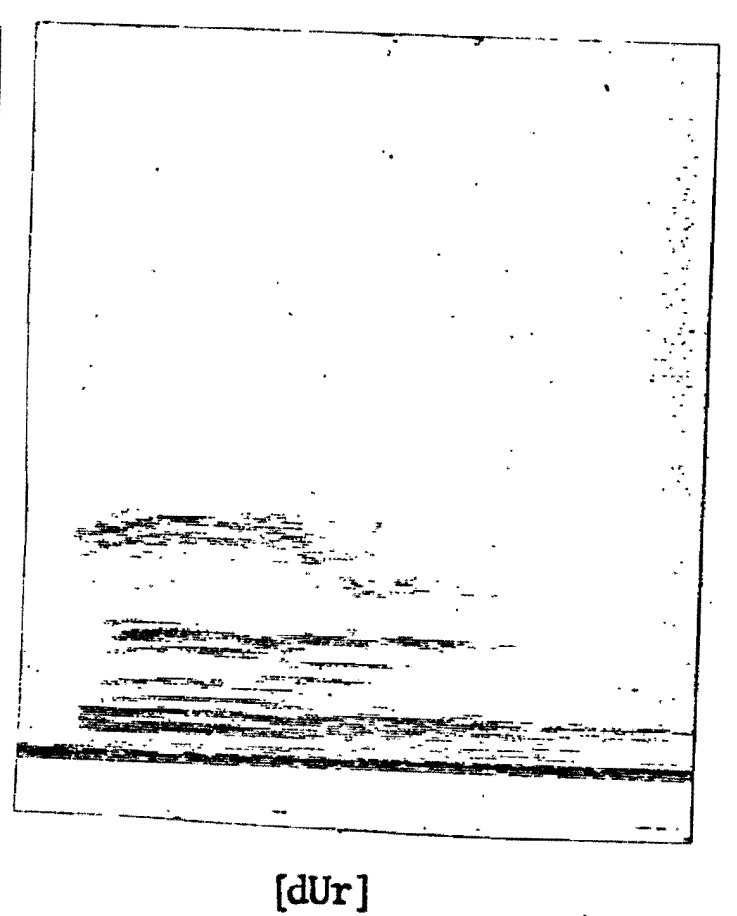

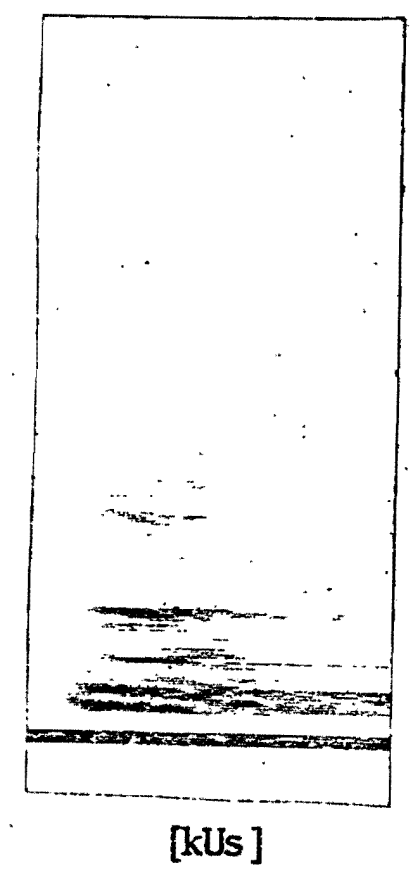



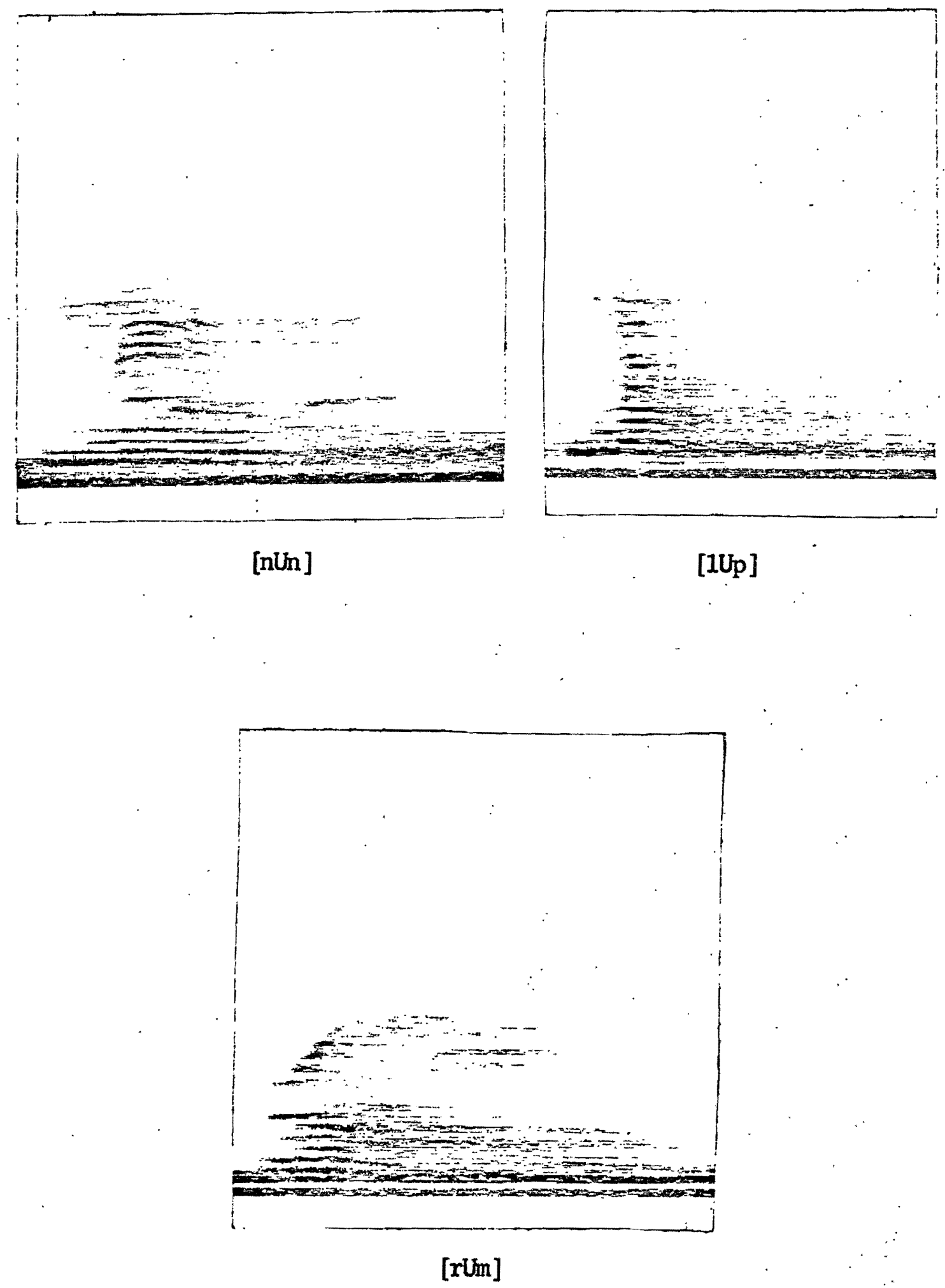

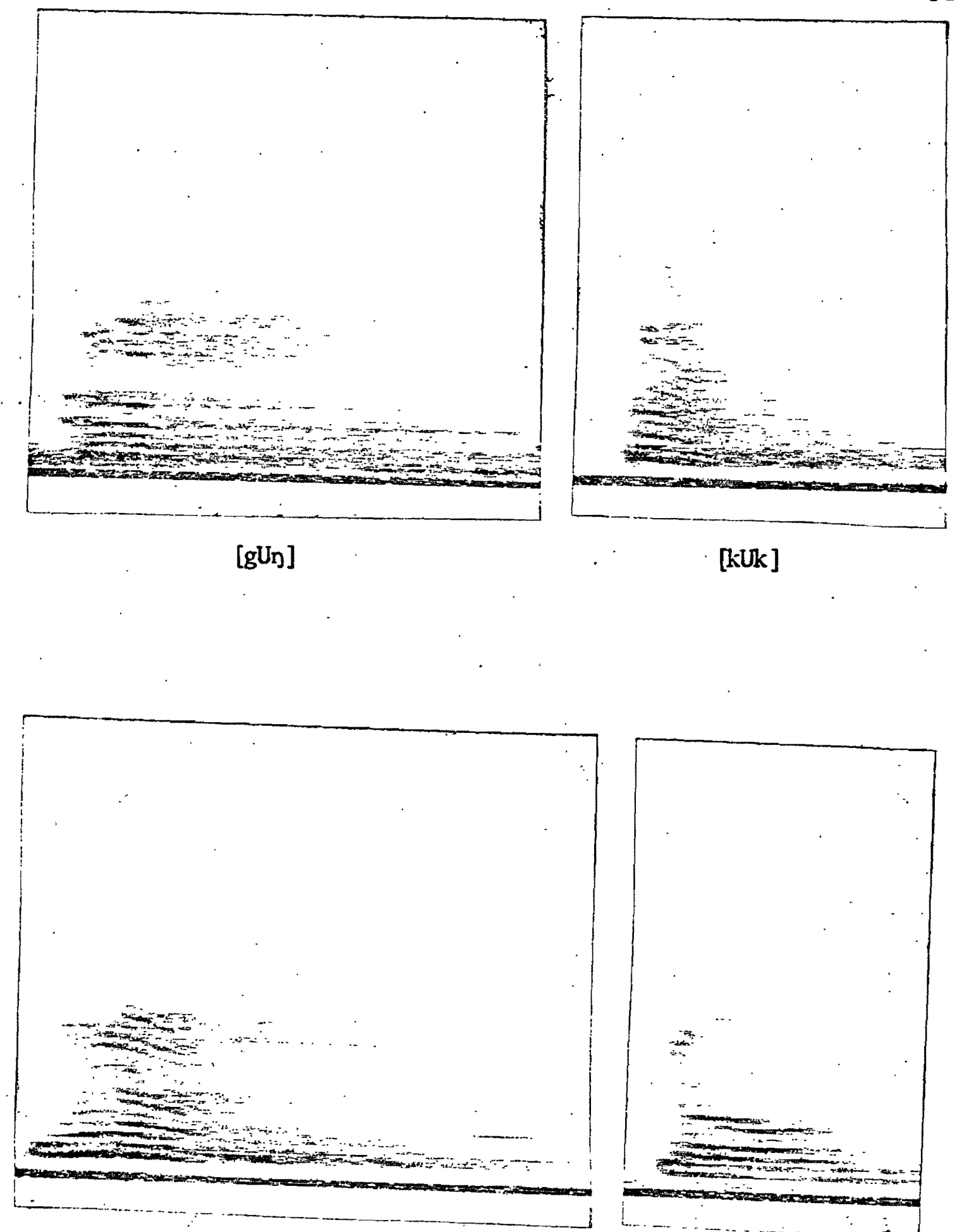

[1Us]

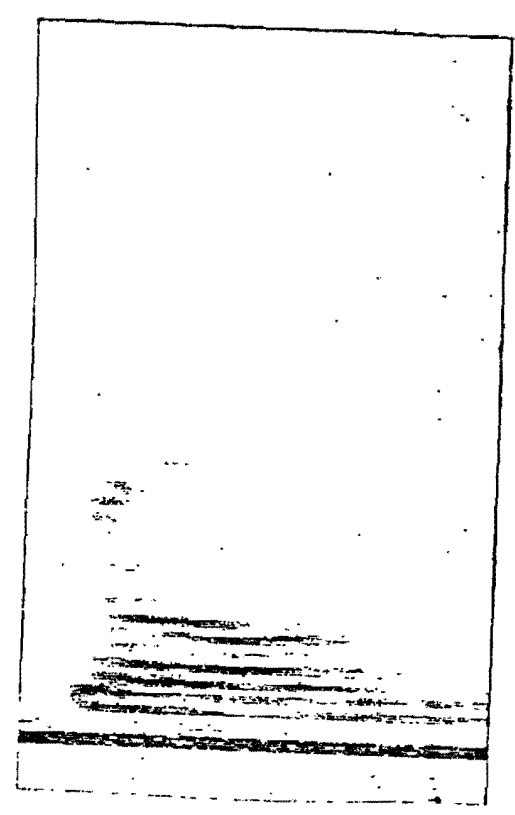

[วัUs ] 


\section{$\angle I /, / E /$ and $/ A /$ Compared}

In comparing the distributions of the vowels /I/, /E/ and /A/, cf. Chart VII on p. 62, it is evident from the plots. that the front-back tongue position is, for all practical purposes, identical; i.e., the core distribution, for all three phonemes, ranges between 1600-2000 hz. This demonstrates, conclusively, that the significant phonetic difference is tongue heigth, i.e., the position of formant 1. The fact of phonemic overlap is illustrated by the crosshatching on Chart VII. The cross-hatched area represents a range of phonetic quality that is identified in one instance as an /I/ and in another instance as an /E/, or in one instance as an /E/ and in another instance as an / $/$ /.

...the sounds which follow one another in a changing sequence constitute the signals of speech and these sounds are produced by movements of the vocal apparatus, i.e., by movements of the lips, tongue, throat, lungs, and so on. It is, therefore, important to understand that these vocal movements, caused by the various muscles involved, tend to slur into one another. Since each variation of movement gives a variation in sound, the slurring of movements produces a slurring of sounds. Furthermore, since specific sound will have different slurs of movement depending upon the movement which it precedes or follows, each sound type resultant from the productive movements will vary somewhat according to the sounds which it precedes or follows (Pike, 1947).

In line with this, the next logical step would be to look for environmental influences which would enable a listener to determine which phoneme was represented when phones were recorded in the overlap area. 
CHART VII

/I/, /E/ and /A/ Compared

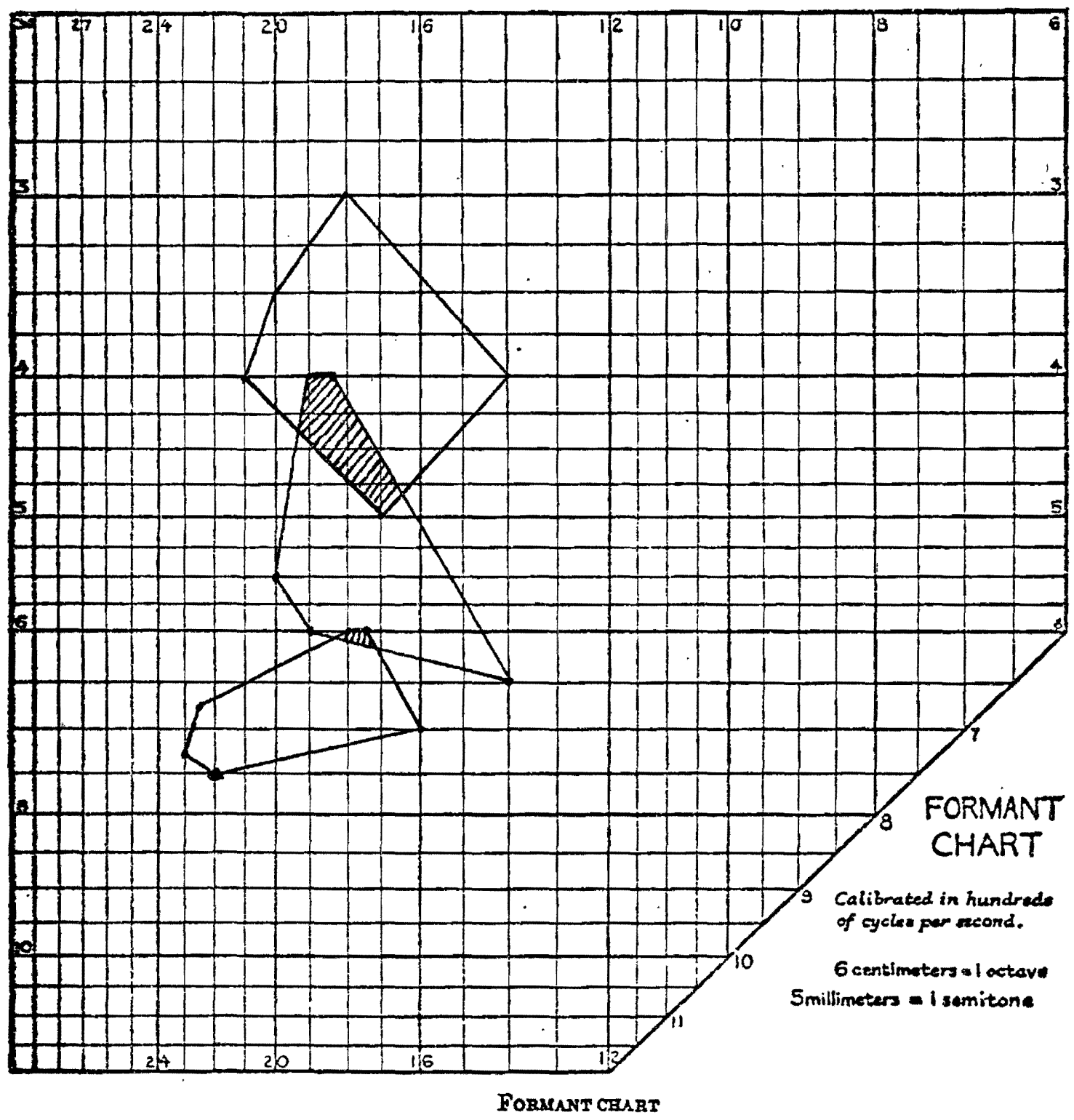

Placing a single point on this chart is an assertion that formants have been observed at two frequencics: one formant at the frequency named siong the right or left edge, the other formant at the frequency named along the top or bottom edge. 
A fairly thorough study of the positions of various. vowel sounds in specific environments did not indicate any consistent variations of a particular type. For example, the vowel in "dim" is in the lower range for the vowel///, but the /E/ in "dem" is in the upper range of the vowel /E/. Thus, it seems probable that those sounds in the overlap area are qualities for which minimal contrasts do not exist. For example, the /I/. in "sih" is in the overlap area, but apparently is clearly recognizable by a native speaker because there is no "seh", at least no such word was known to the informant. nor could one be found in the dictionary (Echols and Shadily, 1968).

\section{LU/ and $/ 0 /$ Compared}

In contrast with the front vowels $/ I /, / E /$ and $/ A /$, the back vowels $/ U /$ and /O/ have a considerable gap, \pm 50 hz., between their two distributions, cf. Chart VIII on p. 64. The distributions appear directly above one another on the chart. In comparing the two ranges, it is apparent that the front-back position, formant 1, is identical, i.e., the core distribution for the phoneme ranges from 700-1000 hz. This demonstrates that the position of formant 1 , i.e., tongue height, is the significant phonetic difference. 


\section{CHART VIII}

/U/ and /O/ Compared

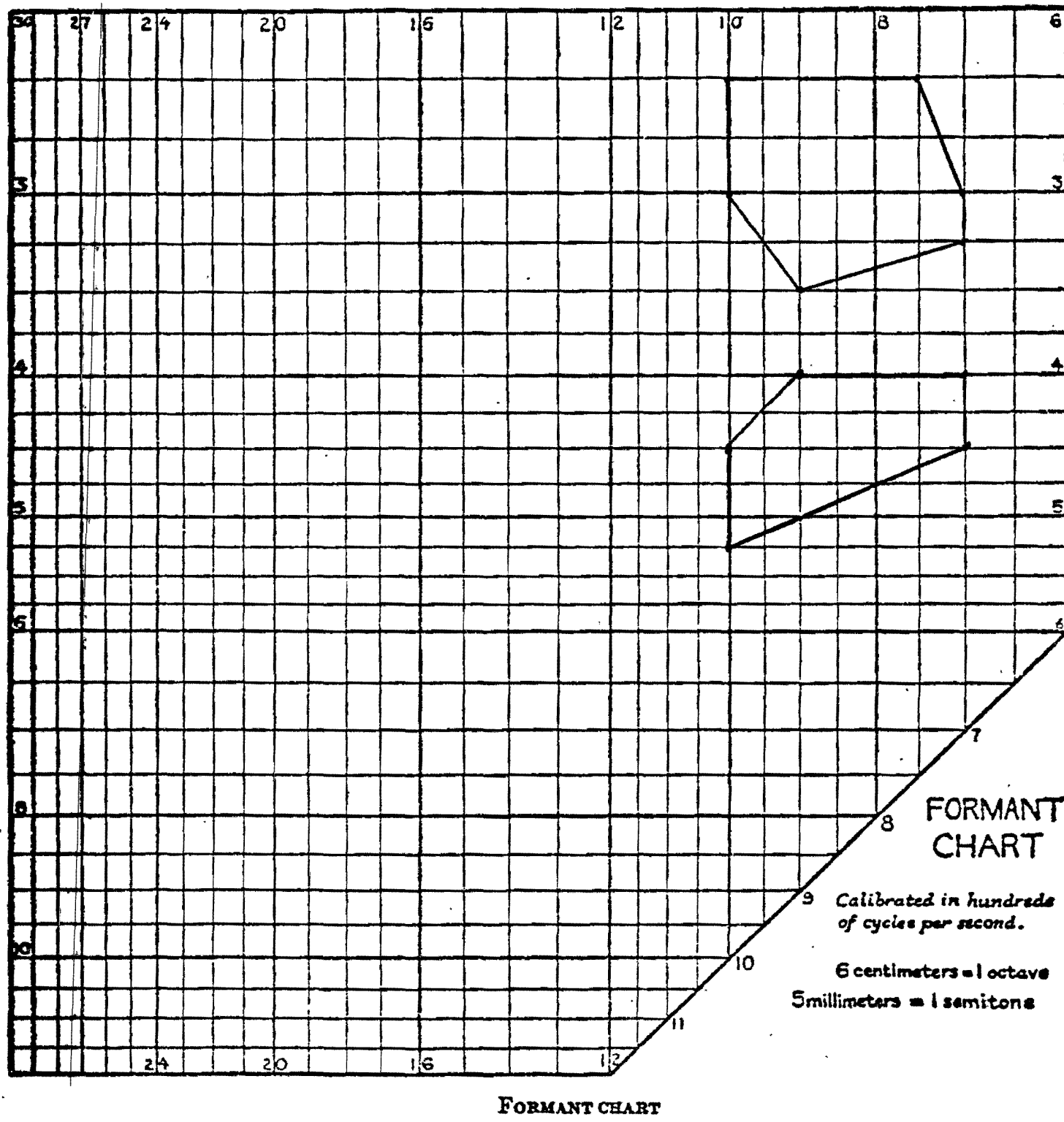

Flacing a single point on this chart is an assertion that formants have been observed at two frequencies: one formant at the frequency named along the right or left edge, the other formant at the frequency named along the top or bottom edge. 


\section{$\angle I /, / E /, / A /, / U /$ and $/ O /$ Compared}

In comparing all three phonemes in their respective position on the vowel chart, cf. Chart IX on p. 66, there seems to be no problem identifying between front and back vowels. There is a gap of approximately $400 \mathrm{hz}$. between the two back vowels and the three front vowels in terms of forment 2. Also, it would appear that there would be no problem in identifying specific vowel qualities so far as fofmant position is concerned for vowels in stressed position, with the exception of the phonemic overlapping discussed in a preceding section, i.e., /I/ $/ E /$ and $/ E /-/ A /$. 
CHART IX

$/ I /, / E /, / A /, / U /$ and $/ O /$ Compared

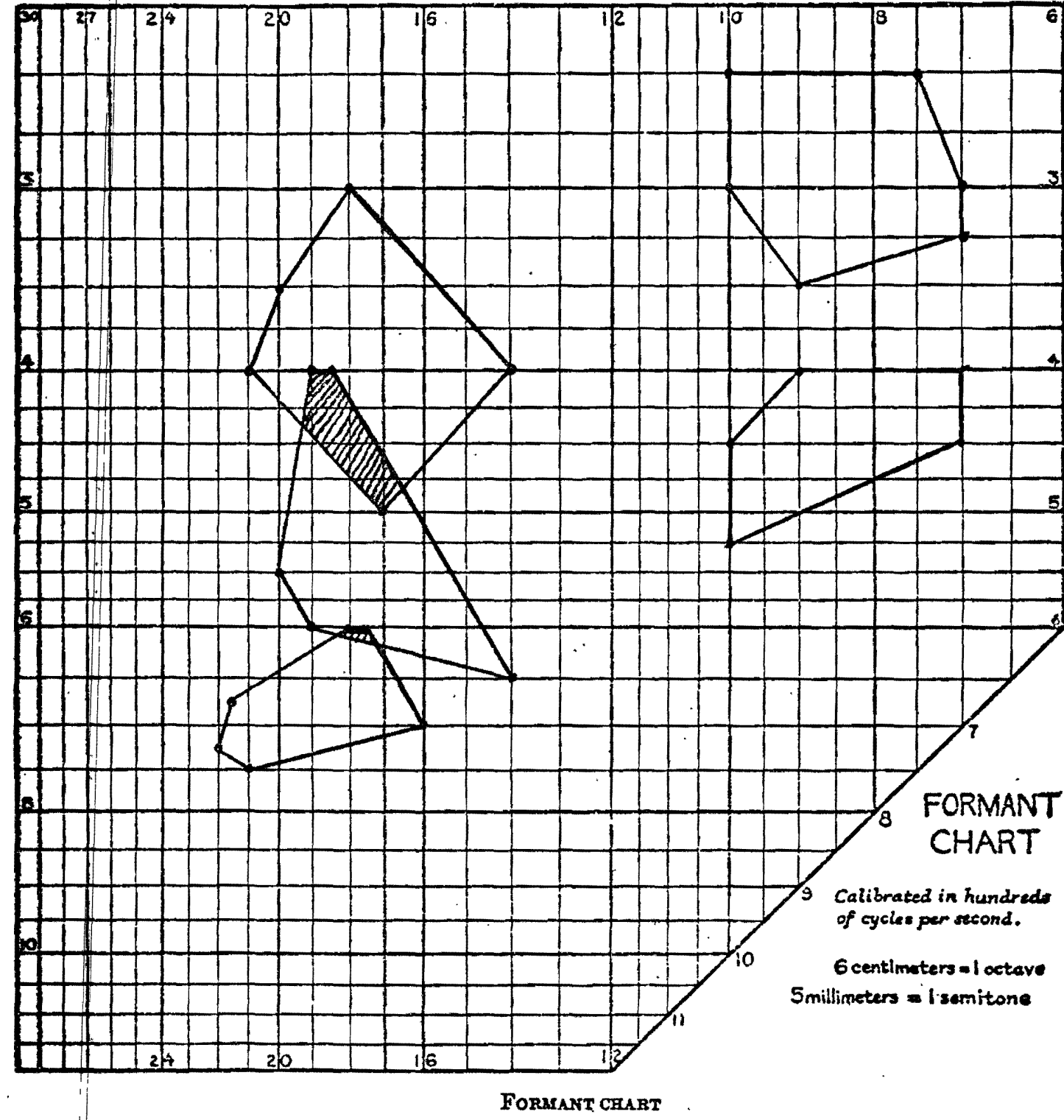

Placing a single point on this chart is an assertion that formants have been observed at two frequencies: one formant at the frequency namcd along the right or left edge, the other formant at the frequency named along the top or bottom edge. 


\section{CHAPTER V \\ SUMMARY AND CONCLUSION}

As is shown on Chart IX, on p. 66, there appears to be a very discernable distribution for each of the vowel phonemes of Bahasa Indonesia. This does not mean that the circumscriptions of each of the various sounds indicate definite border lines for each vowel. Rather, it shows the position of each vowel in relation to the other vowel phonemes. The vowel charts show the position of the phonemes as produced by one native speaker of the language. Thus, no conclusions can and should be made regarding the definite outer boundaries of the ranges of phonemes. As is implied by the term "ranges", the phonemes have no defined boundariels.

Bahasa Indonesia does not appear to have two front vowels, two back vowels, and one central vowel as is implied in the traditional symbolization: Rather, it has three fiont vowels with a three-way contrast between high, mid and low, and a two-way contrast of high vs. mid in the back area of the articulation chart. If a traditional symbolization of the vowel phonemes of the language were now to be drawn, it would look like the following chart: 


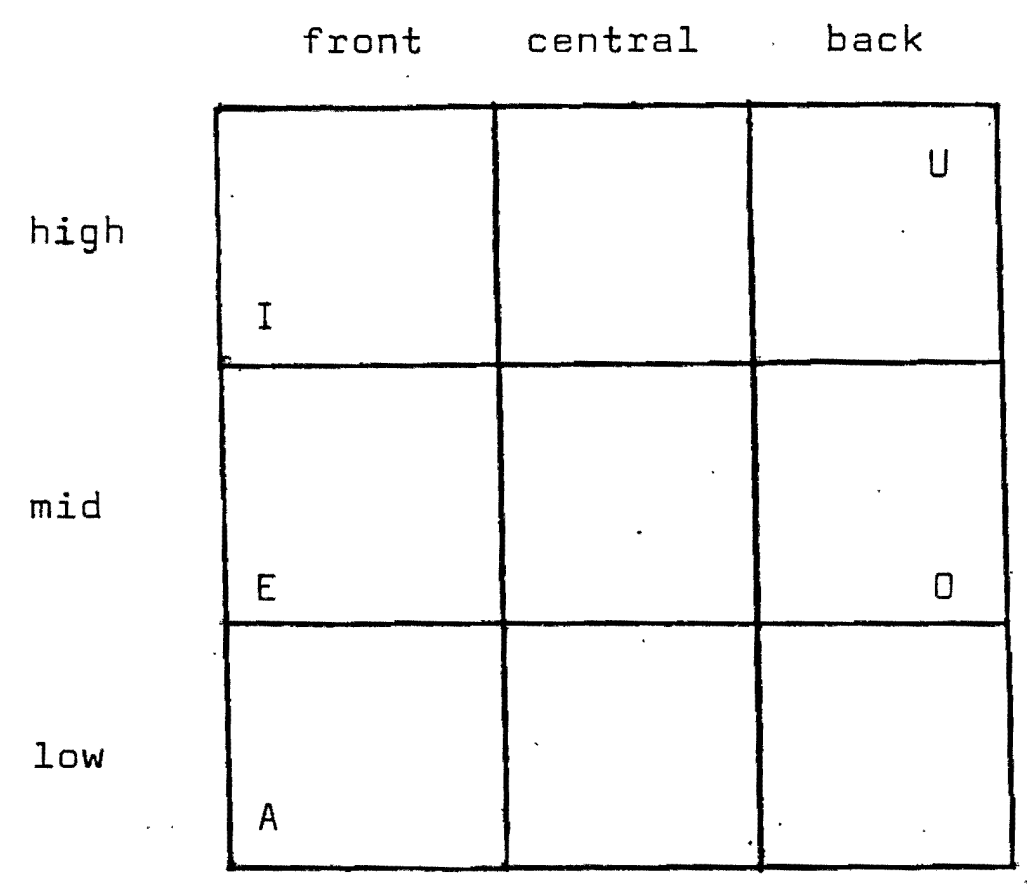

Thus, as has been demonstrated, the impressionistic version of the vowel system was in error with regards to the central phoneme of the language investigated. There appears to be no low-central phoneme in the language; Iather, it is a low-front one. Although the spectrograph cannot establish a phonemic system of a language on its own, it can provide a "yes" or "no" answer about the phone$t$ c qualities of the phonemes in question. After a phone$\mathrm{m}$ c system has been established, the spectrograph can pro$\checkmark$ fde phonetic data which distinguishes one phoneme from apother. 


\section{BIBL IOGRAPHY}

\section{Sources Cited}

Ali sjahbana, Takdir. "The Indonesian Language - By-product of Nationalism." Pacific Affairs, XXII (1949), 388-92.

American University. Area Handbook for Indonesia. Washington D.C.: U.S. Government Printing Office, 1970.

Bldch, B. and G. Trager. Dutline of Linguistic Analysis. Baltimore: Waverly Press, 1942.

Duhn, H. K. "Calculation of vowel resonances." Journal of the Acoustic Society of America, XXII (1950), 740-53.

Ecpols, John M. and Hassan Shadily. An Indonesian-English Dictionary. Ithaca: Cornell University Press, 1963.

Essner, C. "Reserches sur la structure des voyelles orales." Archives Neerlander Phonetic Experiments, $X X$ $(1947), \frac{A}{40-77}$.

Jakobson, Roman, C. Gunnar Fant, and Morris Halle. Preliminaries of Speech Analysis. Cambridge: M.I.T. Press, 1961.

Jobs, Martin. Acoustic Phonetics. Baltimore: Linguistic Society of America, 1948.

Ledefoged, Peter. Three Areas of Experimental Phonetics. London: Oxford University Press, 1967.

Pel, Mario. Glossary of Linguistic Terminology. New York: Columbia University Press, 1966.

Pferce, Joe E. "The Spectrographic Study of Vocalic Nuclei." Language Learning, XI I (1963), 24I-247.

-1--. "Phonemic Theory and the Analysis of English Syllabic Nuclei." Linquistics, XVII (1965), 36-57.

Pfke, Kenneth L. Phonemics. Ann Arbor: University of Michigan Press, 1947. 
Pike, Kenneth L. Phonetics. Ann Arbor: University of Michigan Press, 1943.

Pulgram, Ernst: Introduction to the Spectrography of Speech. New York: Dover Publications, 1966.

Sapir, Edward. Language, An Introduction to the Study of Speech. New York: Harcourt, Brace \& Co., 1921.

Uhienbeck, E. M. "Indonesia and Malaysia." Current Trends in Linguistics, I IX (1967), 55-111.

Wopdman, Dorothy. The Republic of Indonesia. New York: N. Y. Philosophical Library, Inc., 1955.

\section{Sources Consulted}

Andrejev, N. D. "Some Problems of Bahasa Indonesia Phonology." Studia Linguistica, XI (1957), 44-46.

Ebleling, C. L. Linquistic Units. The Hague: Mouton \& Co., 1960.

Jakobson, R. and M. Halle. Fundamentals of Language. The Hague: Mouton \& [0., 1956.

Kennedy, Raymond. Bibliography of Indonesian Peoples and Cultures. New Haven: Yale University Press, 1962.

Pi| erce, Joe E. "Spectrographic Study of English Vowels Under Primary Stress." Linquistics. LXXXIV (1972), 41-84.

Potter, Ralph K., George A. Kapp, and Harriet C. Green. Visible Speech. New York: Dover Publications, 1966.

Teleuw, A. Critical Survey of Studies on Malay and Bahasa Indonesia. The Hague: Martinus Nyhoff, 1961. 


\section{APPENDIX A}

\section{LIST OF WORDS}

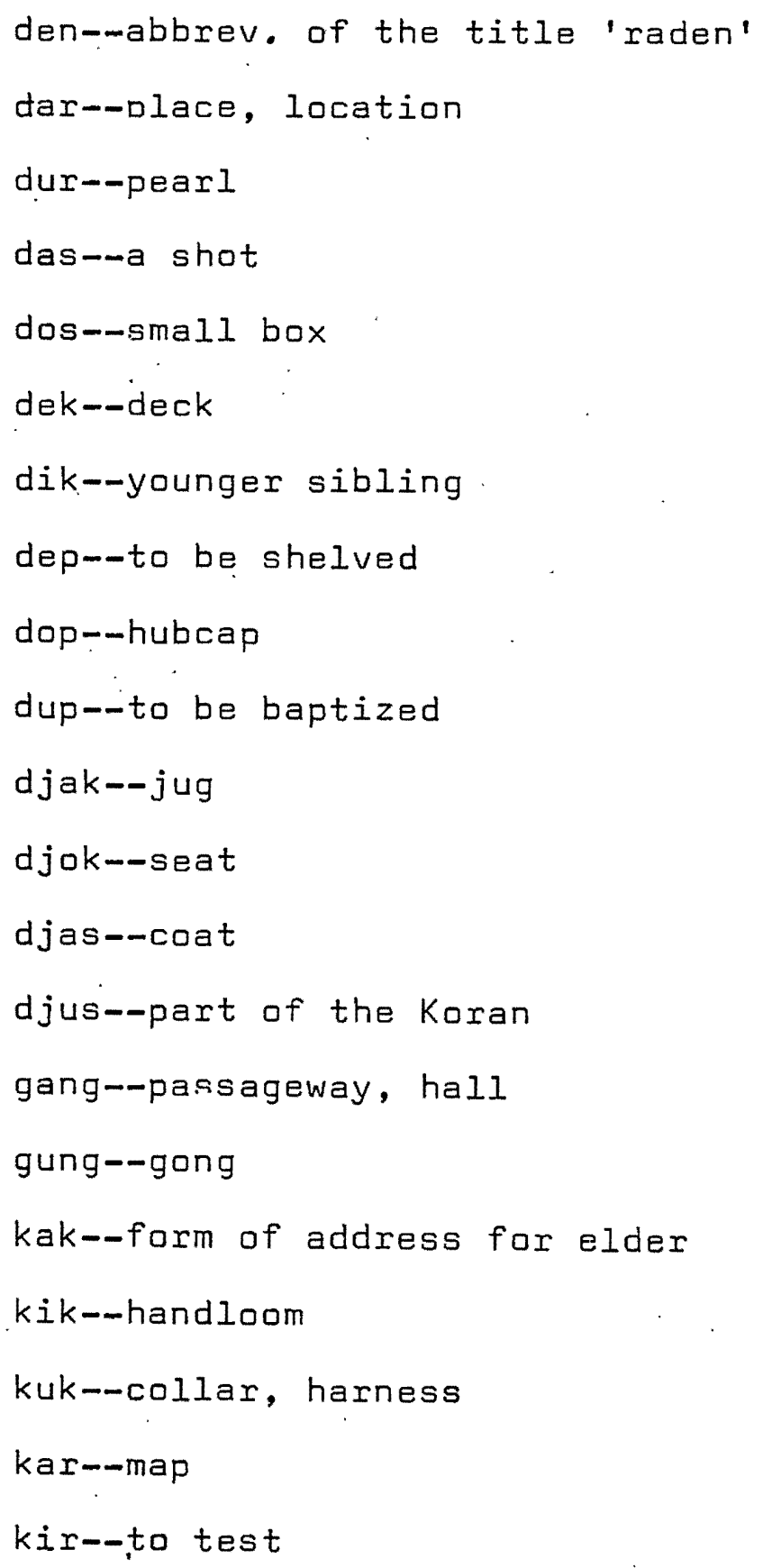




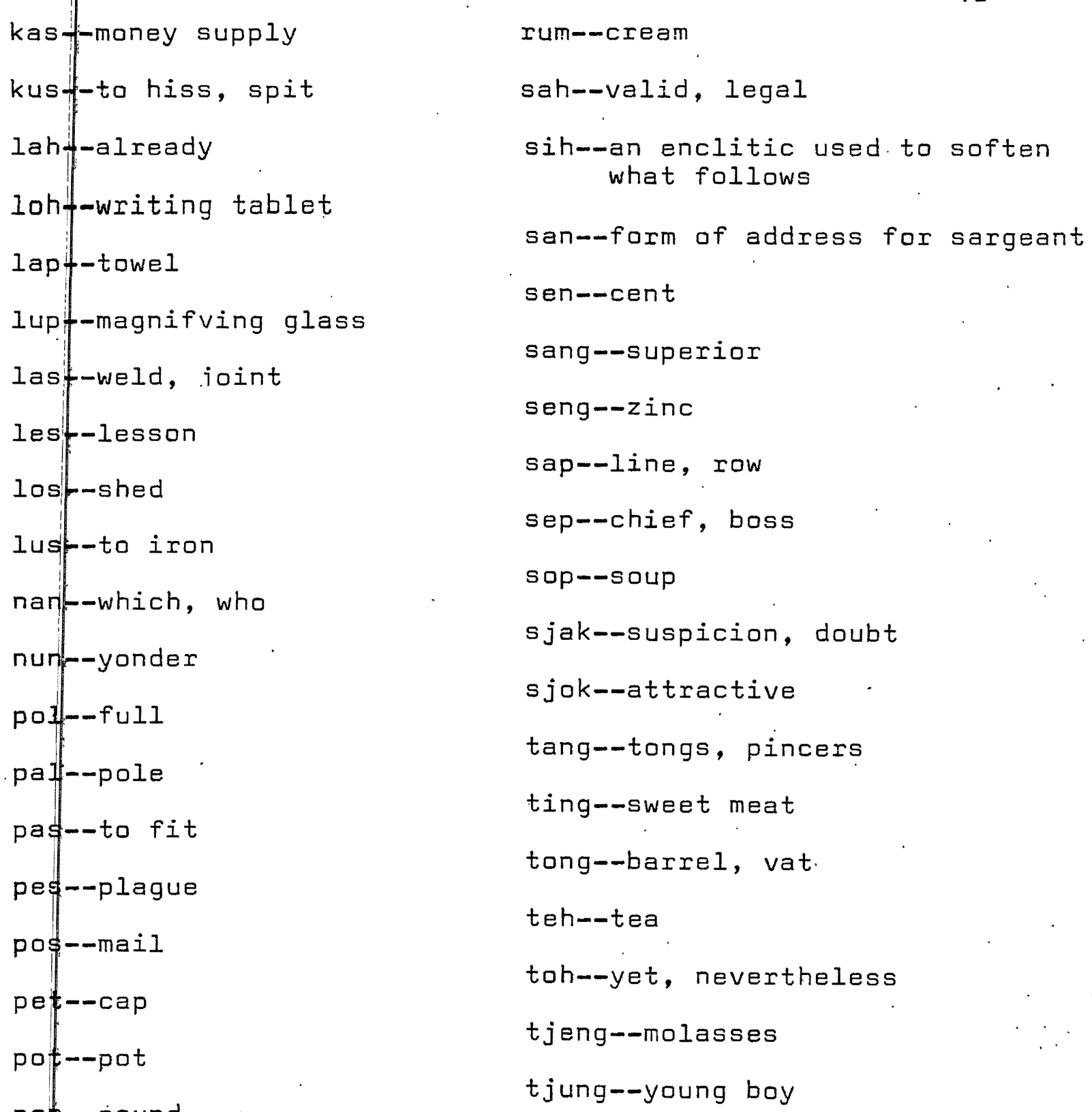




\section{APPENDIX B \\ LINGUISTIC SYMBOLIZATION USED}

Vowels

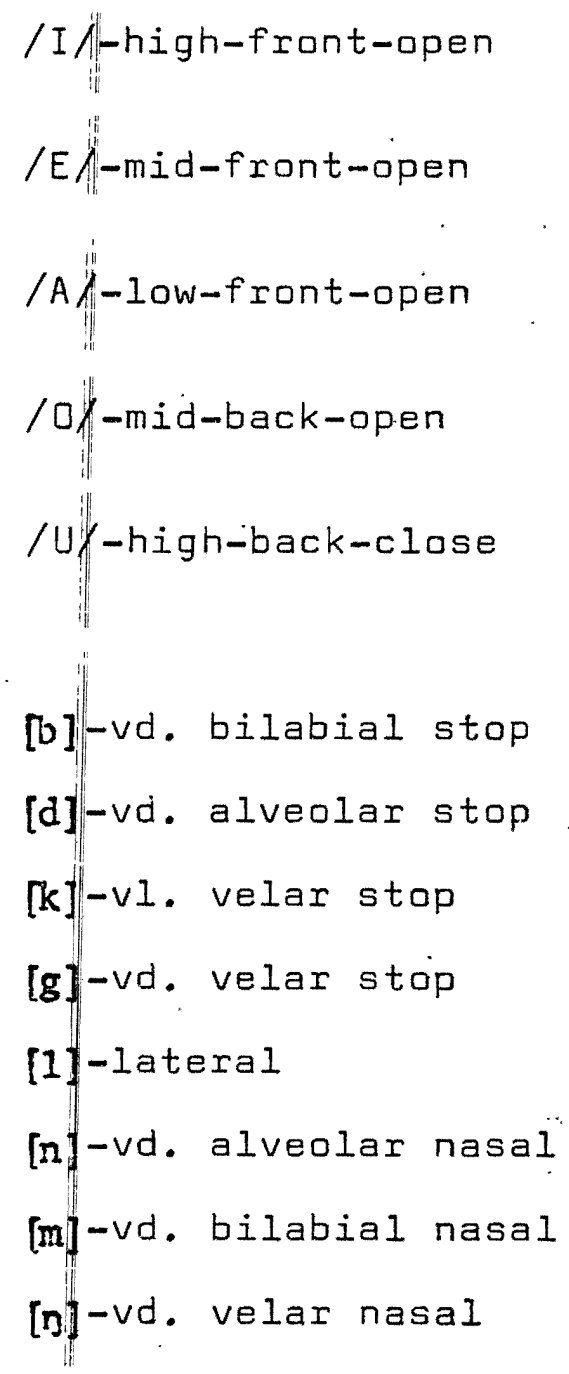

\section{Consonants}

[p]-vI. bilabial stop

[t]-vI. alveolar stop

[r]-vd. alveolar flap

[j]-vd. palatal affricate [č]-vl. palatal affricate [క̌]-vl. alveolar affricate [s]-vl. alveolar fricative [h]- vl. velar aspirant 